\title{
HALF A CENTURY OF ORTHOPAEDIG PROGRESS IN GREAT BRITAIN
}

\author{
H. Osmond-Clarke, London, England
}

This is the help beyond all others; find out how to make useless people useful and let them earn their money instead of begging it-Ruskin.

"In the nineteenth century the pioneers had been perfecting surgical technique, but no schools of orthopaedic surgery existed; the social workers had by Factory Acts attempted to stem the artificial manufacture of cripples, but the causes of crippling diseases were still unsuspected and unopposed. The century closed with little attempt at prevention, with inadequate accommodation and insufficient treatment in general hospitals, and as the army of cripples was no longer reduced by high mortality, the problem was causing deepening public apprehension. The turn of the tide came in the year 1900. It was then that orthopaedic surgery began to see daylight in the care and cure of crippled children."

Thus wrote Frederick Watson, son-in-law of Robert Jones, in 1930. Twenty years later, as we look back to 1900, the year in which died both William Adams-British pioneer of subcutaneous osteotomy, and Lewis Sayre - one of the pioneers of American orthopaedics, it is difficult to believe that orthopaedics was then no more than a name and an aspiration. The first half of the twentieth century has given to that name both substance and meaning. It has been concerned with the development and organisation of orthopaedics as a social service as well as a technique of surgery. There have been advances and many changes of fashion in the details of operative technique, but there has also been increased recognition of the significance of rehabilitation and resettlement; great strides have been made in the orthopaedic training of doctors, nurses, physiotherapists, gymnasts and occupational therapists; injuries have been segregated under the care of orthopaedic and accident departments; the concept of restoring the function of a limb, rather than producing perfect $\mathrm{X}$-ray pictures of a bone, has remained the ideal of British practice; and there have been closer links with the basic sciences, with greater application of the researches of these sciences to the advance of orthopaedics.

Hardly any other speciality has developed so rapidly or so extensively. Originally and by definition concerned with the straight child, this branch of surgery is now responsible for making people of all ages "straight." Its scope is indicated by the definition of Robert Jones himself: "Orthopaedics is based on, and consists of, the recognition and practice of definite principles of treatment, whether operative, manipulative or educational, which lead to the restoration of function in nerves and muscles, and in deformed or disabled limbs."

The field has expanded steadily as fresh knowledge and new methods of treatment have become available. It is now almost impossible for any one individual to keep pace with the literature, and still less to engage in the practice, of every facet of this branch of surgery; and as experience has matured there has been an increasing tendency to specialise within the speciality, and to concentrate on a single but nearly always complex problem like the surgery of the hand, peripheral nerve injury, intervertebral disc derangement, deformity such as scoliosis, the treatment of chronic arthritis, or the management of injuries. 


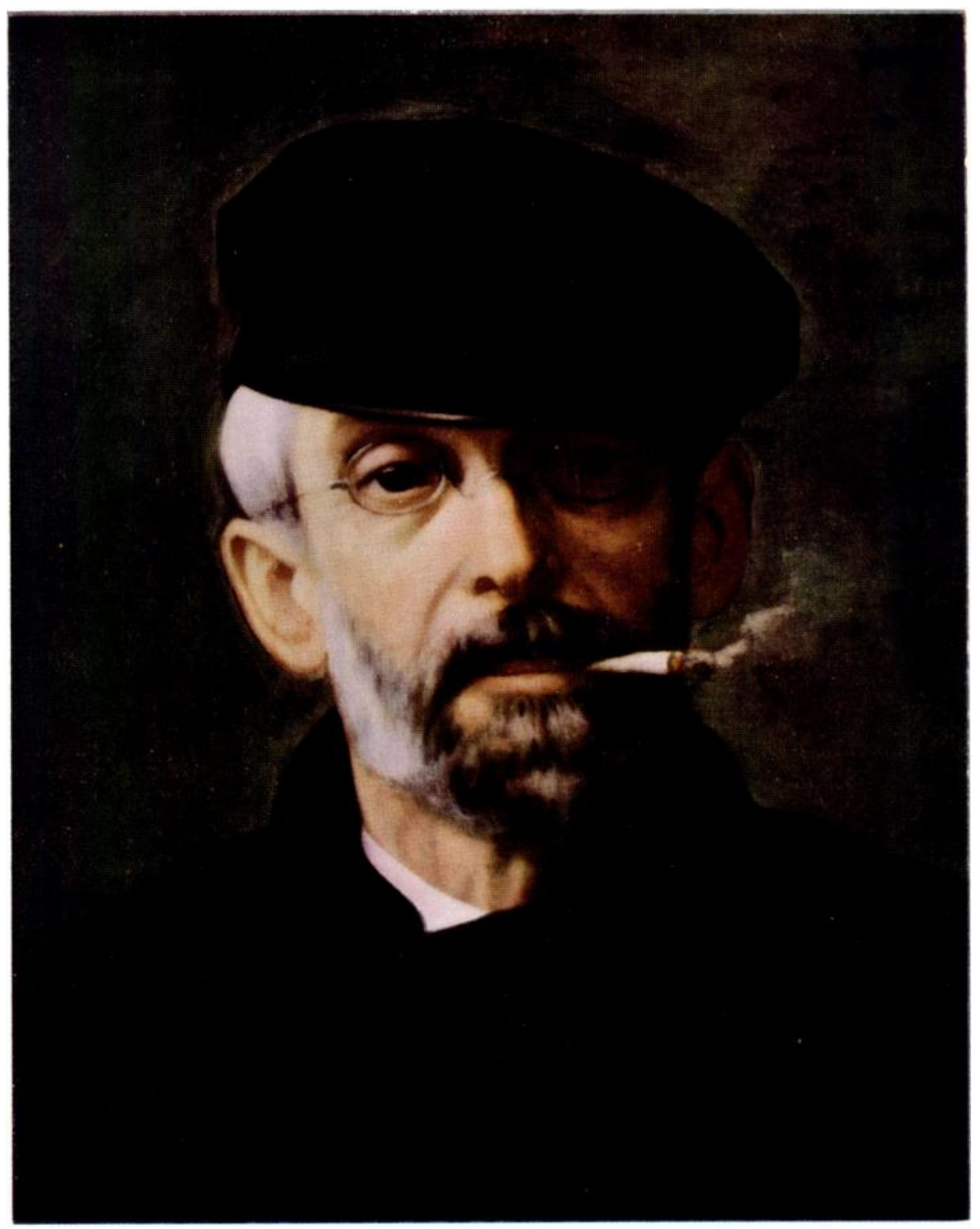

HCiH OWEX ThOMAS (1834 1891).

(Reproduced by permission of the (urator of the National Portrait (iallery). 


\section{EARLY DEVELOPMENT}

Since 1837, the year in which Queen Victoria ascended the throne, orthopaedics had been practised in Britain by W. J. Little (1810-1894), physician on the staff of the London Hospital, pupil of Stromeyer, and "apostle of tenotomy"; and by Hugh Owen Thomas (1834-1891), who if not the "apostle of rest," as were John Hunter and Hilton, was most certainly its great evangelist. Little and Thomas were founders of the two schools of orthopaedics - the London and the Liverpool. These schools dominated the development of orthopaedics in the early years of the twentieth century; between them there was at first friendly rivalry and, for many years now, the most fruitful and agreeable collaboration.

Hugh Owen Thomas deservedly gained renown, albeit posthumously, as the pioneer of conservative orthopaedic treatment with emphasis upon rest-enforced, uninterrupted and prolonged. He died in 1891, but his influence dominated orthopaedic practice throughout the first half of this century. He was an individualist, ardent and combative, intolerant of the theories and practice of the day, and unafraid of expressing his disapproval both pungently and pugnaciously. With the notable exception of Rushton Parker, professor of surgery in Liverpool, he had few friends in medicine, and his message did not spread as it should have done in his lifetime. But whatever the shortcomings of Thomas may have been they were more than counterbalanced by the activities of his pupil and nephew, Robert Jones. A great humanitarian of outstanding ability, with the personal charm so characteristic of his Celtic origin, completely trustworthy, intensely happy, and always human whether at work or at play, he was ideally suited by experience and temperament to advance the cause of orthopaedics. This task he shouldered and accomplished as much by the force and charm of his personality as by the nature of his message and work. He made the practice of Thomas known throughout the world. As was said by John Ridlon, his old American colleague: " One of the greatest things that Robert Jones ever did was to make the main principles of Hugh Owen Thomas acceptable to the medical profession."

Before he reached the age of thirty the writings of Robert Jones had been translated into French, Spanish and German. With the help of his lifelong friend Thurstan Holland, pioneer of radiology in Liverpool, he shared in producing one of the first radiographs ever made in Britain. He established orthopaedics firmly and securely as a special branch of surgery to such an extent that Sir William Osler wrote in 1917: " There has grown up as a department of surgery the branch known as orthopaedics-the original meaning of which was the straightening of crooked children; but it is now applied widely to the relief of deformities and disabilities of all kinds. All of us really needed this art-some in minds, others in bodies, many in both! In a sense, education is a department of orthopaedics. The orthopaedic surgeon is a teacher, a personal teacher and in two directions-of the patient's mind quite as much as of his muscles and joints. It is not simply a surgical matter, but an individual human problem requiring prolonged attention and study of each case. The new specialists in this branch are as much superior to the half-educated osteopaths and bone-setters as are our ophthalmic surgeons to the old vendors of eye-salves." What a magnificent testimony to Robert Jones himself-his practice, his teaching and his outlook.

\section{THE EVOLUTION OF A PATTERN OR ORGANISATION}

Robert Jones had long realised that the crippled child presented a problem that was both surgical and social. As early as $\mathbf{1 8 9 8}$ he pronounced that few children were so incurable that they could not recover if placed in proper circumstances; that there should be country hospitals for children suffering from chronic diseases; that each hospital should have an operating theatre; and that "such a hospital should not be regarded as a convalescent institution or be confused with such an institution." The idea was so revolutionary that it aroused opposition. What, it was asked, would happen to the finances of "Homes for Incurables" if more institutions competed for public money? His arguments prevailed. 
On April 21,1900 , through the generosity of Liverpool philanthropists, the Royal Liverpool Country Hospital for Children was opened at Heswall. The teachings of Hugh Owen Thomas and Robert Jones, described as the trinity of rest, surgical treatment and fresh air, were at last adopted in their own city.

Almost simultaneously, and unsuspected by Robert Jones, the open-air treatment of crippled children was developed with energy and enthusiasm by a dauntless woman in Shropshire-Agnes Hunt. Herself crippled from childhood by suppurative arthritis of the hip joint, she had been impressed at the beginning of her nursing training at the Royal Alexandra Hospital, Rhyl, in 1887, by two important principles in the management of patients

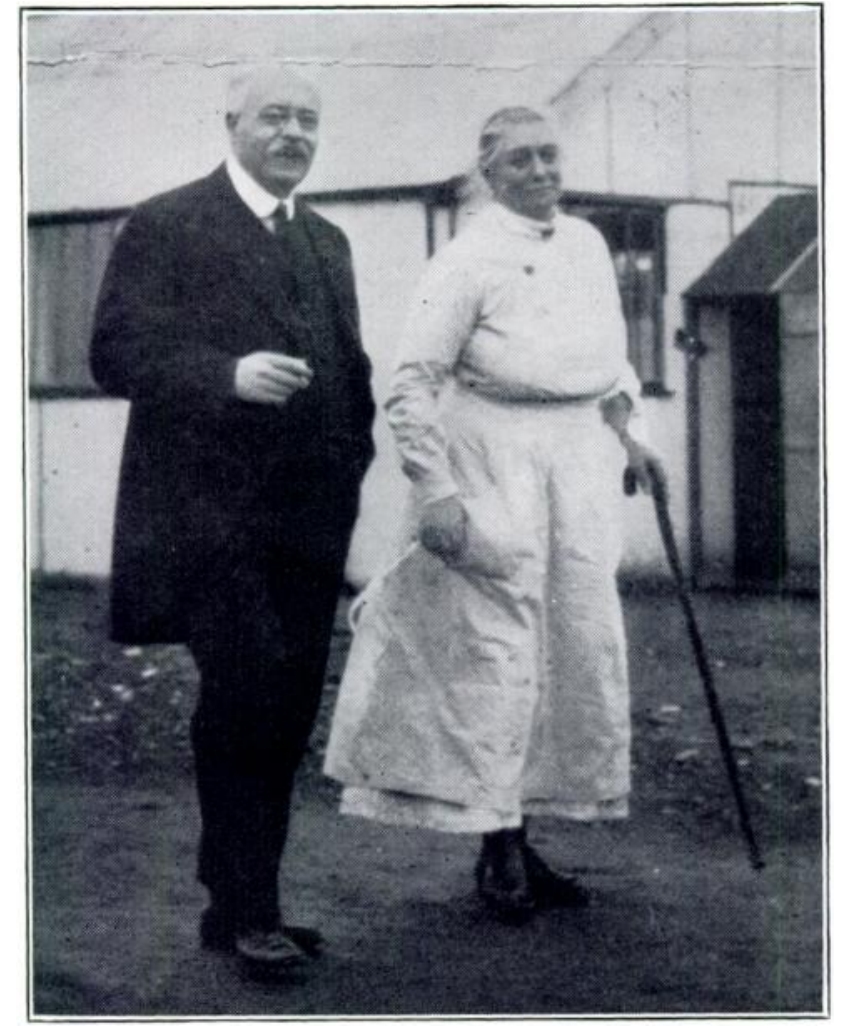

An early photograph of Robert Jones and Agnes Hunt. (Blocks kindly lent by J. Rhaiadr Jones, Esq.)

with chronic illness--open-air and happiness. It is interesting to note that this little hospital, founded by Miss Graham and Miss Vizard who were both trained at the Children's Hospital, Great Ormond Street, London, and perhaps the first institution in Britain to advocate fresh air as part of the treatment of the crippled child, had Hugh Owen Thomas as honorary consulting surgeon.

The story of Agnes Hunt's derotion to the cause of the cripple is well known-the derelict farmhouse and its stables, the primitive drainage, the chronically empty bank account, the four little girls and four little boys who were the first patients-there is no need to recount the story. But the opening of the Baschurch Home in October 1900, some five months after the Heswall centre was established, may be recalled in the words of Agnes Hunt herself: " No splendid vision prompted this open-air hospital, no mighty philanthropic scheme cast its shadow over the humble beginning of the first open-air orthopaedic hospital of the world; no trumpets sounded its advent; no kings, princes or lord mayors rushed to welcome its

VOL. 32 B, NO. 4, NOVEMBER 1950 


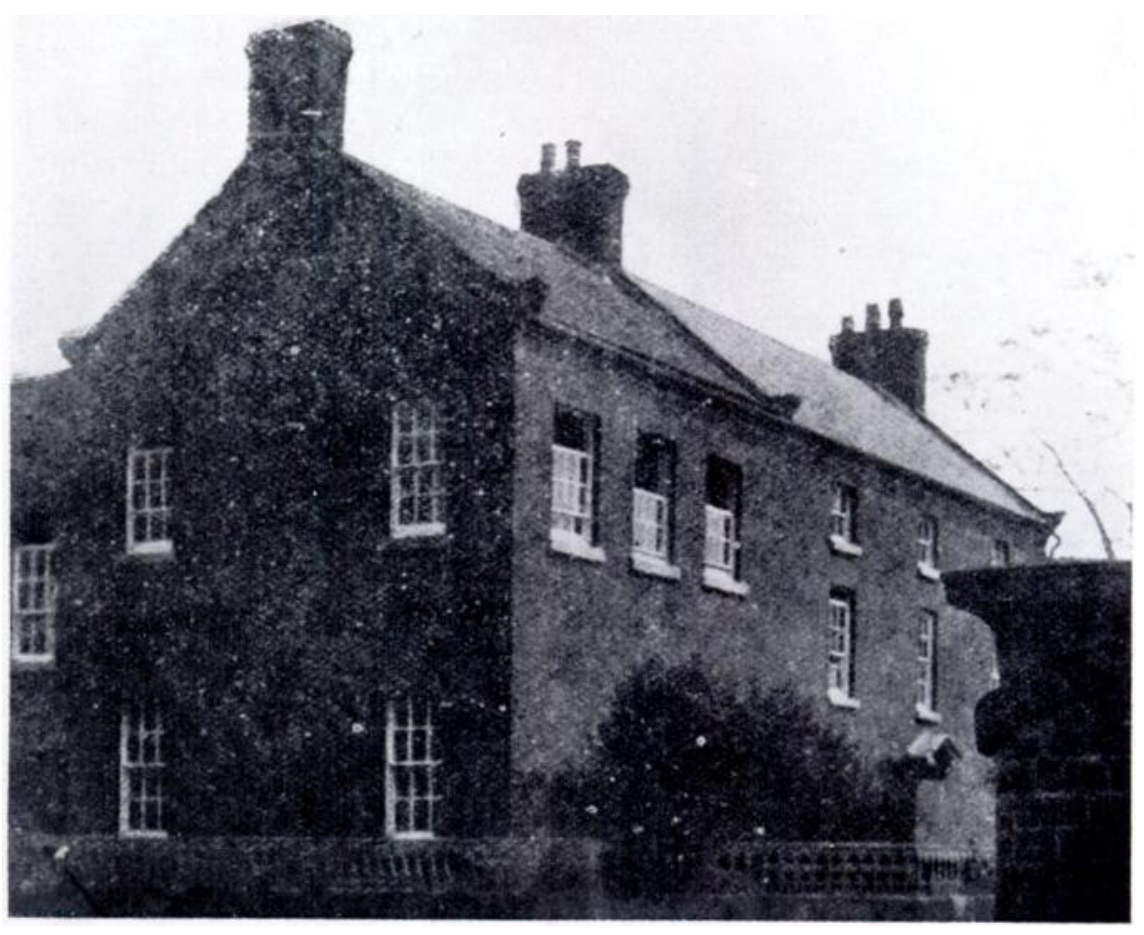

The Baschurch Home-the original farmhouse.

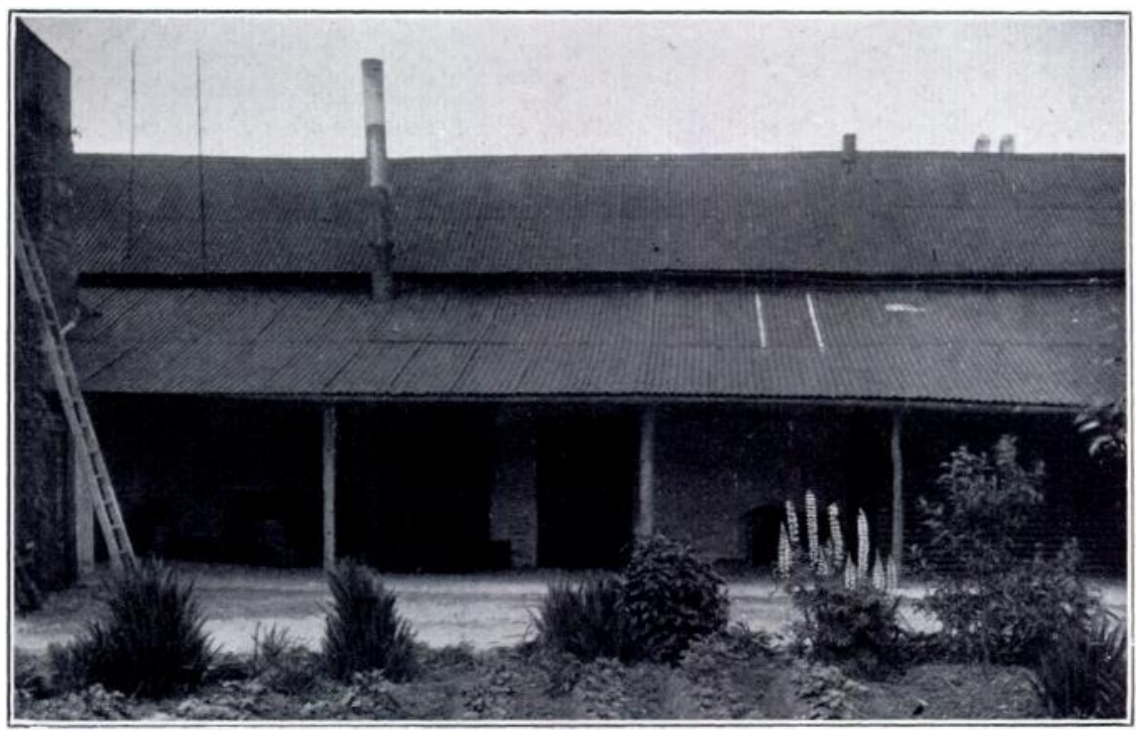

The converted hut at Baschurch used as an open-air ward by Agnes Hunt. Probably the first open-air orthopaedic ward in the world. 
birth; simply an old and derelict farmhouse in a little old-world village opened its doors and became "The Baschurch Home." ",

Towards the end of 1904 . Innes Hunt suffered increasing pain in both hip joints and consulted Robert Jones in Liverpool. She records that this was one of the greatest days of her life. A close and enduring friendship sprang up. Both Agnes Hunt and Robert Jones had the same cause at heart; they shared the same temperament; they were gay, inspiring, enthusiastic and human; they were distrustful of sham and disregardful of authority; and they had a sense of the ludicrous. The alliance was indeed formidable. Robert Jones joined the staff at Baschurch in March 1904 and in that year performed the first operation-by candlelight in the dining-room. He attended the hospital regularly almost until the day of his death. No two people did more to advance orthopaedics as a great social service or to develop orthopaedic technique in surgery and nursing. They emphasized the significance of prevention and the early treatment of deformity, the need for prolonged and adequate after-care supervision, and the importance of industrial training and the securing of emplorment.

In the fifty years that have passed since October 1900 the Baschurch Home has changed. In 19:21 it moved to its present site at Gobowen and, with geographical perversity, was renamed "The Shropshire Orthopaedic Hospital, Oswestry." After the death of Robert Jones in 19333 the name was again changed to the Robert Jones and Agnes Hunt Orthopaedic Hospital. In 1948 much of it was burnt down; but no lives were lost and work was started again within a few dars. Rebuilding is now almost complete, and the twentieth-century pattern of an open-air hospital of five hundred beds is evident in the new buildings.

In 1909 the first after-care clinic of the hospital was begun in Shrewsbury, but further extension was not possible until 1917. By then the number of patients readmitted with broken splints and other evidences of neglected treatment was so great that after-care supervision became an economic necessity. Centres were therefore opened in various

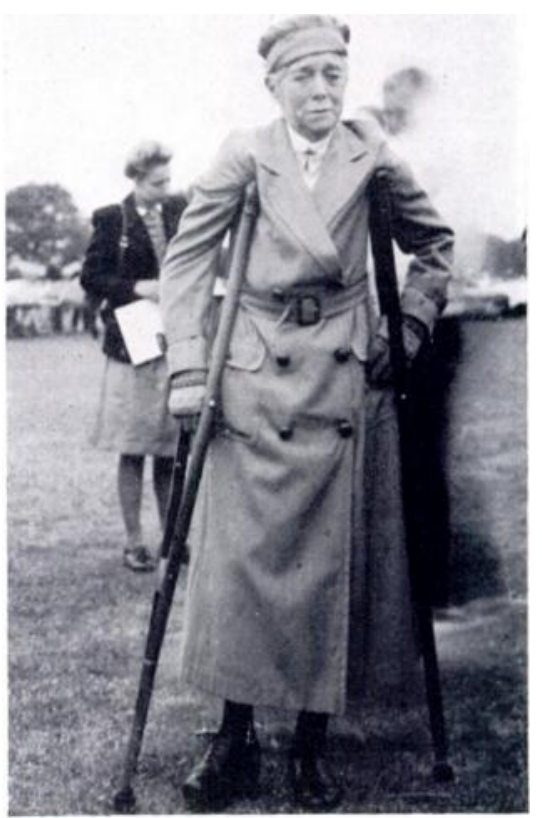

Dame Agnes Hunt in the characteristic garb of her own design. market towns in Shropshire. At first they were visited each week by an after-care sister who travelled on a second-hand motor cycle! By 1918 there were thirteen centres. To-day there are nearly fifty centres, visited regularly by a team of trained orthopatedic nurses and physiotherapists with a fleet of cars, and at less frequent intervals by surgeons on the staff of the parent hospital. Orthopaedics is thus brought to the patient, and economy is maintained by a remote out-patient system which ensures early recognition, prompt treatment and careful follow-up of orthopaedic disorders. Agnes Hunt lived to see her vision fulfilled, including the establishment in 1928, near the orthopaedic hospital, of the Derwen Training College where 90 per cent of Derwen-trained boys and girls earn their own livings, some in the workshops of the College but most in the open labour market.

The Oswestry example was followed in other country areas, and by 1919 the need for these developments on a national scale was at last realised. There were at least one hundred thousand crippled children in Britain. The advantages of an organised plan were so obvious that a voluntary council, representative of all interested bodies, was founded and presided

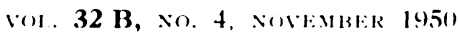


over by Robert Jones. This committee for the care of cripples-now a Central Counciladvocated a scheme which is worth recording because it still represents the ideal for the needs of most communities. It recommended: 1) a central co-ordinating body working with the Ministries of Health, Education and Labour; 2) local committees for the care of cripples in every district ; 3) hospital schools for crippled children with open-air wards where surgical treatment and education could proceed in unison; 4) outpatient or after-care clinics for the examination and treatment of children sent for consultation, supervision of children discharged from the hospital school, and planning of suitable employment for those of more advanced age; 5) invalid schools, both day and residential, for the few children whose disability was

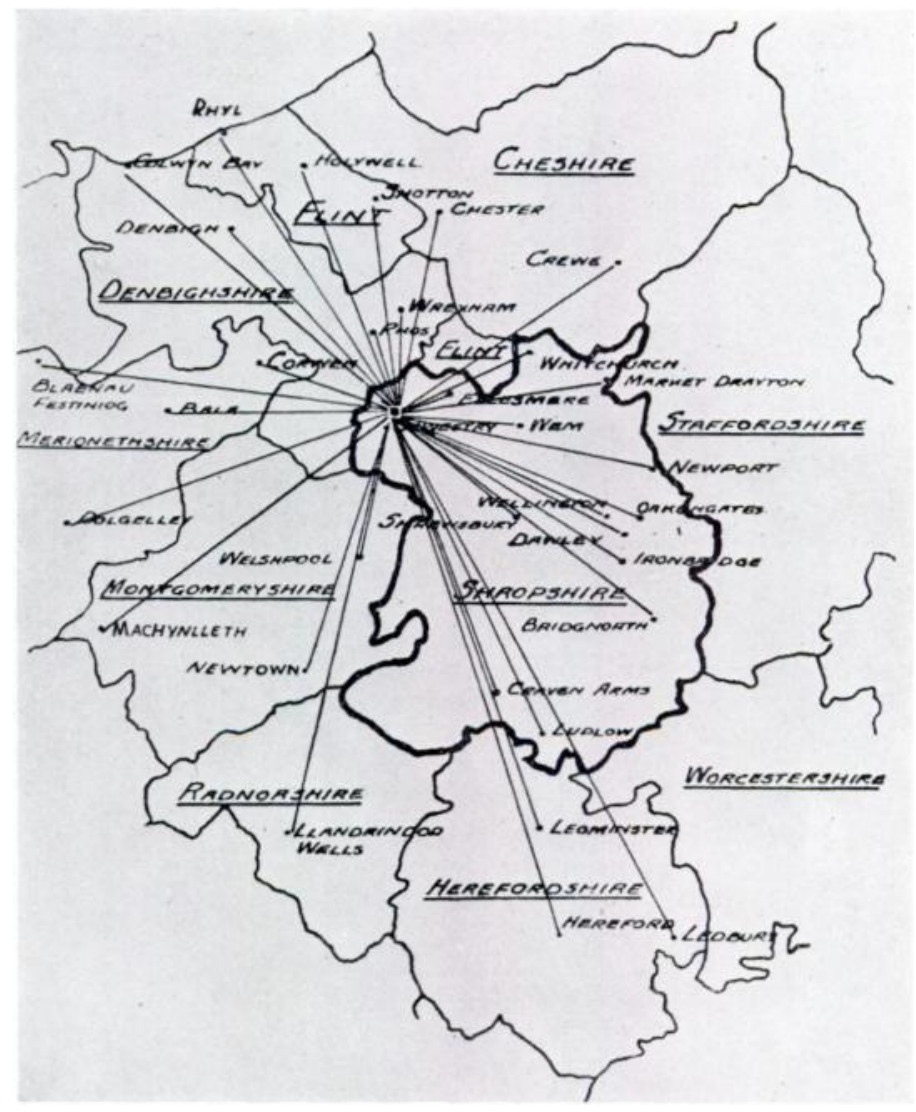

Geographical distribution of orthopaedic prevention and after-care clinics based on the Robert Jones and Agnes Hunt Orthopaedic Hospital, Oswestry.

so great that they could not attend ordinary classes; and 6) surgical wards for the treatment of adolescent and adult cripples who needed orthopaedic treatment.

The Ministries of Health and Education collaborated with the Central Council and encouraged local authorities to develop plans for the education and treatment of crippled children. The co-operation of Medical Officers of Health, School Medical Officers, Tuberculosis Officers, Infant Welfare Centres and County Borough Councils was readily forthcoming. Voluntary local workers, including members of the Red Cross and Order of St John, gave invaluable help in conducting after-care clinics.

It would be impossible to praise too highly the work done since 1919 by the Central Council for the Care of Cripples in conjunction with the Central Council for Infant and Child 
Welfare and many other voluntary bodies such as the Invalid Children's Aid Association, the After-Care Association for Physically Defective Children, the National Council for Maternity and Child Welfare, and the After-care Association for Blind, Deaf and Physically Defective Children. They campaigned together against the old idea of central hospitals or special schools which undertook no more than primary surgical treatment without adequate follow-up, and without planning for retraining and re-employment.

Public bodies had been impressed by the Baschurch experiment. By 1917 the Shropshire County Council sent to that hospital all children suffering from skeletal tuberculosis; and in 1918 they accepted responsibility for the care of all crippled children up to the age of fourteen years. This was probably the first public body in the world to acknowledge its responsibility for the crippled child. Other public bodies, encouraged and helped by the Fisher Education Act of 1918 , followed the example.

While the pattern was developed in Liverpool and Shropshire there was activity in many other fields-philanthropic, religious and governmental. Women of the calibre of Agnes Hunt were at work. In 1903, Mrs Kimmins and Miss Rennie founded the Heritage Crafts School at Chailey in Sussex- " the public school of crippledom." St Vincent's Surgical Home for Crippled Boys was started in 1907 in a semi-detached house in Clapham under the care of the Sisters of Charity of St Vincent de Paul, at first with the object of educating and teaching trades to incurable and destitute cripple boys of the Roman Catholic religion. As in every other school for physically handicapped children it was soon appreciated that surgical facilities were also needed, and under the guidance of another remarkable woman-Sister Teresa Fraser, together with Robert Jones and McCrae Aitken, a modest beginning soon developed into the present splendid country Orthopaedic Hospital and Training School at Pinner in Middlesex.

In 1908, the same year that the Children's Act was passed by which penalties were imposed on parents who neglected to seek treatment for their disabled offspring, Lord Mayor Treloar's Cripples' Hospital and College were founded at Alton in Hampshire for the treatment of surgical tuberculosis. Sir Henry Gauvain was in charge. This hospital has since extended its scope to include the treatment of all orthopaedic maladies. In 1909 the Royal National Orthopaedic Hospital was opened by King Edward VII on its present site in Great Portland Street, London, representing the amalgamation of three rival metropolitan orthopaedic hospitals - the Royal, the National and the City.

In the two years before the first world war, three hospitals were opened: St Gerards Hospital for children suffering from tuberculous disease at Coleshill, Birmingham; the Liverpool Open-air Hospital for Children at Leasowe; and Queen Mary's Hospital at Carshalton in Surrey. In 1917 the Wingfield Hospital at Headington, near Oxford, became part of the Southern General Military Hospital with a separate orthopaedic unit. By 1920, under the direction of G. R. Girdlestone, an after-care clinic scheme had been organised on the Shropshire pattern in Berkshire, Buckinghamshire and Oxfordshire with the Wingfield as its central hospital. Orthopaedic hospitals for children were, as Agnes Hunt said, "springing up in all directions." The pathos of the crippled child had gripped the imagination of the public. In the 'twenties no fewer than twenty-six hospitals, training schools and after-care clinics were opened - the Ethel Hedley Hospital at Windermere with associated clinics in Cumberland and Westmorland under the aegis of Harry Platt; after-care clinics in Hertfordshire in association with St Bartholomew's and the Royal National Orthopaedic Hospitals; and clinics in Surrey with parent hospitals at St Thomas's and St Nicholas, Pyrford, under the guidance of Rowley Bristow. In 1921 the Royal National Orthopaedic Hospital opened its country branch at Stanmore, Middlesex, in the house of Mary Wardell who in 1882 had given the property for a convalescent home for children of the metropolis recovering from infectious diseases. To-day, vastly extended, this is one of our finest country hospitals and training centres.

Heatherwood Hospital at Ascot was established in 1922 by the United Services Fund to

Vol. $32 \mathrm{~B}$, No. 4, NOVEMBER 1950 


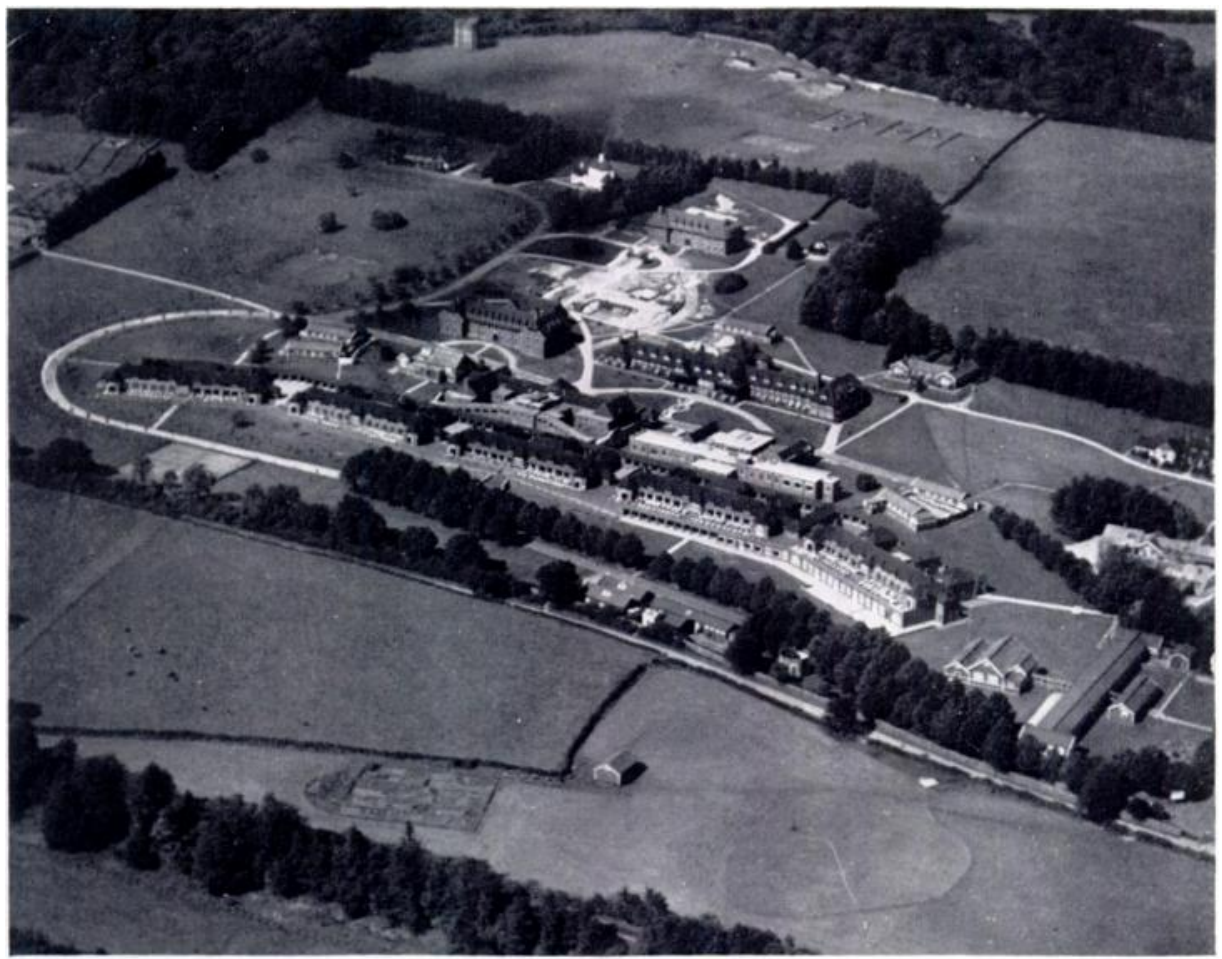

A notable example of the modern type of open-air orthopaedic hospital in (ireat Britain. Lord Mayor Treloar's Orthopaedic Hospital at Alton, Hampshire, photographed from the air. (Photograph by Aero Pictorial Lt.1.)

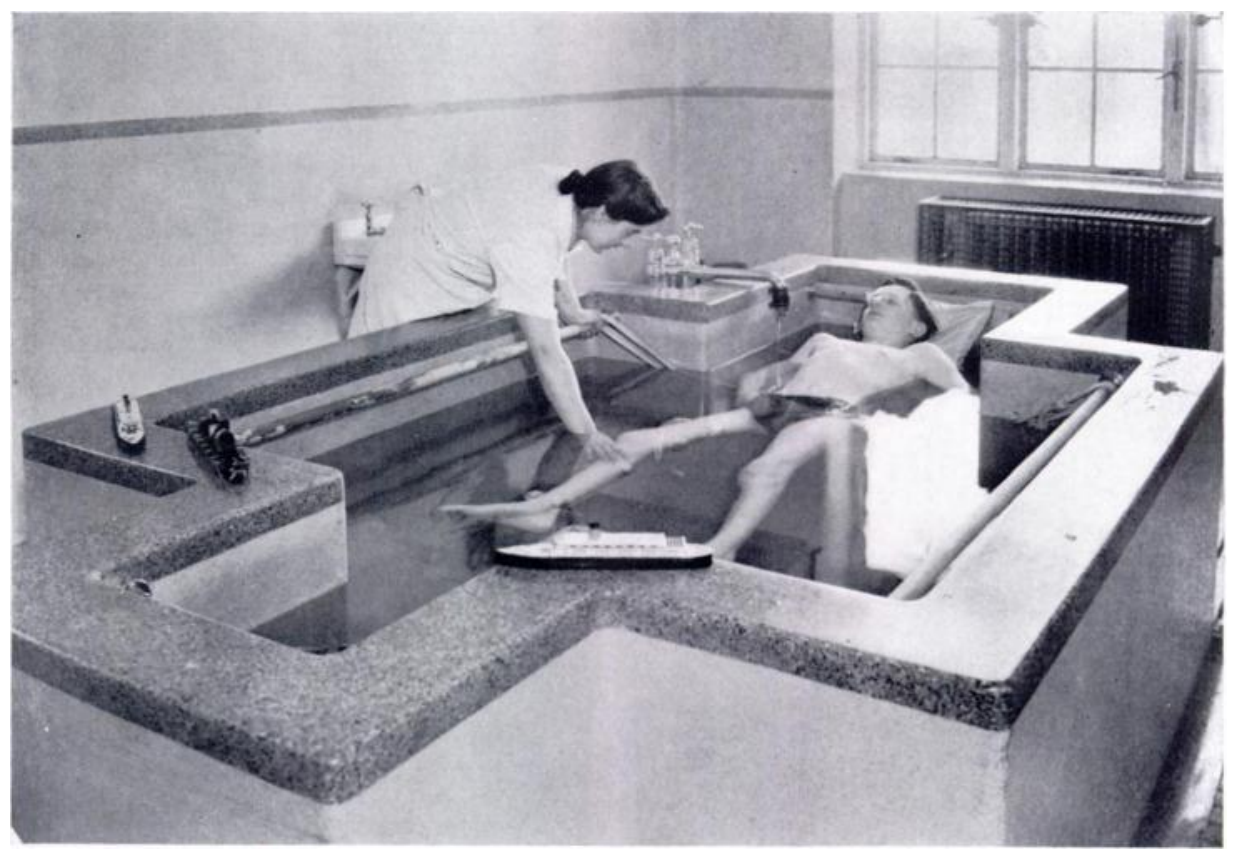

A treatment pool at Lord Mayor Treloar's Hospital, Alton. 
help the crippled children of ex-service men. In 19:4 hospitals were opened at Gosforth, Northumberland; at Brookfield, Hale End, in Essex; and at Coombe Park, Bath. After-care clinics were established in Surrey, Wiltshire, Somerset and Lancashire. A training workshop was added to the Wingtield Hospital. Irybridge at Plymouth, the Manfield Orthopaedic Hospital at Northampton, and the Kirby Moorside Orthopaedic Hospital in Yorkshire were started in 19:5. In the same year the Birmingham Cripples' Union and the Royal Orthopaedic and Spinal Hospital amalgamated to form the Royal Cripples' Hospital, Birmingham, which recently changed its name to the Royal Orthopaedic Hospital. A country orthopaedic hospital was opened at Bretby Hall, Derbyshire, in 1926. In 1927 one of the most attractive of country hospitals, Biddulph Grange, was acquired by the Lancashire County Council for the treatment of non-tuberculous crippled children. The Princess Elizabeth Hospital at Exeter was established in 1928 with clinics in Devon. Through the untiring work of another great

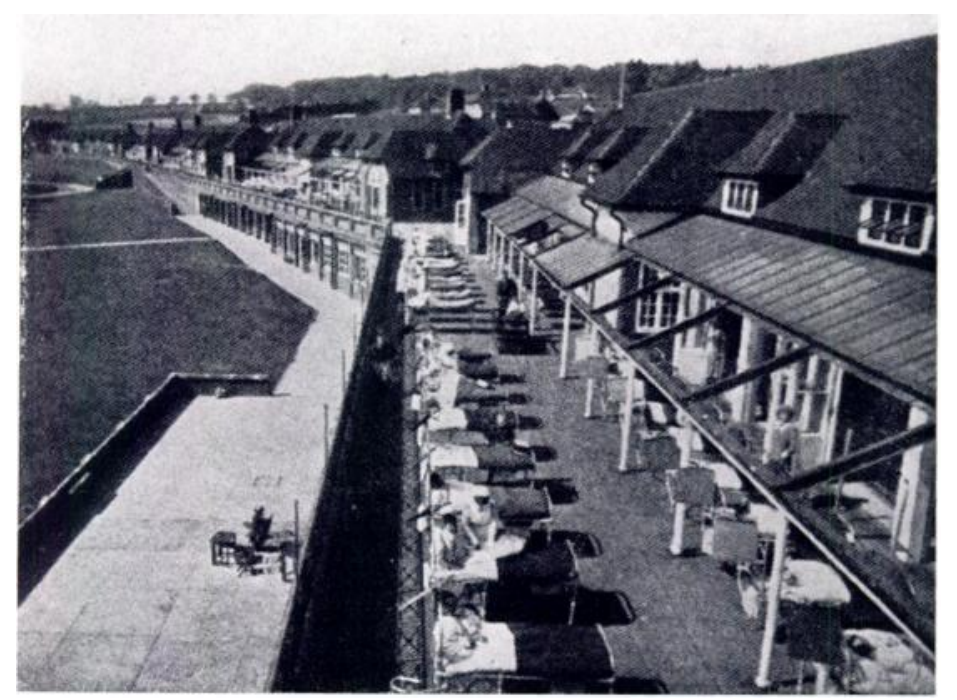

The Great Terrace, Lord Mayor Treloar's Cripples' Training College and Hospital.

pioneer-Dame (ieorgiana Buller, with Xorman (apener, the Devonian orthopaedic scheme is to-day a model of efficiency as a centre of orthopaedic treatment and training of the disabled. Another centre where orthopaedic treatment in hospital is combined with post-operative training of the disabled has recently been completed at Harlow Wood near Nottingham through the efforts of S. A. S. Malkin and the I)owager Duchess of Portland, a life-long: patroness of orthopaedics.

The vears of economic depression, 1930) and 19:31, were lean vears for orthopacdic development in this country. Nevertheless the successful outcome of several fresh enterprises was to be seen in 19:32. Through the persistent efforts of $\mathrm{IV}$. A. Cochrane and others, the Princess Margaret Rose Hospital at Fairmilehead, Edinburgh, was completed for the admission of children. An orthopaedic surgeon was appointed to the Norfolk and Norwich Hospital, and with the Jenny Lind Hospital this has become one of the most active and stimulating centres. Leicester (ity General Hospital and the Bolton Royal Infirmary appointed orthopaedic surgeons. Mount Gold Hospital at Plymouth, and Standon Hall Hospital at Stafford were established. A large hospital for surgical tuberculosis was opened by the Lancashire Tuberculosis authorities at Wrightington in Lancashire; this and the Black Xotley Hospital, Essex, which was opened in 19:30, are among the few open-air hospitals in which patients with combined visceral and skeletal tuberculosis can be treated.

VOL. $32 \mathrm{~B}$, NO. 4, NOVMMBer 1950 
The year 1933 opened sadly for orthopaedics with the death of Robert Jones on January 14. Mourned by many thousands of patients, colleagues and friends in all walks of life, his ashes were laid to rest in Liverpool Cathedral, " here to be sheltered so long as these walls shall stand." The greatest orthopaedic surgeon who was at once " a scientist and a humorist in their perfect association" had gone.

In June 1933 the Prince of Wales opened the Wingfield Hospital which had been rebuilt through the generosity of Sir William Morris-later Lord Nuffield. Since then, as the Wingfield-Morris Orthopaedic Hospital, it has played an important part in British orthopaedics under the guidance first of G. R. Girdlestone, later of H. J. Seddon and to-day of J. C. Scott. Its importance as a centre is greatly enhanced by intimate University connections. It is the home of the Nuffield Professor of Orthopaedic Surgery, a chair now held by Professor J. Trueta. In 1934 a Cripples' Training College for London and surrounding districts was started at Leatherhead for men and boys over school age - an institution which continues to do magnificent work.

Between 1935 and 1937, great stimulus was given to the organisation of orthopaedic services by the munificence of Lord Nuffield who made a gift of $£ 125,000$ to be used in the cause of cripples. Further gifts of $£ 50,000$ and $£ 60,000$ were made to the Governments of Australia and New Zealand respectively for the welfare of crippled children in those countries. In 1937 a grant of $£ 150,000$ was made for orthopaedic development in Scotland and Northern Ireland. Lord Nuffield specifically wished that part of this gift should provide honoraria to enable young surgeons to specialise in orthopaedic surgery. Later in the same year this great philanthropist gave $£ 100,000$ to South Africa for the development of orthopaedic services.

Two important training colleges were opened in 1937-the Stanmore Cripples' Training College under the aegis of the Royal National Orthopaedic Hospital, and the St Loyes Cripple Training Centre at Exeter. It is much to be regretted that the Stanmore Training College has now closed its doors.

During the second world war, from 1939 to 1945 , the emphasis of orthopaedic endeavour was on the treatment, rehabilitation and training of war-disabled in both service and civilian life; but at the same time administrative plans of far-reaching importance were developed for adult cripples. The Ministry of Labour and National Service introduced a scheme for the training and resettlement of disabled persons, incorporated in the Disabled Persons (Employment) Act of 1943, which arranged for registration of the disabled, and insisted that every employer should engage not less than 3 per cent of disabled persons on his staff. The recommendations of Sir William Beveridge, the great Liberal leader, in his well-known report of 1942, were incorporated in a number of Acts of Parliament, prominent among which was the National Health Service Act which recognised the right of every person to gain comprehensive facilities for treatment, rehabilitation and restoration of capacity for work, and for State assistance when the disability was so grave as to make it impossible to compete in the open labour market.

\section{ORTHOPAEDIC DEVELOPMENT IN TEACHING HOSPITALS}

At St Bartholomew's Hospital an orthopaedic department was established in 1864, directed in turn by Willett, Walsham and Howard Marsh. At the Westminster there was Tubby; at the London, Openshaw; and in the provinces, Robert Jones at the Southern Hospital, Liverpool, and Harry Platt at Ancoats Hospital, Manchester. The hospital status of all these surgeons was that of general surgeon in control of an orthopaedic department, and the first orthopaedic surgeon to be given charge of an orthopaedic department with no responsibility for surgical work outside his speciality was Fairbank, who was appointed to Charing Cross Hospital in 1906. In 1912 Elmslie was appointed to St Bartholomew's, and Trethowan to Guy's. These posts involved the systematic teaching of orthopaedics to undergraduate and postgraduate students. 
Gradually, but slowly, orthopaedic units were established elsewhere. To-day, throughout the whole country, there is scarcely a hospital of any size that has not one or more orthopaedic surgeons on its staff. But it is being appreciated more and more that a city hospital, whether teaching or non-teaching, is unsuited for the treatment of chronic illness. The role of these hospitals is to act as "after-care clinics" for the collection, treatment and supervision of out-patients, and with enough in-patient accommodation for investigation, teaching, research and the treatment of "short-stay" problems of disease and injury. It is important therefore that close working liaison should be established between town and country hospitals-a liaison that is being promoted by the regional arrangements of the new National Health Service.

\section{DEVELOPMENTS IN WALES, SCOTLAND AND IRELAND}

Wales-Provision for the treatment of skeletal tuberculosis in children and adults was possible from 1921 onwards under the auspices of the King Edward VII Welsh National Memorial Association. Facilities for the non-tuberculous cripple were not well developed until a scheme was developed in South Wales, centred on the Prince of Wales Hospital, Cardiff, which is affiliated to the Welsh National Medical School. The prime movers in this development were Lynn Thomas and Alwyn Smith, with the support of Robert Jones. Caernarvon and Anglesey developed an association with the Liverpool Children's Hospital at Heswall. The other Northern and Central counties established voluntary orthopaedic schemes in 1928, using the Robert Jones and Agnes Hunt Orthopaedic Hospital as their centre, and eleven very active after-care clinics developed quickly. Within recent years orthopaedic surgeons have been appointed at Newport and Swansea.

Scotland-Despite outstanding early contributions to the science and craft of orthopaedic surgery from Edinburgh and Glasgow, orthopaedic development has been slow in Scotland. Cochrane of Edinburgh, stimulated by his work at the Military Hospital at Bangor under Harold Stiles and Robert Jones after World War I, determined to pursue orthopaedics as a career. After working with Goldthwait at the Massachusetts General Hospital he returned to Edinburgh in 1921 and pursued a vigorous, though not always tactful, campaign on behalf of the establishment of the Princess Margaret Rose Children's Hospital at Fairmilehead in 1932, and for the associated chain of after-care clinics in South-East Scotland. Within recent years Walter Mercer has been appointed professor of orthopaedic surgery in the University of Edinburgh, and efforts are being made to co-ordinate the orthopaedic work of the city with the South-Eastern region. The team of orthopaedic surgeons, of which Robert Stirling is a notable figure, has been strengthened recently by the inclusion of Lawson Dick whose work on bone grafting is in the best Scottish tradition.

In Glasgow the greatest credit is due to a general surgeon-James Russell. Seeing the need for orthopaedic development he deliberately took on to his unit at the Victoria Infirmary in the early 'thirties an orthopaedic surgeon, Alexander Miller, and between them they persuaded the Governors of the Victoria Infirmary in 1939 to convert their beautiful Philipshill Country Branch into an orthopaedic hospital to serve the South-West area of Scotland. The Western Infirmary has a flourishing orthopaedic unit under the command of Roland Barnes, with a country annexe at Killearn; and one of the largest fracture clinics in the country has been organised at the Royal Infirmary by James Patrick.

In Dundee, and the neighbouring Bridge-of-Earn Hospital, orthopaedics is being developed by an excellent team headed by Ian Smillie. In Aberdeen, Alexander Mitchell and his pupil Rennie have a healthy organisation with a large country branch at Stracathro. At Inverness there is a fine orthopaedic unit at Raigmore under the care of R. Murray. Ireland-In 1940 an orthopaedic surgeon was appointed in Belfast and in the same year a chain of clinics was established in most of the important towns of Northern Ireland. There is now a flourishing orthopaedic scheme, centred on Belfast, which engages the time of three

vol. $32 \mathrm{~B}$, No. 4 , NOVEMBER 1950 
orthopaedic surgeons. Fractures are segregated in the fracture clinic of the Royal Victoria Hospital, and there is an increasing number of "long-stay" beds at Musgrave Park. Credit for the development of orthopaedics in Ulster is due largely to S. T. Irwin-one of the oldest members of the British Orthopaedic Association, and R. J. W. Withers.

In Eire development has been slow. Since the days of R. L. Swan, orthopaedic surgery has been practised by Haughton, de Courcy Wheeler, McAuley, Chance and Sommerville-Large. In 1925 it was thought that "professional pride, a public sense of duty, humanity and patriotism were adding fuel to the fire of beneficient enthusiasm." These were pious hopes expressed with the typical eloquence of the Celt! Nevertheless, within the last two years orthopaedic surgeons have been appointed to Kilkenny and Cork; new country hospitals have been, or will soon be, built; and a combined Northern and Southern Orthopaedic Club is being formed. It is hoped that a service long required by the community will soon be working to capacity.

\section{THE DEVELOPMENT OF ACGIDENT SERVICES}

Fractures and dislocations have always received much attention in medical writings but little or no attempt was made to treat them in an organised way until Robert Jones created a fracture service for the workmen who were engaged in constructing the Manchester Ship Canal between 1888 and 1893 . Even after this strikingly successful venture, fractures remained the cinderella of general surgery. In 1912 a committee of the British Medical Association investigated the results of treatment in 3,000 fractures; it was found that there was mal-union in 40 per cent, and that even when the anatomical result was good the functional result was often poor. This was the standard of treatment existing in many if not most parts of Great Britain until twenty years ago.

During the first world war Robert Jones proved the value of organised fracture treatment based upon the three principles of segregation of fracture cases, continuity of treatment from the time of injury until full recovery, and unity of control throughout the whole period of treatment. After that war, enthusiastic attention was directed in almost all civilian hospitals to the many problems of medicine and surgery that had perforce been neglected for a number of years-and the need for organised fracture treatment seemed to be less important. For a time the surgical lessons of the war were forgotten. But Platt had already succeeded in persuading his colleagues at Ancoats Hospital in Manchester of the need for segregation of fractures under unified control, and to him belongs the credit of establishing the first hospital fracture clinic in Britain. Within a few years a fracture clinic was developed at the Liverpool Royal Infirmary by Watson-Jones, and similar clinics were soon in action at Leeds, Cardiff and other centres under the direction of orthopaedic surgeons. It was of course a natural and sensible development that fractures should be treated by surgeons trained and experienced in the surgery of bone, joints, muscles and nerves, but much opposition had to be overcome by these pioneers.

In other countries organisations were developed which provoked interest and enthusiasm. In the United States, O'Neill Sherman, chief surgeon to the Carnegie Illinois Steel Trust, after visiting this country during the 1914-18 war, established a comprehensive scheme for the treatment of industrial injuries sustained by employees. It included a series of dressing stations, casualty clearing stations and hospital beds based on the pattern instituted by Robert Jones for the wounded soldier. In 1926 the Vienna Accident Insurance Company established a special hospital in Vienna under the direction of Lorenz Böhler for the treatment of injured workmen.

From 1929 onwards there was energetic activity in Britain initiated by Gwynne Maitland who, as medical superintendent of the Cunard-White Star Line, was fully aware of the disasters that arose from the inefficient treatment of fractures. He inspired Watson-Jones, Griffiths, Platt, Rowley Bristow and others to campaign for the general development of 
fracture services throughout the country. A special committee of the British Medical Association was set up under the chairmanship of Henry Souttar to investigate the problem. A comprehensive and convincing report, published in 1935 and based largely on the evidence of Platt's clinic in Manchester and Watson-Jones's clinic in Liverpool, presented so strong a case for the development of organised fracture services that industrial leaders and trade union organisations were stimulated. Their interest was aroused still further at a dinnerparty of historic significance, held in the Reform Club, London, when His Majesty the King, then Duke of York, was host to almost every industrial leader of Great Britain. A cinematograph film prepared at the Liverpool Royal Infirmary by Watson-Jones, contrasting old and new methods of fracture treatment and illustrating the principles of rehabilitation, made a powerful impression. In response to the pressure that arose, the Government appointed an interdepartmental committee of the Home Office and Ministry of Health to "inquire into the arrangements at present in operation with a view to restoration of the working capacity of persons injured by accidents, and to report as to what improvements or developments are desirable, and what steps are expedient to give effect thereto." This Delevigne Interdepartmental Committee made unanimous recommendations in its reports of 1937 and 1939 in favour of the institution of special fracture services, and added: "We have little doubt that the principles of the continuity of treatment and after-care until working capacity has been restored should be applied in the accident departments of hospitals to the treatment of all injuries entailing disablement ... We believe that the results of organised fracture treatment will lead to the adoption of similar measures for dealing with other disabling injuries."

It was then recognised that prolonged disability after accidents arose not only from fractures but also from soft-tissue injuries which occurred with ten times greater frequency. If treated inadequately, as so often they were during the first thirty-five or forty years of the century, these injuries gave rise to serious and protracted disablement. The casualty officers of hospitals, recently qualified medical graduates often working without supervision from senior colleagues, had been asked to accept responsibility for the treatment of a multitude of injuries which in fact called for no less experienced judgment and skill than the treatment of acute abdominal emergencies. It became obvious that comprehensive accident services were needed for the treatment of skin wounds, burns, infections of the hand, tendon and nerve injuries, and indeed all injuries of the locomotor system.

The experiences of the second world war emphasized the need for these services both in military and civilian life. In 1943 the British Orthopaedic Association published a memorandum, prepared by its Fracture and Accident Services Committee under the chairmanship of Watson-Jones, stating the case in detail and advising how such services might be put into effect. And so it has come about that in many hospitals there are now combined orthopaedic and accident departments-a policy which it is hoped will gain universal acceptance.

The Birmingham Accident Hospital is a notable example of the application of these principles. Organised by William Gissane, with the co-operation of the other city hospitals, the municipality, and both sides of industry together with their medical advisers, the hospital was planned for the treatment of all visceral and skeletal injuries including burns. Though housed in a separate building it is part of the Orthopaedic and Accident Services of the Birmingham region. It is a large and highly organised prototype for the less ambitious but essentially similar units needed in all general hospitals throughout the country.

Rehabilitation-It is true that most patients, including children, housewives and sedentary workers who suffer from domestic injuries and are treated in efficient accident departments do not require residential rehabilitation facilities. If good treatment of the injury is combined with good "doctoring" of the patient so that the will to recover is constantly imbued, and morale is sustained by doctor, nurse and physiotherapist, recovery is usually complete within

vol. $32 \mathrm{~B}$, No. 4, NOVEMBER 1950 
a few weeks of the time that splints are discarded. Nevertheless there are many patients for whom the gap between the demands of remedial activity in the physiotherapy departments of hospitals, and the stresses of heavy work on the open labour market, should be bridged by a final period of intensified rehabilitation. The aim is to harden the patient through increasing activity of every type, and to concentrate not only on the pursuits of physical activity but also on the inculcation of an attitude of mind-" the will to recover." To some thoughtful doctors who were dealing with industrial injuries it became obvious than many patients were demoralised by long periods of invalidism, and that worry for the present and anxiety for the future were in no way lightened by half-hour visits to a massage department three times each week. Indeed apathy and despair were often induced by such passive treatment.

This had, of course, been recognised by Robert Jones when he established curative workshops in military orthopaedic centres during the first world war. But H. E. Moore was the real pioneer of rehabilitation of injured workmen in this country. In 1925 he began his work at the Railway Rehabilitation Hospital at Crewe. Most of his patients had already received long periods of treatment elsewhere; they were dispirited and seemingly incapable of improvement. Of 165 patients of this type, 115 were returned to their former employment after an average period of seventeen days of rehabilitation by Moore. This was startling indeed, and interest was aroused. That indefatigable worker, Gwynne Maitland, arranged the meeting of such leaders of surgery as Robert Jones, McMurray, Platt, Bristow, Moore, Griffiths and Watson-Jones, together with Robert Hyde of the Industrial Welfare Society and industrial leaders. Slogans were invented-" Getting fit is a whole-time job "; "Rehabilitation starts in the ambulance" ; and so on.

Hospitals with well-organised fracture services began to use their gymnasia more and more, and their machines for passive therapy less and less. Patients attended for several hours each day, and meals were provided. Successful out-patient rehabilitation centres of this kind were established in 1938 by H. E. Griffiths at the Albert Dock Hospital, Greenwich; by Miller of Glasgow who concentrated on the social service aspect of rehabilitation and succeeded in rescuing some 80 per cent of injured Lanarkshire miners threatened with permanent incapacity; and by E. A. Nicoll who established a residential rehabilitation centre for miners at Berry Hill Hall, Mansfield. The merit of residential rehabilitation centres was proved beyond doubt in the second world war-as will be discussed in a later section of this review.

It will be generally agreed that rehabilitation has made very real progress in the last two decades. To-day physiotherapists spend as much or more of their training time in hospital wards as in departments of physical medicine. It is part of the training of a physiotherapist to organise class exercises for medical and surgical patients so that the ill-effects of complete and prolonged bed rest are minimised-and to participate with doctors and nurses in the maintenance of morale. It was remarked by a foreign visitor who was observing a ward class with envy: "It is a sight as stimulating for me as it must be for the patients." Active exercise in the gynnasium, rather than passive treatment on the plinth, is the theme of physiotherapy departments.

The miners of Great Britain now have a series of splendid residential centres; and so has one of the military services - the Royal Air Force. Some industries with enlightened surgical guidance have organised workshops for their injured employees, for example, the motor firms Austin and Vauxhall. There are sporadic rehabilitation units throughout the country; there is an adviser in rehabilitation to the Ministry of Health; and one of the Metropolitan Regional Boards has appointed a consultant in rehabilitation. Nonetheless there is still much to be done and it is to be hoped that the lessons of World War II will not be forgotten as quickly or as completely as were those of World War I. We look with confidence to workers in rehabilitation to continue their efforts-Watson-Jones, Harold Balme, Cooksey, Griffiths, Nicoll, O'Malley, Zinovieff, Ling, Kiernander, Mason, Maxwell-Jones, Gissane, Plewes and many others. As the speed of machinery increases, accidents will cause injuries of greater 
severity and complexity than ever before. Whatever improvements there may be in methods of treatment, and however great may be the benefits of social security, there will always be need for those whose task is not only to indicate how joints should be mobilised and muscles redeveloped, but also to instil into patients the confidence without which they cannot, because they will not, recover.

\section{HELPFUL LEGISLATION}

Throughout the whole of the period under review, constant help was given to the orthopaedic crusade by various Acts of Parliament. The Factory and Workshop Act of 1901 introduced factory inspection and improved hygiene, and it banned many of the practices that had been responsible for injury and disease. The Children's Act of 1908 imposed penalties on parents who neglected to seek treatment for their families. In the years immediately before World War I there were the Trade Board Act of 1909, the Choice of Employment Act of 1910 which allowed grants to after-care committees, and the Lloyd George National Health Insurance Act of 1911 which introduced the panel system whereby wage-earners received general practitioner advice and treatment even if their dependants did not. After the war came the Maternity and Child Welfare Act, and in 1918 the Fisher Education Act which made compulsory the education and treatment of physically defective children of school age. Though it did not come into effect until eight years later it was a signal advance because the liaison created between the Ministries of Health and Education enabled prolonged treatment to be undertaken in hospital without interruption of education. In 1921 the Education Act sanctioned expenditure for the education and training of adult cripples; but national moneys were not yet made available for their treatment. The Public Health (Tuberculosis) Act of 1921 required county councils and boroughs to make adequate arrangements for the treatment of tuberculous patients, including payment for in-patient treatment. After the Milk and Dairies Act was passed in 1922, with insistence on increased cleanliness of milk, there was no further important legislation until the Local Government Act of 1930 altered the old Poor Law and encouraged co-operation between voluntary and municipal hospitals. This helped in extending orthopaedic facilities by the creation of new orthopaedic units in municipal hospitals, working in close harmony with similar units in voluntary hospitals.

The public Health Act of 1936 added further to the responsibilities of county council and borough authorities in respect of the detection and prevention of spread of tuberculosis. The Factories Act of 1937 was a further elaboration of the Factory Act of 1901. Working conditions were improved, hazards were lessened and many devices were introduced by which to reduce the incidence of industrial accidents.

The Workmen's Compensation and allied acts of 1906, 1925, 1931 and 1938, though designed to safeguard the interests of both employee and employer, caused great difficulty to orthopaedic surgeons who were concerned with the restoration of injured men to full working capacity. The two main problems were the "lump sum " settlement and "light" work. A frame of mind conducive to chronic invalidism was often created. As long as compensation was being paid there was little or no organised effort to restore working capacity. Patients and their non-medical advisers often increased the difficulty by refusing treatment lest it might reduce compensation payments. Some workmen were afraid to return to full work because they had no assurance that "cure" was permanent; a few were tempted by the attraction of lump sum settlements and they exaggerated their disabilities; many became chronic invalids, physically and mentally, by reason of the lack of organised rehabilitation, want of appropriate work and failure of sensible reassurance; they lost confidence in themselves and the trouble was aggravated by the insecurity of employment at a time of great industrial depression.

Several Acts of recent years-the Disabled Persons (Employment) Bill (1943), the new Education Act (1945), the National Assistance Act (1948), the National Insurance Act, and

Vol. $32 \mathrm{~B}$, No. 4, NoVember 1950 
possibly the National Health Service Act (1946), have notably forwarded the cause of orthopaedics. Needless to say, these measures have not been accepted without controversyin particular the National Health Service Act, which is still regarded by many members of the medical profession as a hostile political intervention tending to regiment the profession, reduce its professional and social standing, and destroy the doctor-patient relationship. It would be foolish, however, to make hasty predictions about legislation which came into force as recently as July 5, 1948. The merit of other Acts of Parliament passed in the last ten years is undoubted. Formerly an injured man was "paid for his incapacity" by weekly compensation or a lump sum settlement, and if he returned to work despite his disability he lost his compensation. To-day the lump sum settlement has been almost completely discarded: a pension, related to the degree of permanent disability, is granted whether the man returns to work or not; and funds are being expended not just to provide a meagre living for the injured workman and his family but also to restore him to health and work. At long last the adult cripple can receive treatment curtailed only, and we hope temporarily, by the shortage of nurses and hospital beds. At long last, artificial limbs and other appliances are available to all who need them. At long last, it is a Government responsibility to train and place in employment those whose injury or disease has made it impossible for them to learn a trade or who are unable to follow their former trade. A young doctor wishing to specialise is no longer prevented from doing so for economic reasons; he earns an adequate income during apprenticeship. Increases of pay have made the indispensable ancillaries of orthopaedics more attractive careers. To state all this is not to imply that the methods devised to secure these advantages have already been perfected-far from it; but it would be a miracle if such radical changes of medical, hospital and welfare services were already perfect. On the contrary, it is perhaps surprising that the transition from voluntary to State control did not produce even greater dislocation. One reason is without doubt the public-spirited attitude of skilled and experienced voluntary workers who despite initial discouragement have continued to offer help and give guidance to the disabled. It is gratifying to find that local authorities are now ready to use established voluntary societies as their agents in advising the disabled on statutory provisions for their welfare. It is even more gratifying that all Ministries are concerned to encourage co-operation with voluntary bodies. All of us who have worked with local voluntary workers in hospitals, after-care clinics or committees know how personal is their contribution to the cripple. The fear that, by its very nature, a bureaucratic machine cannot provide this personal touch makes us hope that democracy will always ensure an economy that allows the spirit of voluntary service to remain a permanent contribution to our civilisation.

\section{TEAGHING AND TRAINING IN ORTHOPAEDICS}

Undergraduate education-Early in the twentieth century, orthopaedic surgeons contributed to teaching as members of the staff of teaching hospitals. In Liverpool and Manchester, Robert Jones and Harry Platt were quick in developing a university connection as lecturers in orthopaedic surgery. Students attended ward rounds; out-patient sessions and visits to country hospitals were organised; and systematic lectures were given. These activities continue to-day and in most teaching hospitals students have one or more periods of dressership on orthopaedic and accident units. Patients in orthopaedic wards and out-patient departments provide excellent clinical material on which to base the teaching of principles of medicine and surgery, and by which to train students in the elicitation of physical signs. Well organised orthopaedic departments should play an even greater part in the future in training medical students.

In 1937, through the generosity of Lord Nuffield, several new professorships were established in the University of Oxford. G. R. Girdlestone was the first Nuffield Professor in 

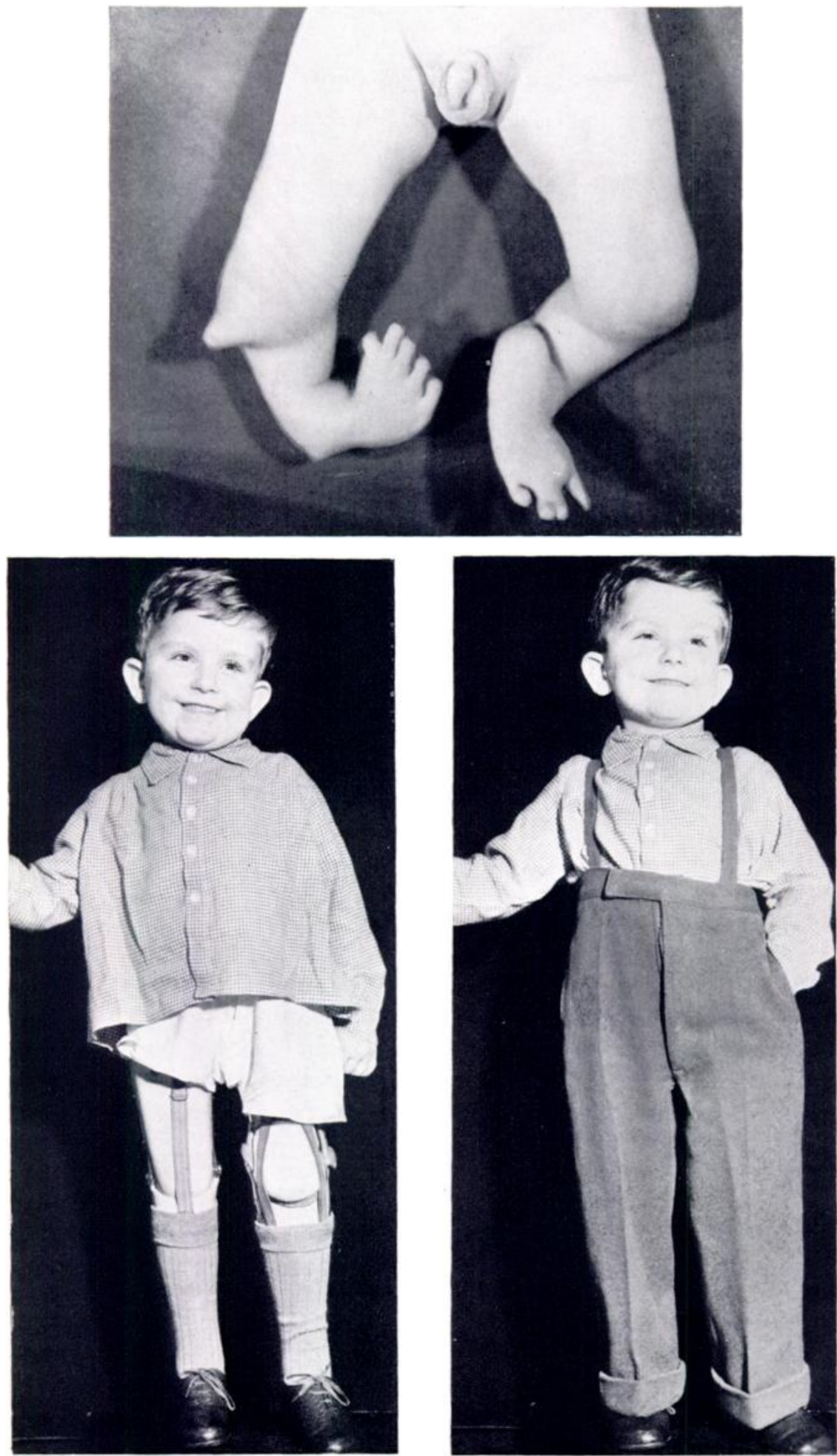

Congenital deformities of legs. The parents realised that amputations would be inevitable and after five vears of continued effort they had saved $£ 200$ to provide artificial limbs. But during growth the limbs would have to be renewed, perhaps more than once. Even before the introduction of the National Health Service, funds from charitable sources were often available for the provision of appliances and prosthese's Now, the National Health Service ensures that this happy little boy and others like him will be provided with the very best prostheses whatever their economic circumstances may be. (Permission of Watson-Jones).

VOL. 32 B, NO. 4, NOVEMBER 1950 
orthopaedics, and the first professor of orthopaedic surgery in this country. He was followed in the chair by H. J. Seddon who resigned in 1948 when he became Director of Studies of the Institute of Orthopaedics at the Royal National Orthopaedic Hospital in London. Seddon was succeeded in Oxford by the present holder, J. Trueta. University departments of orthopaedics were established in Liverpool with the late T. P. McMurray as professor; and in Manchester in 1939, where Sir Harry Platt still holds the chair. More recently Walter Mercer has been appointed Professor of Orthopaedic Surgery in Edinburgh University.

For some time it has been obvious that the duties of a professor of general surgery in a university centre can be performed by the surgeon most suited by teaching ability, organising capacity and intellectual stature, regardless of the particular branch of surgery he practises; and this has been recognised in the appointment to the Chair of Surgery of St Thomas's Hospital of George Perkins who has so long served as orthopaedic surgeon to that hospital.

Postgraduate training-Robert Jones gained his training in orthopaedics by apprenticeship with his uncle, Hugh Owen Thomas. Some of his contemporaries in London were self-trained; others studied in continental clinics or were disciples of the group of surgeons who formed the staffs of the Royal, the National and the City orthopaedic hospitals; but the men who emerged as the leaders of orthopaedics were all directly or indirectly pupils of Robert Jones. Many of them worked in intimate relationship with him-T. P. McMurray, his staunchest supporter, assistant and successor at the historic house, 11 Nelson Street; McCrae Aitken; Alwyn Smith; Naughton Dunn; Gathorne Girdlestone. Others were members of the team Jones gathered around him in World War I-Elmslie, Trethowan, Bankart, Laming Evans, Rowley Bristow, Harry Platt, Ollerenshaw and Whitchurch Howell. Many became established after the war in other centres-Birmingham, Oxford, Cardiff, Manchester, London, there to introduce their teachings and often to reproduce their plans of organisation.

Apprenticeship in a first-class orthopaedic unit is still the popular method of training in Britain. In 1943 the British Orthopaedic Association recommended that after completing practical and academic training in general surgery over a period of some three years, and acquiring by examination a Fellowship of one of the Royal Colleges of Surgeons, an additional four years of orthopaedic apprenticeship was essential. A special diploma, the now much coveted Mastership in Orthopaedic Surgery-M.Ch.(Orth.) was established by Liverpool University in 1924 through the efforts of Robert Jones and T. P. McMurray. The course extends over fifteen months and provides comprehensive practical and academic teaching in every aspect of orthopaedic surgery. The standard of knowledge required at the examination by local and external examiners is very high. McMurray devoted an enormous amount of his time, energy, enthusiasm and vivid personal dogmatism to the teaching for this diploma which could then almost be called the McMurray degree. He left an indelible stamp of sound but conservative orthopaedic practice on his pupils who are to-day some of the leaders of orthopaedic surgery in many centres of the British Commonwealth of Nations. In recent years, under the guidance of Bryan McFarland, now Director of Orthopaedic Studies, the training has been extended and broadened. Students must have completed their basic training in general surgery and hold a Fellowship of one of the Royal Colleges of Surgery before beginning the special training in orthopaedics; before examination they must gain knowledge of orthopaedic practice not only in Liverpool but in other centres in Britain; a comprehensive study of the literature of orthopaedics and the basic sciences is demanded; and the academic standards of a L'niversity Degree, as opposed to the qualifying standards of a College Diploma, are jealously guarded.

In 1946 the British Postgraduate Medical Federation of the University of London established the Institute of Orthopaedics at the Royal National Orthopaedic Hospital with H. Jackson Burrows as Dean. In $1948 \mathrm{H}$. J. Seddon was invited to become Director of Studies. The Institute, though still young, is making a powerful impression as a centre of academic and clinical activity and as a training centre. 
In 1948 the Joint Committee for Postgraduate Orthopaedic Training was formed under the aegis of the Royal College of Surgeons of England, the Roval College of Surgeons of Edinburgh, the Roval Facultr of Phrsicians and Surgeons of Glasgow, the British Orthopaedic Association, the Institute of Orthopaedics of the British Postgraduate Medical Federation, and the Iepartment of Orthopaedics of the Lniversity of Liverpool. Its committee is representative not only of these bodies but also of every region into which the country is now divided for the purposes of administration under the National Health Service Act. Its purpose is to advise and assist those who seek postgraduate training in orthopaedics, and to recommend suitably sponsored candidates from Britain, the Commonwealth and foreign countries to British training centres. The bureau has been used extensively for these purposes and it is hoped to extend its activities in the future. Britain has all the facilities in its first-class orthopaedic units for providing a complete training in every facet of orthopatedic activity, and the large numbers of repuests from all over the world for the use of these facilities underlines the need for a central advisory bureau such as this Joint committee, working in close harmony with its constituent bodies:

since the end of World War II there has been another important development in orthopaedic training. In 1948 a group of thirteen voung British orthopaedic surgeons visited many orthopaedic centres in America and canada and presented papers at the combined meeting in Quebec of the Orthopaedic Associations of America, (anada and Britain. The next year ten American and five canadian surgeons toured representative clinics in Britain and presented papers at the British Orthopaedic Association Meeting in Nottingham. This interchange was made possible by the generosity of many surgeons in America, Canada and Great Britain and by the help of Lord Nuffield. The value of these visits in establishing friendship and promoting knowledge by observation, exchange of riews and critical stimulus can hardly be over-emphasized. Long may ther continue.

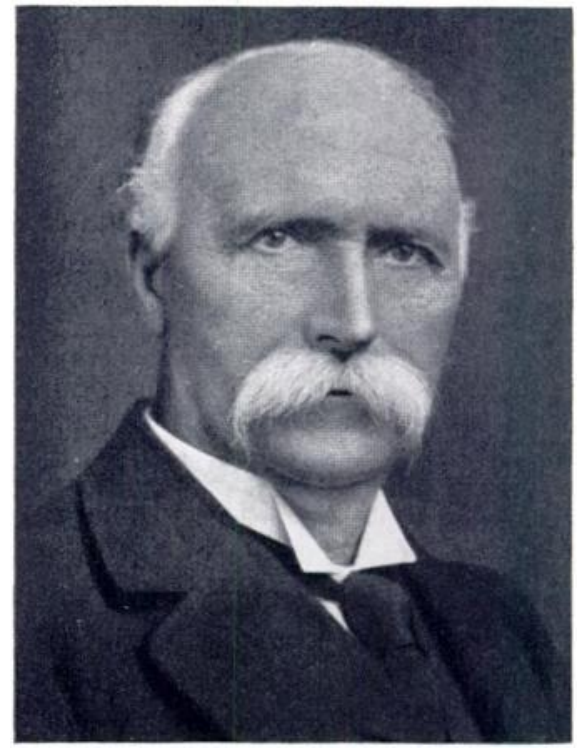

WILLIAM MACEWEN $(1848-1926)$.

\section{DEVELOPMENT OF THE ART, SCIENCE AND CRAFT OF ORTHOPAEDICS}

At the turn of the century orthopaedics had already started to expand as a surgical craft. The "strap and buckle" stage that dated back to the age of Hippocrates was being replaced. Subcutaneous surgery had been practised in Britain since 18:37-tenotomy by Little and osteotomy by Milliam Adams. The tremendous discoveries of anaesthesia and antisepsis increased very greatly the scope of surgical activity. In 1877 Lister himself performed an open reduction and wiring of a fractured patella. His pupil, William Macewen, inventor of the osteotome, had by $\mathbf{1 8 8 0}$, at the age of thirty-two, established osteotomy as a routine procedure and performed the first bone-grafting operation. His book on growth of bone published in 19l2 is one of the orthopaedic classics of this century. Another pupil of Lister,

1* The successful activities of this Joint (ommittee for Postgraduate ()rthopaedic Training have depended almost entirely on the tireless enerey of its Executive Officer. Osmond-Clarke, whose great contribution to orthopacdics in Britain during the last fifteen years has been related to his capacity for friendship, understanding and wise guidance of young orthopaedic surgeons- a facility that has been applied faithfully. in the work of the Committere which he does week by week at the Roval College of Surgeons of England, I.incoln's Inn Fields, I.ondon.-- Editor.

VOI. $32 \mathrm{~B}$, NO. 4, NONEMRER 1950 
Thomas Annandale of Edinburgh, was also a pioneer of osteotomy and one of the first surgeons to explore the knee joint for a meniscus injury in 1879. He thus opened a field of joint surgery in which, by reason of the frequency of these injuries in Association football, British orthopaedic surgeons became greatly experienced. On January 8, 1894, another remarkable pioneer of bone surgery, Arbuthnot Lane, performed for the first time in Britain open reduction and internal fixation of a fracture of a long bone-an unstable fracture of the lower third of the tibia which he held reduced by two obliquely placed metal screws. His book on Operative Treatment of Fractures published in 1905 is another of the ornaments of the period under review.

With these advances in operative technique, and with the conservative principles and methods so firmly established by H. O. Thomas and Robert Jones, the twentieth century opened with considerable promise for continued development-and so it proved. Moreover, advances in other fields-anatomy, physiology, pathology, bacteriology, chemistry, morphology and genetics added much to orthopaedic knowledge and widened its application. It is quite impossible in this review to do more than pay brief tribute to the workers in these fields. Arthur Keith, Wood Jones, Stopford and Arnold Henry are outstanding among our anatomical friends. The discovery of the enzyme phosphatase by the British workers Robison and Kay has probably been one of the greatest single advances in bone physiology since Goodsir's observations on osteogenesis. The work on vitamins by Mellanby, Bourne and others has virtually led to the disappearance of scurvy and rickets. The range of experimental study has been greatly increased by the dramatic work of Honor B. Fell on chick embryo explants. Beevor, Sherrington, A. V. Hill, Fletcher, Hopkins, Adrian and others have made significant contributions to our knowledge of muscle and nerve physiology. Fleming, Florey, Garrod and other bacteriologists have added much to our armamentarium. The British discovery of penicillin has created one of our most powerful aides. The help of pathologists of the calibre of Turnbull, Matthew Stewart and S. L. Baker has been invaluable. Elmslie and Platt made valuable contributions in clinical, pathological and radiographic studies of neoplasms. An early glimpse of the hormonal control of bone growth was given by the work of Dawson and Struthers in 1923. An air of tidiness has at last been given by Elmslie and Fairbank to the bewildering array of bone dystrophies and dysplasias. A promising approach to the solution of problems of congenital anomaly, and familial and hereditary disorder has been made not only in America but by Duraiswami in the Department of Orthopaedic Surgery in the University of Liverpool. His fascinating experiments have demonstrated the noxious effects of substances administered early in the life of the fertilised ovum; and not only has he induced congenital deformities almost at will, but he has shown that once induced by interference with development of the ovum the deformities may thereafter be hereditary and familial.

Since the pioneer days of Thurstan Holland and Robert Jones, X-rays have been of great value in diagnosis and treatment, but we have all learned to recognise the shortcomings of radiographic study which represents no more than the evidence of a structural shadow, and seldom interprets accurately the responses of living tissue except in so far as they are represented by the limited reactions of porosis and sclerosis. Brailsford notwithstandingradiographic dogmatism is unacceptable. At the same time we are more than ready to acknowledge the contribution made by Barclay in cine-radiographic studies of joint movement, and by Sissons in microradiography.

Antisepsis and asepsis-It was obvious to Arbuthnot Lane that something more than antiseptic technique was necessary if surgical operations were to be safe from the risk of infection. He wrote: "The very moderate cleanliness necessary to obtain a good result in ordinary operations is quite insufficient to meet that required when a large piece of metal, whether steel or silver, is left buried in the wound." Operating theatres had to be improved. Looking at a modern operating theatre-roomy, light and with a minimum of dust-collecting 
contents-it is almost impossible to visualise the conditions under which surgeons worked in the early years of the century. We read that at the National Orthopaedic Hospital, London, operations were performed by the whole staff on one morning each week in the out-patient waiting hall which was converted temporarily into an operating theatre. At the Roval Orthopaedic Hospital the house surgeon's sitting-room was used as a theatre each Mondaty afternoon and, as was recorded by Laming Evans, " the entry of the massive wooden operating table temporarily terminated his tenance!" BV 190\% Lane had already introduced sterile caps, gowns and masks for theatre wear. The object of his aseptic technique was to ensure that a gloved finger never came into contact with the wound or with anything that was introduced into the wound. It was based on the facts that gloves were unreliable and that they would often be perforated if instruments were used forcibly; that powerful antiseptics had an injurious effect on tissues and expecially on bone in which metal was implanted ; and that the introduction of infection from outside was a supreme tragedy in bone and joint work.

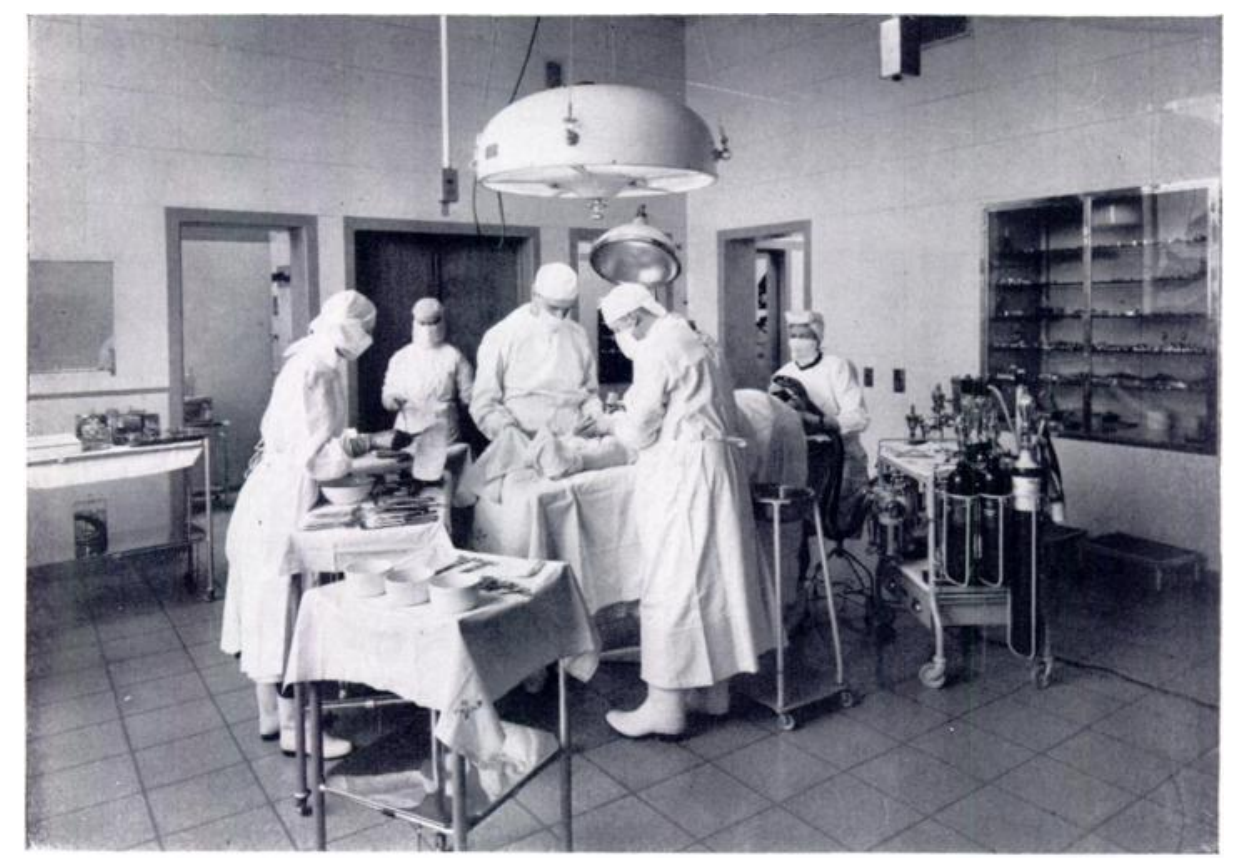

In operation in progress in a typical operating theatre of modern design.

Swabs and dressings were sterilized in drums; instruments were boiled; all were used dru. The knife used for incising the skin was discarded; the wound edges were shut off with tetra cloths and a fresh knife used to continue the deeper dissection. His instruments had handles of such length that the surgeon's and assistant's hands were distant from the wound. Swats. ligatures and sutures were held with forceps: needles were similarly threaded and needleholders used even for skin suture. Drills, screws, plates, and the instruments for holding them, were all kept at boiling point in a small sterilizer. The "active" ends of drills and screw-drivers were returned to the sterilizer after the insertion of each screw. A pupil of Lane and the greatest living exponent of the "no-touch" technique, Sir H. A. Thomass Fairbank, wrote: "Any non-absorbable foreign body to be left in the wound, and every instrument coming into contact with it, were thus guarded from air-borne infection so far as possible." We would all agree with sir Thomas when he said of Lane: "None of his other pioneer work had a greater influence on the practice of surgery than his no-touch technique."

VOL. 32 B, NO. 4, NOVEMBER 1950 
It very greatly increased the margin of safety with which operations on bones and joints could be performed. In the "abdominal era " of surgery many surgeons failed to realise that periosteum, bone, synovial membrane and articular cartilage were less effective in combating infection than peritoneum. "Bone is filled not with

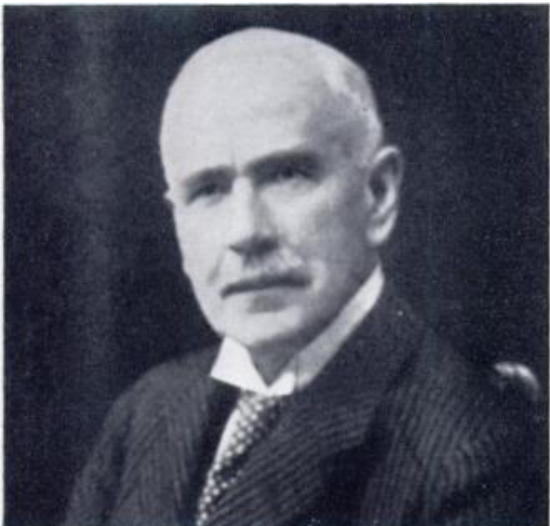

ARBCTHNOT LANE (1\$56-1943). good red marrow but with black ingratitude."

In fifty years the technique of Lane has not been bettered. It is a tedious discipline that some have not the patience to acquire, but many of us believe that despite every modern advance of chemotherapy it is still an essential technique in orthopaedic operations if every precaution is to be taken in aroiding the disasters of infection. Occasionally the use of a gloved finger is less traumatic than the use of an instrument; and sometimes it is more accurate to feel than to see; but these rare exceptions do not detract from the virtue of Lane's method which is not an example of "exaggerated asepsis," as one foreign writer described it, but simply a link in the chain of precautions that every well-trained surgeon should use if he is to be confident in the great repertoire of operative measures by which so manv disabilities of the locomotor ststem can now be treated.

The Conservative Approach-In Britain there has always been emphasis on conservative treatment and this tradition has been handed on br nearly all our great teachers. It is easy to acquire skill as an operative technician, and more difficult to gain experience in the traditional conservative methods that are so often more successful-treatment by rest, support and immobilisation, the use of splints, the protection of supporting bandages skilfully applied, and the later more active régime of physiotherapy, occupational and diversional therapy with rehabilitation and rocational training. Even the application of three layers of cotton wool of loose texture, alternating with three lavers of domette bandage evenly and firmly applied, as taught by Robert Jones for the protection of a damaged knee, is not always practised, and indeed is sometimes scorned by those whose training has been superficial. The splints devised by Hugh Owen Thomas and Robert Jones-the bed knee-splint, the walking caliper, the spine and hip frames and the posterior spinal support are still essentials in orthopaedic practice. They have survived, as have few other splints. Plaster of Paris is still used extensively although there are signs that it may be replaced in the future by plastic materials. The design of splints is constantly improring. No surgeon has done more than Yorman Capener to apply modern principles and, by various spring devices, to support and protect tissues without immobilising them rigidly. His pioneer activity in the modernisation of splints is now supported by a special committee of the British Orthopaedic Association.

Despite the promise of antibiotic and hormonal therapy the time has not yet arrived when tuberculosis, subacute arthritis and rheumatoid affections can be treated without bed rest and immobilisation; and meanwhile increasing attention is being paid to the unfortunate consequences of excessive immobility-hypoproteinaemia and osteoporosis, disturbance of calcium metabolism and renal calculus formation, premature arrest of epiphysial growth, stiffness of joints and wasting of muscles, and the psrchological consequences of immobility. The progress of the fut ure depends almost certainly on recognising the validity of former principles of conservative treatment, but applying to them the modifications indicated by the pioneer work of Capener.

Manipulation-The art of manipulation appears to have been the secret of successive generations of bone-setters until Wharton Hood's famous publications in 1871. Robert 
Jones used it extensively and successfully, as did all his pupils. He maintained that its object was to stretch or " break down " adhesions which formed in the soft tissues around a joint and caused persistent discomfort after injury, and that it was indicated when there was painful restriction of one of the arcs of movement of a joint. Restriction of all ranges of movement indicated intra-articular damage which was unlikely to be helped by manipulation. There is no magic in the manoeuvres of manipulation; the rationale is to stretch or tear the adhesions by putting the joint through a full range of movement, usually with the patient anaesthetised. It is important that this procedure, like all other forms of passive movement, should never be used in the early stages of joint mobilisation after fracture or dislocation. As Robert Jones pointed out, when discussing the treatment of injuries around the elbow joint in 1912, passive stretching of an irritable joint causes more fibrinous exudate, more adhesions, and eventually a stiffer joint. As Watson-Jones admirably puts it - "the balance between adhesions cured and adhesions produced may be a very delicate one." Manipulation is nowadays used less and less for stiff joints and, instead, reliance is placed on the supervised exercises of the patient. Moreover if, for example, a knee joint is stiff after fracture of the femur and it is decided to manipulate under anaesthesia, no more than about twenty degrees of movement is expected to be regained at any one manipulation. The attempt to regain full movement by forcible manipulation is always followed by reaction so severe that the object is defeated. The role of manipulative treatment is now largely restricted to the painful but mobile joint in which adhesions are so localised that reaction in minimal. Watson-Jones wrote of the paradox that " the stiffer the joint the less valuable is manipulative treatment. The more movable the joint the more valuable is manipulative treatment." The knee joint that is stiff after fracture of the femur, the elbow joint stiff after supracondylar fracture, and the shoulder joint stiff after periarthritis with adhesions, usually respond better to graduated exercise. Only the painful " flat foot," the strained knee, the very early arthritic hip, the recent low back strain, and the shoulder with minimal adhesion formation, respond well to manipulative treatment. Moreover, even in this group of cases, manipulation is now used far less often than formerly. Whereas in the 'twenties and 'thirties it was not uncommon for the orthopaedic surgeon to manipulate half a dozen spines each week for chronic backache, nowadays one manipulation every second or third month is the average for most surgeons.

Deformities-When it is recalled that modern operative technique is so extensive that it cannot be contained fully in a text-book of two volumes with 1,643 pages, and that a short treatise on fractures and joint injuries occupies almost one thousand pages in two volumes, the task of ensuring brevity in recounting the treatment of deformity seems insuperable. Early diagnosis and the increasing co-operation of physicians and surgeons in all branches of medicine, which has been one of the bright features of the last fifty years, has greatly minimised the incidence of acquired deformity from injury, arthritis and poliomyelitis; but there is still very limited prophylactic control of congenital deformity, and such acquired deformities as idiopathic scoliosis remain a challenging mystery. It is still true that the best results of treatment are gained by conservative correction with the support of splints until muscle control is regained and bone configuration restores alignment and stability. This is particularly true of club foot, congenital dislocation of the hip, and knock-knee deformity. Contracted soft tissues may sometimes require division or excision, as, for example, in Fairbank's operation for tight internal rotation of the shoulder in birth palsy, and the operations of Elmslie, Trethowan and Brockman for resistant club foot.

The treatment of congenital dislocation of the hip joint is, of course, based on the pioneer work of the old masters Paci, Lorenz, Putti, Galeazzi and Haglund; but notable contributions have been made by British workers, especially Hey Groves, Laming-Evans, Fairbank and Platt. Simple correction of deformity with splinting in the corrected position does not always lead to the development of normal architecture, and in congenital hip dislocations it is sometimes necessary to stabilise the joint by rotation-osteotomy, the construction of a

VOL. $32 \mathrm{~B}$, No. 4, NOVEMBER 1950

$\mathrm{N}$ 
postero-superior lip, or by complete reconstruction of the acetabulum. The latter procedure, which is again becoming fashionable, is commonly known in America as the Colonna operation, and in France as the Leveuf operation, but it was, in fact, first described by Hey Groves in 1927, though deepening of the acetabulum had already been performed by Paggi, Hoffa and Lorenz.

McCrae Aitken's thoughtful studies on scoliosis published between 1906 and his retirement in 1948, emphasizing the importance of the postural reflex and breathing exercise in balancing the spine, have never gained the recognition they deserve. There is no doubt that he restored stability to the spines of many patients with scoliosis, and even in this age of turn-buckle jacket correction with surgical fusion of the spine, his work merits reconsideration.

The field of reconstructive surgery needed for the correction of paralytic deformity, initiated by Nicoladone of Innsbruck in 1880, was already well established in this country in early years of the century. In 1899 Robert Jones and Tubby reported fourteen examples of tendon transplantation, and in 1903 they published Modern Methods in the Surgery of Paralysis. Tubby was the originator of transplantation of the pronator radii teres for the restoration of supination. One of the best of all these operations is the classical flexor to extensor transplant devised by Robert Jones for irreparable lesions of the musculo-spiral nerve. Harold Stiles, Forrester-Brown and Girdlestone contributed procedures for clawed fingers and clawed toes. Transference of the peroneal and toe tendons to the insertion of the tendo achillis by which to strengthen a weak gastrocnemius and soleus was used extensively by Robert Jones, Elmslie and others.

The segregation of peripheral nerve injuries during World War II provided a fresh spate of material for tendon transference, and by then knowledge of muscle physiology and dynamics had greatly increased. Many beautiful results have been achieved by modifications of old operations, and some new operations have been devised. Hendry, J. P. M. Clark, and Seddon and his co-workers, have been foremost in their contributions. Clark's pectoralis major transplant for biceps paralysis-an operation frequently but wrongly ascribed to the writer of this review-is a particularly valuable addition to our repertoire.

When tendon transference is not applicable, or when it fails to ensure stability and balance, stabilisation of deformed joints is often indicated. This can sometimes be achieved by the bone-block procedures advised by Hendry for the paralysed elbow; but more often surgical fusion of joints is indicated, particularly for example in severe and progressive paralytic scoliosis and in paralytic deformities of the feet. Outstanding contributions to stabilisation of the foot were made by Naughton Dunn, Elmslie and Lambrinudi for equinus and calcaneus deformities, contributions of which we were reminded by the most impressive long-term results presented at the most recent meeting of the British Orthopaedic Association.

When paralysis results in disparity of length in the lower limbs there is to-day a choice of procedures for leg equalisation. The methods favoured in Britain are shoe alterations, temporary epiphyseodesis by Blount's method of stapling, shortening of the sound leg, and lengthening of the short leg. Allan of Birmingham has a remarkable series of splendid results of leg lengthening, using a machine of his own design.

Fractures-The treatment of fractures by closed methods reached a peak of perfection in the hands of Hugh Owen Thomas, Robert Jones and their pupils. The detailed technique of manipulative reduction has recently been described with admirable clarity by John Charnley in his book, The Closed Treatment of Common Fractures, which should be read by every surgeon who proposes to treat fractures. In this volume is reaffirmed the principle that scientifically controlled manipulation is still the ideal treatment for the majority of fractures. Despite all advances in operative technique, the sheet anchor of fracture treatment is manipulation.

The use of operative reduction and internal fixation has been stimulated by the discovery of penicillin in London by Fleming and the resulting antibiotic control of infection; by the discovery by Ménégaux and Odiette in France, and later by Venable and Stuck in the United 
States, of the significance of electrolysis of metals; and by the work of Arnold K. Henry in Dublin on his intermuscular non-traumatic approaches. In Britain operation is reserved for comminuted fractures of the patella, olecranon and head of the radius, which are often excised, and for unstable fractures of long bones-oblique fractures of one or both forearm bones, oblique fractures of the tibial shaft, most transcervical and some intertrochanteric fractures of the femur. There is an increasing tendency to employ intramedullary nailing in fractures of the upper and mid-shafts of the femur. Credit for the revival of this procedure, which was first described by Hey Groves in 1921, must go to B. H. Burns. He and his colleague R. H. Young are the main British advocates of routine open reduction of fractures of the shafts of long bones. Most surgeons, however, feel that closed and open methods have each their indications and that unless ideal operating conditions are available it is far safer to rely on conservative measures. Current British practice may be said to hold a balance between the two extremes. The virtues of this unbigoted compromise are powerfully advocated in Watson-Jones's Fractures and Joint Injuries-already a classic.

In the treatment of non-union, grafting operations have been used widely since the days of Macewen and Lane. Until World War II tibial grafts were used almost exclusively. Failure of the graft to incorporate was high because there was no way of ensuring secure fixation to the host bone. The technique of Albee, ensuring an exact fit, was not always applicable; nor was his superb carpentry within the capacity of many surgeons. Indeed, it is probable that only one British surgeon, W. H. Trethowan of Guy's, was Albee's equal in craftsmanship. Results improved when in 1936 the Americans, Stuck, Venables and Beach, introduced to orthopaedic surgery a metal alloy-vitallium-which did not react with the body tissues. This has been one of the outstanding contributions in this century. In bone grafting, vitallium screws enabled inlay or onlay grafts to be locked securely to the recipient bone. Some of their limitations are becoming obvious, particularly when used in old compound injuries and, as Watson-Jones stressed in his Hunterian Professorship Lecture (1948), it is wise to use as few as possible and not to insert them close to the fracture line. During World War II attention was directed to the use of cancellous bone chiefly by surgeons concerned with reconstruction of the mandible. The work of former advocates of spongiosa bone was reviewed-Ollier, Willis Campbell, Gallie, Matti, Stuck and Ghormley. The claim that cancellous bone chips produced the most rapid and certain new bone formation was substantiated and it was soon observed too that chip transplants were more resistant to infection than cortical grafts. It is nowadays common to use a combination of massive onlay (first described by Hey Groves in 1918) or double onlay tibial grafts, reinforced with chips usually taken from the ilium, in all major reconstructive procedures. It is important to realise that, quick as it is to unite, cancellous bone does not mature any faster than cortical bone and protection must be prolonged.

Intramedullary nailing, combined with bone grafting, has an important role in the treatment of non-union in certain long bones. The internal fixation provided is often sufficient to protect the grafts while allowing active mobilisation of the joints immediately above and below the fracture. Bone banks-for the early work on which we owe so much to the United States of America-promise to lighten markedly the burden of the patient and the surgeon. Joint abnormalities-Recurrent derangement of joints has been a special British study. It was indeed a Leeds surgeon, William Hey, who in $\mathbf{1 7 8 4}$ coined the term "internal derangement of the knee joint." Brodhurst of St George's Hospital was probably the first British surgeon to remove a medial meniscus in 1866 . The surgery of the menisci was, however, really established by Annandale of Edinburgh in 1879 and later by H. W. Allingham. The importance of the torn meniscus as a source of disability was appreciated early by Robert Jones who in 1906 published the results of one-hundred successful operations. He was the founder of the modern technique of removal of a meniscus through a limited antero-medial or antero-lateral approach. Derangement of the knee consequent upon stretching and tearing of ligaments has received much attention from British surgeons. Hogarth Pringle, whose

VOL. $32 \mathrm{~B}$, No. 4, NOVEMBER 1950 
observations on fractures of the tibial spine were remarkably accurate, reported the first repair of the cruciate ligament system in 1907 . The cruciate laxity was, however, due to avulsion of the tibial spine which can be reduced readily by manipulation and is by no means the same problem as rupture of the ligament itself. Hey Groves first, and later Alwyn Smith, introduced about 1917 an ingenious operation for the replacement of torn cruciate ligaments by fascia lata. Edwards in 1926 advocated the use of the tendons of the gracilis and the semi-tendinosus instead of fascia lata. These operations have never been wholly successful. The regrettable position is that if intensive development of the thigh muscles with or without a knee cage does not produce sufficient stability, arthrodesis is the only satisfactory procedure. Experiences of ruptures of the lateral ligaments in World War II indicate that immediate repair and adequate immobilisation offer the best chance of a stable joint.

Recurrent subluxation of the ankle has been studied by many British surgeons, notably Elmslie, Watson-Jones and Rowland Hughes. The mechanism is now clearly understood and a reliable operation is available for its treatment. Elmslie replaced the torn external ligament with fascia lata. Watson-Jones's contribution was not so much the use of peroneus brevis as a simpler and more effective repair but the prevention of recurrent dislocation by distinguishing in the acute stage self-reducing dislocations which needed long immobilisation in plaster from simple sprains which needed no special treatment; he showed that the displacement could be demonstrated with accuracy in radiographs taken with the ankle subjected to inversion strain.

The pathogenesis and treatment of habitual dislocation of the shoulder was greatly clarified by Bankart's work. In 1923 he re-emphasized the importance of detachment of the glenoid labrum and advocated for the first time an operation for its reattachment to the bony margin of the glenoid. Curiously enough, the exact pathogenesis, including an account of the defect in the postero-lateral aspect of the humeral head, had been described as long ago as 1837 by Curling, a surgeon of the London Hospital, but his very accurate observations had passed almost unnoticed. The operation advised by Bankart, or that devised by Putti and independently by Platt, are the standard procedures in Britain to-day. Their use affords lasting relief in about 95 per cent of patients.

Platt has aptly christened the prolapsed intervertebral disc " the internal derangement of the spine." Orthopaedic surgeons have realised what perhaps some of their colleagues in allied specialities have not-that once a disc is damaged there is mechanical instability of the spine which may increase with age. Pressure on a nerve root is only an incident, albeit a very painful one, in which not more than about 10 per cent of patients require an operation for its relief. It is important that the damaged intervertebral disc should be regarded as an abnormal joint, comparable to one ankylosed unsoundly by fibrous tissue. If it is treated with care by corseting and some modification of activities the joint may remain painless. If it becomes painful, arthrodesis as for other joints with unsound ankylosis, may be necessary. In Britain most orthopaedic surgeons undertake the whole treatment. A few prefer to tackle it in collaboration with neurosurgical colleagues. Of orthopaedic surgeons, Burns and Young, and more recently Armstrong, have studied intervertebral disc lesions most extensively in this country. No one, however, has yet found a solution for the tragic case of the patient in whom nerve roots become adherent to the site of disc protrusion after its removal. The persistent sciatic discomfort arising from fibrosis in and around such nerve roots is not always cured by lumbo-sacral fusion-at any rate in Britain!

Tuberculous arthritis-It is a sad commentary on an otherwise admirable public health service that orthopaedic surgeons in Britain are still confronted with considerable numbers of patients suffering from skeletal tuberculosis. Our experience is that splinting and bed rest until the disease is quiescent, with later fusion of the affected joint, is still the best we can offer. Orthopaedic surgeons in general, and H. O. Thomas and Robert Jones in particular, deserve great credit for eradicating the disastrous practice of excision of active tuberculous 
joints which was nearly always followed by multiple sinus formation and amputation. Amputation for tuberculous disease of the ankle and tarsal joints, performed almost on sight in the first two decades of the century, is now seldom necessary.

There has been a remarkable profusion of techniques for ensuring bony fusion in tuberculous joints. Extra-articular arthrodesis with free grafting of bone is still the most favoured procedure. H. A. Brittain's contributions in the last fifteen years to the technique of arthrodesis have been outstanding, particularly his operation for ischio-femoral fusion. Some have felt it wise to modify his approach but none disputes the soundness of his architectural principles. Streptomycin has been valuable, especially in the healing of sinuses, and there can be little doubt that we are entering a new phase in the treatment of skeletal tuberculosis. We have already found it possible to abort acute tuberculous synovitis, though older lesions in the same patient remain unaffected. The lesson of the moment appears to be that we must establish the diagnosis earlier while the disease is confined to the synovial membrane. This may well mean more joint biopsies which, with the protection of streptomycin, no longer carry the same risk of sinus formation and dissemination of disease. Another advance is the treatment of Pott's paraplegia in selected cases by a modification of costo-transversectomy which allows accurate inspection of the site of disease and evacuation of pus, debris and sequestra. Norman Capener was the first to develop this antero-lateral decompression operation, which he has called lateral rachotomy.

Chronic arthritis-This is an enormous subject which cannot be discussed here in any detail. We should note, however, that the increasingly close liaison between orthopaedic surgeons, physicians and biochemists has ensured that for the past twenty years orthopaedic out-patient departments have ceased to be crowded with sufferers from rheumatoid polyarthritis with quiescent disease but with joints grotesquely deformed. It looks as if the new pituitary and adrenal hormones will make our task easier in the future. In the field of degenerative arthritis there is no such promise. Correction of deformity, redistribution of body-weight, arthrodesis and arthroplasty, make the chronological story of our practice in the operative field. It is interesting to find that an arthroplasty in constant use to-day for the treatment of hallux rigidus and hallux valgus - excision of the base of the proximal phalanx of the great toewas first performed by N. Davies-Colley of Guy's Hospital on February 13, 1885. In 1904 it was reported by Keller, whose name has since been coupled with the operation. The hip is perhaps the joint most commonly affected by degenerative changes in Britain. It is agreed that when the disease is bilateral arthroplasty is the only justifiable operative procedure. Though the cup arthroplasty of Smith-Petersen is most widely practised there are other methods in use-excision of the head and neck of the femur advocated by Girdlestone and his pupils, and the same operation combined with subtrochanteric osteotomy by Batchelor. The old pseudarthrosis of Robert Jones and Whitman's reconstructive excision of the femoral head extensively used in the 'twenties and 'thirties are no longer popular. Replacement of the femoral head by plastic replicas as advocated by the French surgeon, Judet, is still very much on trial in Britain. For the single hip affected by osteoarthritis controversy still continues about the relative merits of arthrodesis, arthroplasty and displacement osteotomy. It is not proposed to extend the controversy here other than to say that the soundly fused hip is one of the most satisfactory results known, and arthrodesis is still practised widely in this country, particularly by its keenest proponents, Watson-Jones and Brittain.

Hand surgery-Thanks to the work of the Americans, Kanavel, Bunnell, Koch and Mason, disabilities of the hand are at last receiving the attention they deserve. It is a curious fact that surgeons the world over should have been so slow to concentrate on the hand-perhaps the most priceless possession of the human animal. World War II underlined the importance of tendon injuries and burns. R. G. Pulvertaft and R. Furlong have done work of outstanding merit in the repair of damaged tendons, and our colleagues in plastic surgery have done much to salvage the gross mutilations caused by burns.

VOL. 32 B, NO. 4, NOVEMBER 1950 
Tumours-The contributions of Elmslie and Platt to knowledge of bone tumours have been noted already. That outstanding authority on malignant disease, Stanford Cade, has given us the benefit of an unrivalled personal experience of the treatment of bone tumours by surgery and by radioactive substances. In his recent Bradshaw lecture at the Royal College of Surgeons, Platt reminded us that amputation is still the only treatment that can offer a few extra years of comparative comfort to the sufferer from primary malignant disease of bone. In this field radiotherapy has so far been disappointing; it remains to be seen what may be offered by future developments in the science of nuclear fission.

Two British surgeons have made notable contributions in this century to the technique of amputation. The hindquarter amputation so lucidly described, and to this day so ably executed, by Gordon Gordon-Taylor has been responsible for the prolongation of many lives. Within the past few years Brittain and others have diminished the post-operative disability by their success in providing useful prostheses. Forequarter amputation, fortunately even more rarely indicated that the hindquarter, is usually considered a formidable technical feat, as indeed it is through the usual anterior approach. The method described by the Leeds surgeon, Littlewood, in which an initial posterior approach frees the vertebral and upper borders of the scapula and allows the shoulder to fall forwards, thus exposing the great vessels and nerves which can be dealt with easily, seems almost to have escaped attention.

These hasty glances must suffice to indicate current British practice, how it has changed since the early days, and how much we owe to colleagues past and present. The writer was once chided for criticising senior colleagues, for some of whom he had often more affection than respect. He was told: "You young fellows have climbed up on the shoulders of giants." It has indeed been so, and I hope that in this sketchy survey the debt is to some extent acknowledged, though briefly and with a very inadequate pen.

\section{THE LEADERS}

Orthopaedic surgery did not develop without nurture from great men and women. Reference has already been made to the predominant efforts of Robert Jones who must be regarded as the pioneer of organised orthopaedic surgery in this country; and to the contribution of Arbuthnot Lane in operative technique. But there were others of commanding stature whose influence was far-reaching.

E. Muirhead Little (1854-1935), youngest son of W. J. Little, the founder of London Orthopaedics, was a contemporary of Robert Jones and a graduate of St George's Hospital. He was the first president of the British Orthopaedic Association and was elected a corresponding member of the American Orthopaedic Association as early as 1894. For practically all his professional life, from 1888 to 1919 , he was on the staff of the National Orthopaedic Hospital (later the Royal National Orthopaedic Hospital). When Queen Mary's Hospital was founded at Roehampton during World War I for the limb-fitting of soldiers with amputations, Muirhead Little was surgeon-in-charge until after the armistice when he became a member of the Advisory Council of the Ministry of Pensions and one of the advisers on artificial limbs to the Minister. He was considered in those days to have a greater knowledge of artificial limbs and their fitting than any other living surgeon. His knowledge of orthopaedic literature was encyclopaedic and he himself wrote with erudition and scholarship; much of his writing was, with characteristic modesty, contributed anonymously to the British Medical Journal. His most important work was "Artificial Limbs and Amputation Stumps" (1922) and an interesting contribution was his essay on "Orthopaedics before Stromeyer " in the Robert Jones Birthday Volume (1928). A man of singular charm and modesty without an enemy, he was, as Rocyn Jones wrote in his obituary, " about the last link with the tenotomy period in the development of orthopaedic surgery."

A. H. Tubby (1863-1930) qualified from Guy's Hospital and after a period of study in Germany he was appointed to the National Orthopaedic Hospital and to the Westminster 


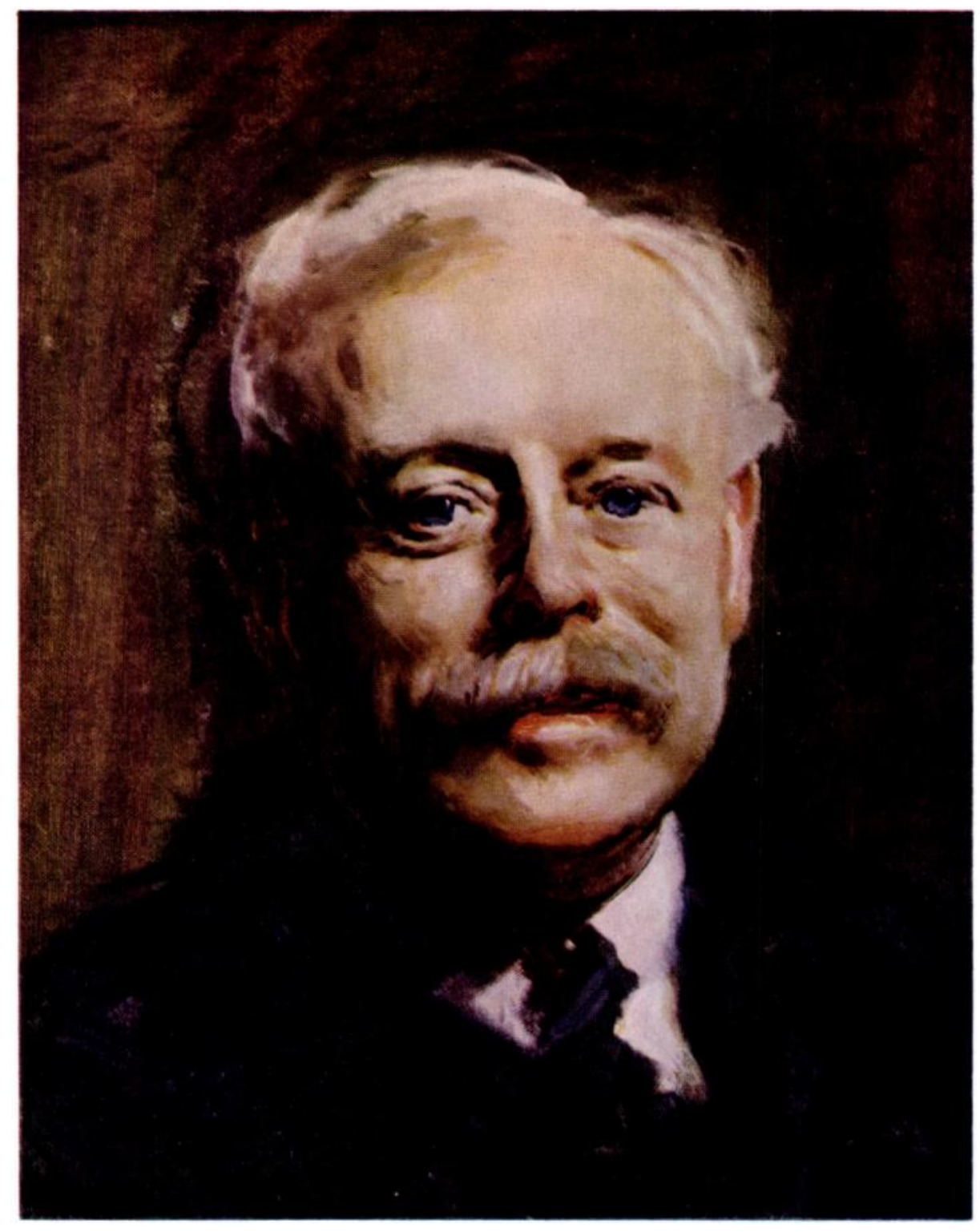

ROBERT JONES (1857-1933).

(Repreduced by the kind permission of Lady l'robyn Jones). 
Hospital. Next to Robert Jones he was the outstanding genius of his day in British orthopaedics. A man of great mental and physical activity, he worked extremely hard both at his profession and his pastimes. In 1903 he published in collaboration with Robert Jones a book, Modern Methods in the Surgery of Paralysis, advocating the most up-to-date principles of tendon transplantation. But his magnum opus was Deformities: a Treatise on Orthopaedic Surgery, published in 1906 and demanding a second edition in two volumes in 1912. This book was remarkable for its erudition and in those days for its scope; it dealt not only with deformities but with diseases of joints and especially tuberculosis. It indicated the broadening of the field of orthopaedics which had begun at the turn of the century and which owed so much to Robert Jones and Tubby. This book made Tubby an international figure. He wrote extensively also on sport and archaeology. Indeed, had it not been for his active interest in sport and the demands of an enormous private practice his contribution to the development

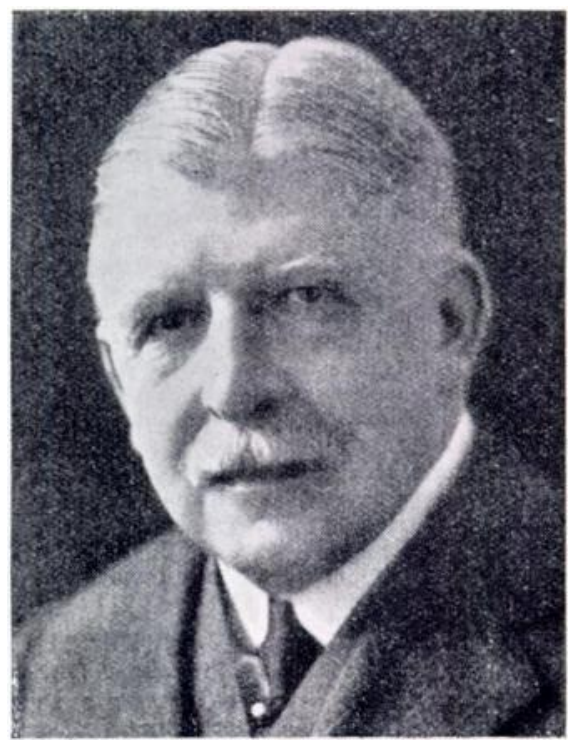

A. Н. Тевву (1863-1930).

of orthopaedics might have been greater. He was secretary of the short-lived British Orthopaedic Society and an original member of the British Orthopaedic Association, in the work of which, like his rival Openshaw, he took but little part. In World War I he acted as consultant, mainly in the Mediterranean and Egyptian theatres, from the experience of which he wrote a fascinating and popular little book, A Consulting Surgeon in the Near East.

T. H. Openshaw (18:56-1929) was one of the great " characters " of his day. "Tommy" to all his colleagues, a Lancashire man by birth, he retained his native accent and abruptness of manner and speech throughout a long life of practice in London on the staff of the London Hospital and the Royal National Orthopaedic Hospital. He was indeed the first surgeon to be in charge of the Orthopaedic Department of the London Hospital. He wrote little and his particular forte lay in the acuteness of his clinical observation and his ability as a forthright teacher. He did not always see eye to eye with his orthopaedic colleagues, either during World War I or after. Though one of the signatories of the circular letter calling a preliminary meeting in 1918 to discuss the formation of the British Orthopaedic Association-the other signatories being Robert Jones and Muirhead Little-he refused subsequently to hold office in the Association and took little or no part in its meetings.

E. Laming Evans (1871-1945) qualified at St Bartholomew's Hospital and took up the speciality of orthopaedics on his return from the South African War. He was for many years 


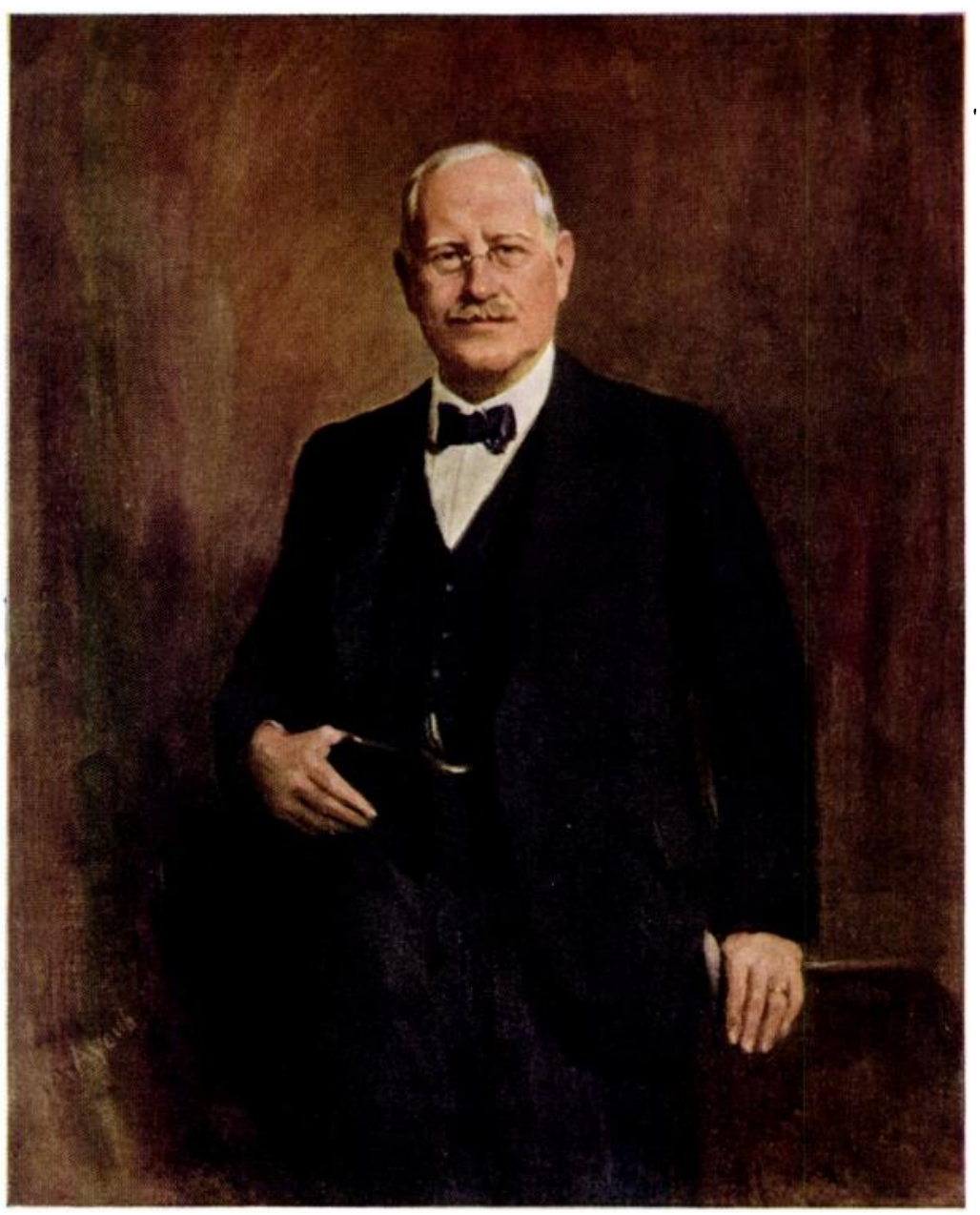

E. W. HEY (IRONES $(1872 \cdots 1944)$.

(Reproluced by permission of the British Journal of Surcery.) 
on the staff first of the Royal and later the Royal National Orthopaedic Hospital. His main interest in orthopaedics was in the manipulative treatment of congenital dislocation of the hip and in the treatment of paralytic calcaneo-cavo-valgus by astragalectomy. Selecting his cases with remarkable care and uncanny judgment he obtained results in these two conditions which can hardly ever have been surpassed. Conscientious to the point of extreme irascibility, he was difficult to please-but there was much to be learnt from him. His derotion to orthopaedics was shown by the bequest to the Royal College of Surgeons of England of the whole of his estate, from which has been founded the Laming Evans Research Fellowship in Orthopaedic Surgery.

E. W. Hey Groves (1872-1944) qualified from St Bartholomew's Hospital in 1895. After a period as resident accoucheur at his teaching hospital he settled in general practice near Bristol. He gained a considerable local reputation by performing major surgical procedures in his own house, assisted by his wife. These were early signs of an adventurous operative spirit which persisted throughout his life. In spite of his busy practice he had by 1905 obtained

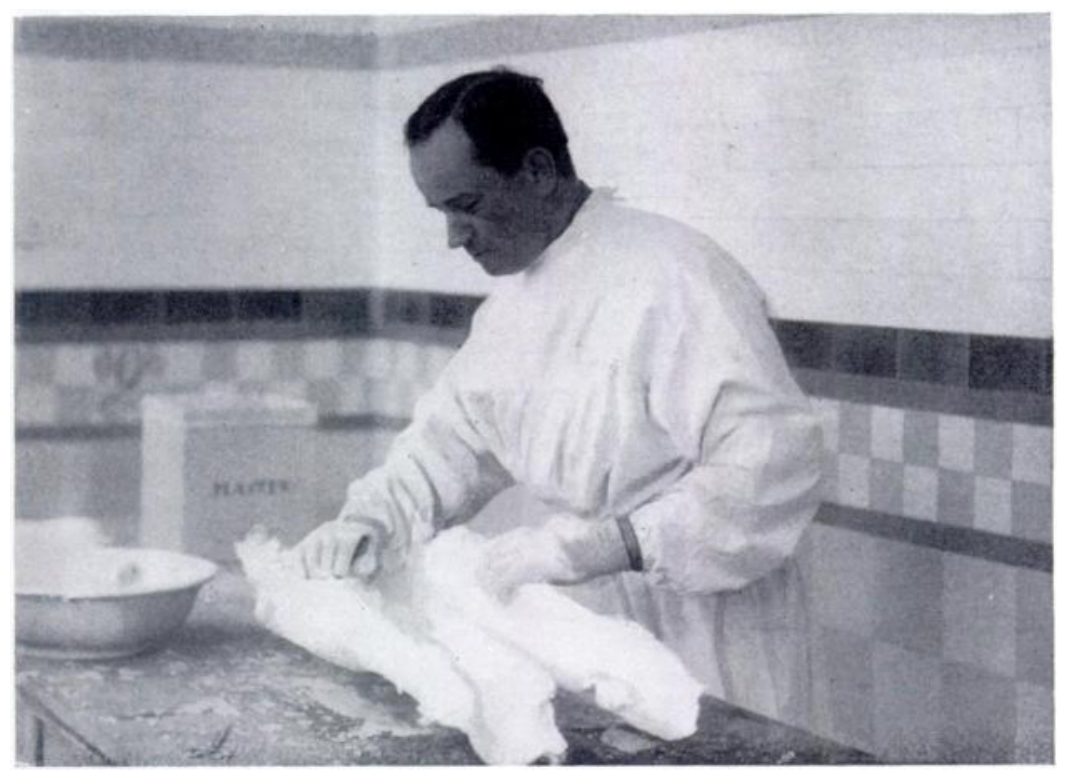

R. C. ElMishe (1S78-1940).

his higher degrees and was appointed to the staff of the Bristol General Hospital. Early in his career he turned his attention to bone surgery, and it was in orthopaedics that he established an international reputation. He was a most ingenious surgeon. Many of the procedures now increasingly popular-for example, intramedullary nailing for fractures, acetabular reconstruction for unreduced congenital dislocation of the hip-were first performed by Hey Groves. He was one of the pioneer bone-grafters, using bone, ivory and even walrus tooth! Many of the operations advocated by him required better anti-shock measures than were available in those days and a far stricter aseptic ritual than existed outside Arbuthnot Lane's own practice. He was a prolific writer. Perhaps his greatest contribution to British surgery was the making of the British Journal of Surgery, which he founded in 1913 and edited for nearly twenty-five years. As Moynihan said when presenting him with a gift from the editorial committee - "You were one of those in whose mind was conceived the idea of founding in this country a journal worthy of the contributions to the art and science of surgery which England and the British Empire were making. Difficulties were many and opposition and 
indifference were found in high places ... All our plans, all our ambitions, all our efforts, found in you a most willing, most competent and tireless worker. Your industry, your wise judgment, your enthusiasm and unwearying tact have been of value beyond reckoning in maintaining year after year our corporate efforts." The spirit of this eulogy is shared by British orthopaedic surgeons for the help which in many ways and in many places Hey Groves gave to our speciality.

R. C. Elmslie (1878-1940) spent the whole of his professional life as student and surgeon at St Bartholomew's Hospital and at the Royal National Orthopaedic Hospital, except during World War I when he was in charge of the Military Orthopaedic Hospital, Shepherd's Bush. He spent five years as a demonstrator of pathology and his knowledge of this subject coloured his work in orthopaedics. To it we owe the classical work on fibrocystic disease of bones first published in 1914 and expanded subsequently in the Birthday Volume. As an orthopaedic surgeon Elmslie was one of the greatest of his day, next only to Robert Jones and perhaps Tubby. His ability to think clearly, his wisdom, imperturbability and admirable judgment were his powerful assets. Indeed the writer has never worked with anyone whose judgment always proved so sound; it seemed that he was incapable of being wrong. He was a competent and neat operator who devised several first-class procedures. His only expressed vanity was to pride himself on sewing skin in, as he put it, " the manner of those who know best how to sew-women." Like Robert Jones, he deroted an enormous amount of time to the social welfare, education and after-care of crippled children. He was in great demand for committee work in his own hospital, Government departments, the Royal College of Surgeons (on the council of which he served from 1933 until his death), the British Orthopaedic Association, the British Medical Association, the Chartered Society of Physiotherapy, and the Central Council for the Care of Cripples. His clear and logical exposition before the Select Committee of the House of Lords is said to have carried the greatest weight in deciding the Committee to reject the osteopaths' claim for recognition. As a man Elmslie lacked the warmth of Robert Jones, whose friend and admirer he always was. He was not easy to know-but his reserve did not prevent him inspiring the greatest enthusiasm and devotion in his pupils which they still retain.

IV. H. Trethowan (1882-1934) was a student of Guy's Hospital and was appointed its first orthopaedic surgeon in 1912. He was one of Robert Jones's team at Shepherd's Bush in World War I. After the war he joined the staffs of the Royal National Orthopaedic Hospital and Queen Mary's Hospital for Children, Carshalton, and quickly established one of the largest private practices in London. He was a genius; but unfortunately he seldom committed his ideas to print. Indeed, his only writings were "The Treatment of Simple Fractures" in Robert Jones's Text-book of Military Orthopaedic Surgery in 1920 and an article of singular clarity and

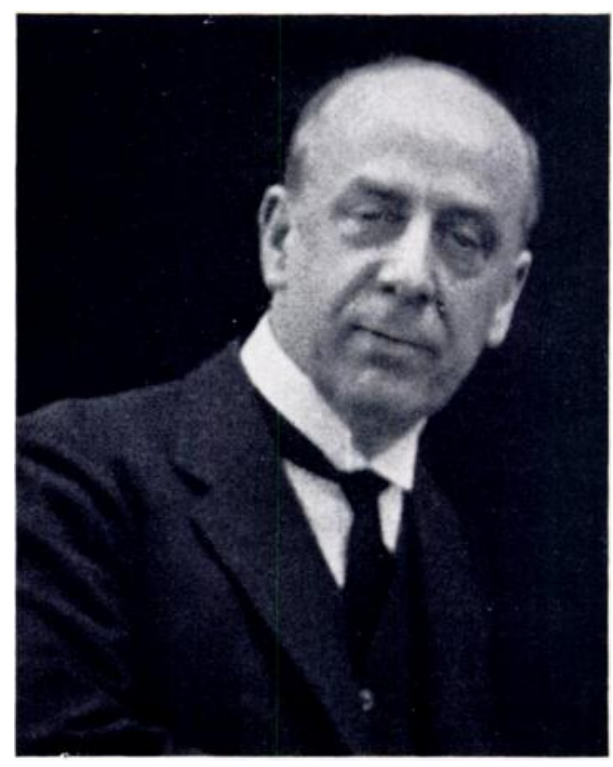

W. H. TREThowan (1882-1934). brevity on orthopaedics in Choyce's System of Surgery. It was his custom to make full notes and to write long explanatory letters to doctors. Fortunately, a selection of these letters expressing Trethowan's views on topical orthopaedic conditions (foot anomalies, abnormalities of the back, disorders of the knee and bone grafting) have been published in book form by his associates, Lambrinudi and Stamm. Reading these is almost to hear the

VOL. $32 \mathrm{~B}$, No. 4, NOVEMBER 1950 
fervent advocacy or condemnation all over again. It is to be hoped that this remarkably fine little book, containing the views of one of the greatest, if not always the soundest, of teachers will be reproduced. One recalls his out-patient sessions: there was never a dull moment. His imitations of gaits in various orthopaedic conditions can never be forgotten by any who had the good fortune to be present. He maintained that the object of orthopaedic surgery could be written on a thumbnail-function. As an operator he has never been equalled. Indeed, a house surgeon of his once said: "I would insist on Treth (as he was known to all) doing my operation if Elmslie decided that an operation was necessary." A disciple of Arbuthnot Lane, he quickly mastered the no-touch technique and applied it to every operation, great and small. His incisions were long, to enable him to see before he cut and to make it unnecessary to use the sense of touch. He never ligated vessels, maintaining that if a surgeon exposed bone at its most superficial point and stayed close to bone he was unlikely to cut any vessels of importance. Bone-grafting was perhaps his special forte. He favoured long intramedullary insertion of the graft at one end and a mortise fit to the circumference of the bone at the other. In the writer's judgment he was a greater technician in this field than Albee, who was not embarrassed by adherence to a no-touch technique!

At conferences he often favoured the dramatic touch. Few will ever forget seeing him during a discussion, probably on foot deformities, spring to his feet brandishing a Thomas's wrench and exclaiming, " This is a barbarous weapon!" as he threw it to the floor. His good friend Robert Jones was not perturbed and let the remark pass with a kindly smile. Trethowan was a generous friend and a remarkable host. No one enjoyed a party more and he was always the last to leave. Many will recall parties at his Hampstead home where in the billiard room he had installed an enormous organ. An able performer, he would begin to play perhaps at midnight and continue fortissimo well into the early hours of the morning. He was a great figure, a most stimulating chief, and a good friend.

Naughton Dunn (1884-1939), a graduate of Aberdeen University in 1909, became in the following year house surgeon to Robert Jones in Liverpool. Thus began his career in orthopaedic surgery and a friendship that lasted until Jones died. He worked at Number 11 Nelson Street as a private assistant until, on the recommendation of Jones, he was appointed in 1913 to the Birmingham Cripples' Union-now the Royal Orthopaedic Hospital, Birmingham. In the 1914-18 war Dunn worked first at Shepherd's Bush and later at a military orthopaedic centre in Birmingham. His association with Robert Jones and Agnes Hunt-he was also on the staff of the Robert Jones and Agnes Hunt Orthopaedic Hospital-had given him the training and the knowledge to develop orthopaedic schemes in the Midlands. He did this well, for he was a shrewd and competent organiser. In time he became Lecturer in Orthopaedic Surgery in the University of Birmingham. His main contribution to the craft of orthopaedic surgery was his work on the operative treatment of paralytic deformities of the foot. He was a man of striking appearance with white hair, his strong features relieved by a friendly smile, and his perpetual cigarette. As a host he was genial and friendly to juniors and seniors alike but his good humour did not always survive the strains of the operating theatre! In some respects he was an exacting taskmaster. But the evening always found him at his best and never more so than when entertaining at the Boot Inn, an ancient hostelry close to the Robert Jones and Agnes Hunt Orthopaedic Hospital. Some of us were privileged to be his guests as officers of the British Orthopaedic Association when he was president just before the outbreak of World War II. Few will forget the friendliness and charm of the man in his own beautiful home where he entertained us. He died in office a few months after war was declared.

Constantine Lambrinudi (1890-1943) of Guy's Hospital died at the age of fifty-three. British orthopaedics lost too early one of its most brilliant thinkers. For long he had been overshadowed by his volatile, exuberant senior colleague, Trethowan. Within a few months of the latter's death, Lambrinudi was stricken with his first attack of coronary thrombosis, 


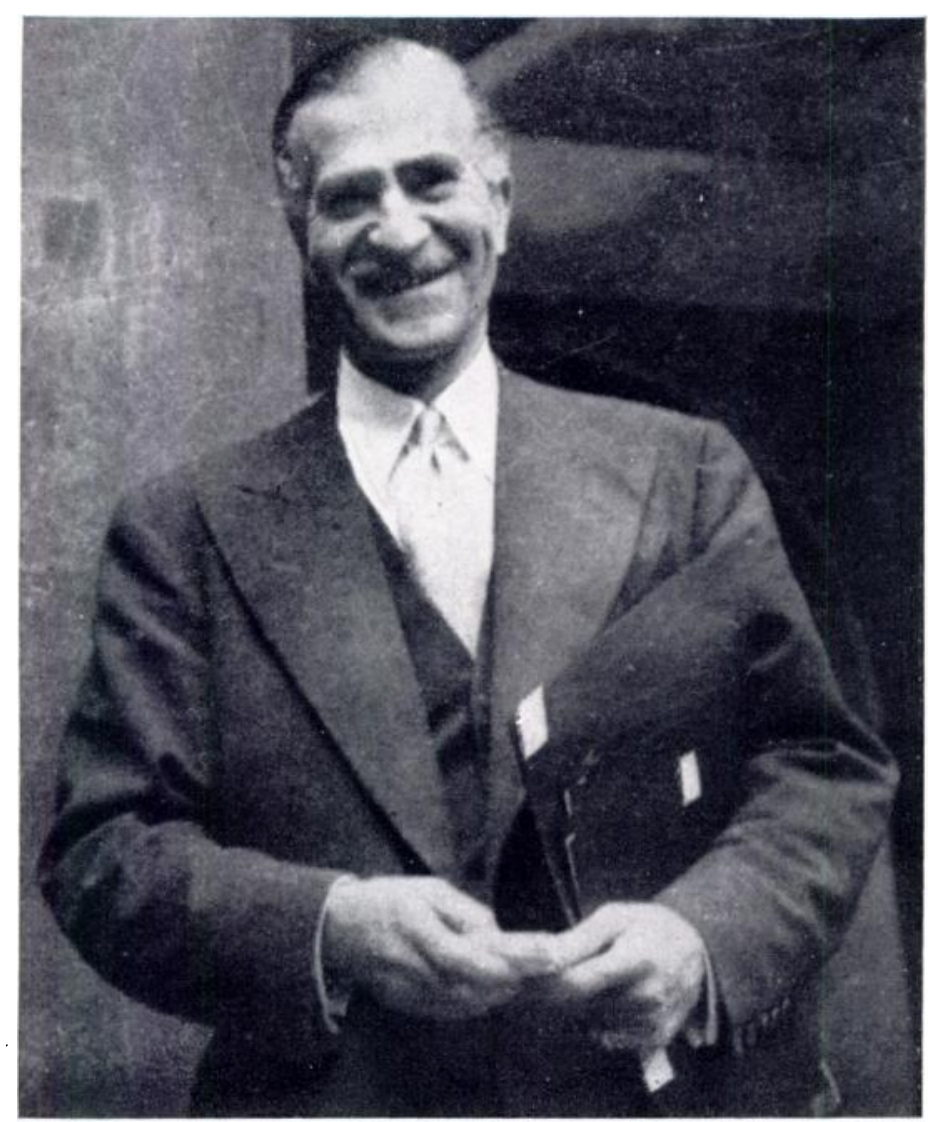

C. LAMBRINUDI (1890-1943).

but he lived as normal a life as he could until he died. He was at heart a phrsiologist immensely interested in errors of posture and function, their cause, and how to correct them. He appreciated, perhaps even more than most orthopaedic surgeons, that operations were only. incidents in the restoration of function. It is not surprising that the procedures he has bequeathed us have the merit of simplicity and have stood the test of time-interphalangeal arthrodesis for claw toes and carus feet: and a particular pattern of subastragaloid mid-tarsal arthrodesis for drop foot and for talipes calcaneo-cavo-valgus. One of his most thoughtful essays on the mechanism of carpal scaphoid fractures published in the Guy's Hospital report is far too little known. His attractive appearance confirmed his Greek parentage. His progressive thought on many topics outside orthopaedic surgery, his nimble intellect, his sense of humour, and his unfailing charm and courtesy, made him one of the most engaging and stimulating companions in British orthopaedic circles.

IValter Rowley Bristow (188:3-1947) was trained at St Thomas's Hospital and was the architect of the orthopaedic department of that hospital. His interest in orthopaedic surgery began in 1916 when he was appointed surgeon at the Military Hospital at Shepherd's Bush. At first chiefly interested in electro-therapeutics he came under the influence of Robert Jones and from then onwards devoted himself to orthopaedics. After World War I an orthopaedic department was established at St Thomas's Hospital with Robert Jones as its titular head and Bristow his assistant. In fact. Bristow was the director, and the combination of Bristow 


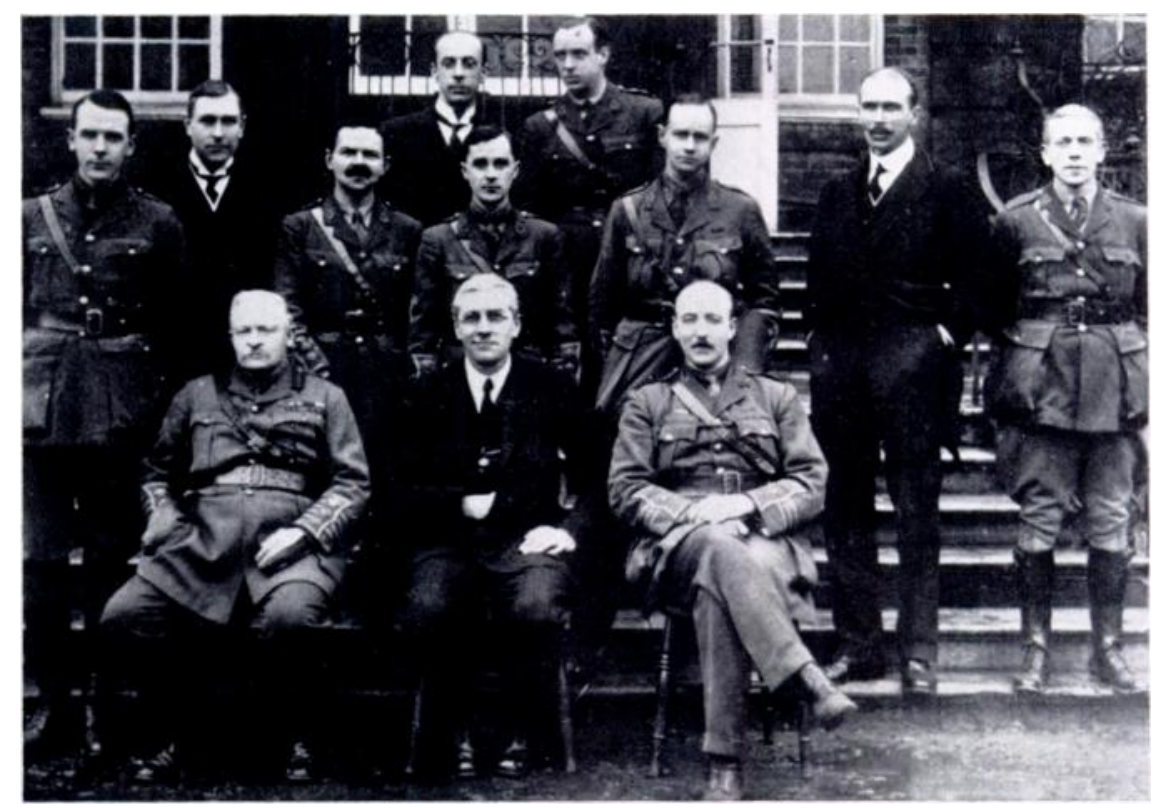

Many of the original members of the British Orthopaedic Association photographed in 1918 outside Queen Mary's Auxiliary Convalescent Hospital, Roehampton, London. Sitting (left to right)-Openshaw, Muirhead Little (President). Bennett. First roaMcllurray, Blundell Bankart, McCrae Aitken, Harry Platt, Elmslie, Laming Evans, Naughton I unn. Back row-Trethowan, Rowley Bristow.

TREASURER'S REPORT OF RECEIPTS AND EXPENSES, MAY-ALGL'ST, 1918.

\begin{tabular}{|c|c|c|c|c|c|c|}
\hline \multirow[t]{2}{*}{$\begin{array}{l}\text { Cr. } \\
\text { By Subscriptions ... }\end{array}$} & $\ldots$ & $\ldots \quad \begin{array}{ccc}6 & \text { s. } & d . \\
& 6 & 0\end{array}$ & $\begin{array}{l}\text { Dr. } \\
\text { By. Stationery } \\
" \text { Printing } \\
\text { Stamps } \\
" \text { Cheque Book } \\
" \text { Capt. Platt } \\
\text { " Balance ... }\end{array}$ & $\begin{array}{l}\ldots \\
\ldots \\
\ldots \\
\ldots \\
\ldots \\
\ldots\end{array}$ & $\begin{array}{l}\cdots \\
\ldots \\
\ldots \\
\ldots \\
\ldots \\
\ldots\end{array}$ & \begin{tabular}{rrrr} 
& \multicolumn{6}{c}{$\begin{array}{c}6 \\
\ldots\end{array}$} & d \\
$\ldots$ & 0 & 5 & 7 \\
$\ldots$ & 1 & 3 & 6 \\
$\cdots$ & 0 & 2 & 11 \\
$\cdots$ & 0 & 2 & 6 \\
$\cdots$ & 8 & 5 & 9 \\
$\cdots$ & 59 & 5 & 9
\end{tabular} \\
\hline & & 66960 & & & & 66960 \\
\hline
\end{tabular}

Audited and found correct,

(Signed) D. McAitken.

NaUghton DUnN.

E. MUIRHEAd LITTLE,
July $28 \mathrm{th}, 1918$.
W. EdWARd BenNetT,

Treasurer.

The first balance sheet of the British Orthopaedic Association. Small beginnings indeed! 
and Perkins was to become one of the most formidable in British orthopaedics. The county hospital at Pyrford-now the Rowley Bristow Orthopaedic Hospital-to which he was soon appointed, formed an admirable country hospital annexe for long-stay orthopaedic patients. He was never a prolific reader or writer but his contributions on internal derangement of the knee and on peripheral nerve injuries were of value. Though an exceedingly shrewd orthopaedic surgeon his real forte lay in his supreme ability to handle patients with sound common-sense psychology - in a word, he was a great, a very great, doctor. In World War II he occupied the post of his old chief and friend, Robert Jones-consultant in orthopaedic surgery to the British Army with the rank of brigadier. A good mixer, he carried through this enormous task with conspicuous success. His many friends regret that this, perhaps his greatest contribution to British orthopaedics, received no official recognition. As a man Bristow was, like Robert Jones and Trethowan, a most colourful personality. He worked prodigiously hard and enjoyed himself with equal verve. He was an epicure of food and wine and without doubt one of the finest hosts in London. The writer saw much of " Rowley " in the years of World War II. It is a pleasure to have the opportunity to acknowledge publicly a great debt to this warm-hearted man for wise counsel, help and hospitality.

T. P. McMurray (1888-1949) was more intimately connected with Robert Jones's professional life than any other, though as individuals the contrast could hardly have been greater. McMurray was an Ulsterman and he retained the unmistakable characteristics of speech, thought and conduct all his life. He was first a house surgeon and subsequently Robert Jones's private assistant. They worked in unison at Number 11 Nelson Street until Jones died. McMurray remained at this famous home of orthopaedics until it was destroyed by a bomb in World War II. In the first war McMurray worked chiefly at the military orthopaedic centre at Alder Hey on the outskirts of Liverpool. He was steeped in the teachings of Thomas and Robert Jones and he remained a rigid advocate of their methods and a sceptic about most others all his days. He was sound in judgment, a dexterous operator and a fine teacher. He devoted himself, with Robert Jones and after the latter's death, to establishing orthopaedics in its proper place in academic circles in the University of Liverpool. Under his influence a university department of orthopaedic surgery was founded and in 1938 McMurray was appointed Professor of Orthopaedics. The Mastership of Surgery degree in orthopaedics (M.Ch.Orth.) was his life-long interest. He carried most of the enormous burden of teaching for this degree himself. It can truly be said that when a candidate acquired the M.Ch.Orth. he was certain to be a sound conservative orthopaedic surgeon. The British Commonwealth of Nations is fortunate in being well supplied with men of this calibre who remain devoted disciples of McMurray. In October 1948 they came from far and near to honour him by presenting on the occasion of his retirement a leather-bound volume inscribed on vellum which embodied the signatures and portraits of men who have passed through the Liverpool school of orthopaedic surgery during the last twenty-five years. He will be remembered for his work on knee-joint injuries, his displacement osteotomy for ununited fractures of the femoral neck and for osteoarthritis, and for his orthopaedic text-book which will remain as a record of all that was so good in the teachings of a great Liverpool triumvirate-Hugh Owen Thomas, Robert Jones and T. P. McMurray.

Space does not permit a detailed account of all who have helped to build the edifice of British orthopaedics: Jackson Clarke, W. E. Bennett, Lynn Thomas and Alwyn Smith who did so much for the development of orthopaedics in South Wales; Henry Gauvain, the genial founder of Alton; Ollerenshaw of Manchester; William Cochrane of Edinburgh; Mitchell Smith of Stoke and others. The debt is heavy, too, to senior colleagues who are happily still amongst us-Fairbank, McCrae Aitken, Bankart, Girdlestone, Platt, Rocyn Jones, Forrester-Brown, Whitchurch Howell, Alan Todd, Buxton, Perkins, Alexander Mitchell, James Russell, S. T. Irwin, Wilson Stuart, S. F. H. Haughton. Of all it may well be said that they hoarded neither gifts nor strength in the service of British orthopaedic surgery.

vol. 32 B, No. 4, NOVember 1950 


\section{BRITISH ORTHOP EDIC ASSOCIATION.}

OfFice BeARERS For 1918 and 1919.

President :

E. Muirhead Little.

Vice-President :

Sir Robert Jones, C.B.

Honorary Treasurer :

W. E. BenNetT.

Honorary Secretary.

Harry Platt.

Executive Committee :

A.S. B. BANKaRT.

D. M. Aitken.

T. P. MCMURRAY.

Nomination Committee :

A.S. B. Bankart. H. A. T. Fairbank.

R.C. ElmsLie.

Sir ROBERT JONES, C.B.

A. H. Tubby, C.B.

\section{Publication Committee :}

T. R. W. ARMOUR.

R. C. ElmsLie

W. H. Trethowan.

Official Organ (in conjunction with the American Orthopædic Association), "The Journal of Orthopædic Surgery," published monthly.

American Editor : Mark H. Rogers.

British Editor: R. C. Elmslie.

The first office-bearers of the British Orthopaedic Association. Reprinted from the 1918 Report. 


\section{ORTHOPAEDIC SOGIETIES}

The British Orthopaedic Society was the first of its kind in Britain. Its first meeting was held in 1894, when A. H. Tubby of London and Luke Freer of Birmingham were appointed secretaries. It did not last long; its last meeting was held at the Westminster Hospital on December 9, 1898. Fifteen years were to pass before in 1913 orthopaedic surgeons succeeded in promoting a new venture. After some negotiation the Section of Surgery of the Royal Society of Medicine consented to the formation of a sub-section of Orthopaedic Surgery. The council of this sub-section met on July 8 with Muirhead Little as president and Blundell Bankart and Rock Carling as secretaries. Several members of the defunct British Orthopaedic Society were members of the council-Muirhead Little, Robert Jones, Tubby, Jackson Clarke and Openshaw. Orthopaedics in general and the new orthopaedic sub-section in particular received a great stimulus from the meeting in London, in August 1913, of the International Congress of Medicine. Orthopaedic surgeons from Europe and America came in impressive numbers to its orthopaedic section, presided over by Robert Jones. Arthur Rocyn Jones, our outstanding historian and biographer, reminds us of the wide range of subjects discussed, and the stature of the openers of the discussions; club foot by Lucas Championiere and Whitman; scoliosis by Lovett and Schanz; spastic paraplegia by Kuttner, Muirhead Little and Vulpius; the treatment of ankylosis by Baer and Putti; the treatment of tuberculosis of joints by Dollinger, Ridlon and Rollier; and, breaking new ground, Fred Albee reporting "Original uses of the Bone Graft as a treatment for Ununited Fracture, certain Deformities and Pott's Disease," based on an experience of 17.5 cases.

This important meeting, so propitious in its timing, gave British orthopaedics such prestige that the orthopaedic sub-section of the Royal Society of Medicine could hardly fail; and it did not. Though its meetings were suspended during the war years they were resumed in the autumn of 1919. By then the body was sufficiently powerful and successful to petition for the formation of a full section. The petition was presented with singular tact, defining orthopaedics as "the surgery of congenital and acquired deformities of the extremities and spine." There was nothing in this to arouse suspicion or increase hostility from general surgeon colleagues of the section of surgery. Accordingly, a section of orthopaedics was constituted and held its first meeting on February 7,1922 , with T. H. Openshaw as its president. Since then the section has flourished, and it plays an important and very active role in providing a forum for discussion and debate and for the presentation of difficult and interesting clinical problems, all of which are reported monthly in the Proceedings of the Royal Society of Medicine. Fellowship of the Society allows attendance at the meetings of all sections and makes available one of the finest medical libraries in the world. Happily, arrangements can be made which allow visiting foreign surgeons access to the meetings and to the library.

In 1918, at the instigation of Robert Jones, Muirhead Little and Openshaw, the British Orthopaedic Association was founded with Muirhead Little as president, Harry Platt as secretary and W. E. Bennett as treasurer. Unlike its predecessor, the British Orthopaedic Society, the Association survived and has grown in authority and in membership, uninterrupted by World War II. At first there were twenty-one members; to-day there are $\mathbf{5 1 3}$ fellows and members. This increase in numbers, though inevitable with the growth of this branch of medicine, is a mixed blessing, for the two meetings each year have become overcrowded. There is too little informal discussion and it is almost impossible for the Association to travel abroad en famille - a pleasant feature of the early 'thirties, when spring visits were made to Mürk Jansen at Leiden, to Paul Guildal at Copenhagen, to Haglund and Waldenström at Stockholm and to Jacques Calvé and Marcel Galland at Berck.

The Association has changed its function with the years. At first it concerned itself only with the scientific and clinical aspects of orthopaedics, meeting twice a year in the spring and

VOL. 32 B, NO. 4, NOVEMBER $195($ )

() 


\section{MEETINGS IN 1918.}

Inaugural Meeting February 2ND, 1918.

The British Orthopædic Association was formally constituted at a meeting held on Feb. 2nd, 1918, at Queen Mary's Auxiliary Convalescent Hospital, Roehampton House, London, S.W. Mr.E. Muirhead Little acted as Chairman, and put to the meeting the following resolution: "That this meeting declares that a Society to be called the British Orthopædic Association is hereby constituted, and that the following surgeons be the original members thereof-D. M. Aitken, T. R. W. Armour, A. S. B. Bankart, W. R. Bristow, J. Jackson Clarke, Naughton Dunn, R. C. Elmslie, E. Laming Evans, H. A. T. Fairbank, Sir Robert Jones, W. S. Haughton, E. Muirhead Little, T. P. McMurray, T. H. Openshaw, Harry Platt, W. H. Trethowan, A. H. Tubby." Of these members all were present at the meeting with the exception of Messrs. Armour, Jackson Clarke, Fairbank, Sir Robert Jones, Haughton and Tubby. Major R. B. Osgood, of Boston, U.S.A., who had helped very considerably in the preliminary steps which had led to the formation of the Association was present as a specially invited guest.

A Constitution and Bye-laws which had been drawn up in anticipation of the meeting was adopted and officers elected for the years 1918-1919. In accordance with the provisions of the Constitution, certain distinguished surgeons in the British Isles and abroad were elected as honorary and corresponding members. The executive proceedings concluded after the President had chosen the members of the three committees, Executive, Nomination and Editorial.

Extract from the first annual report of the British Orthopaedic Association. 


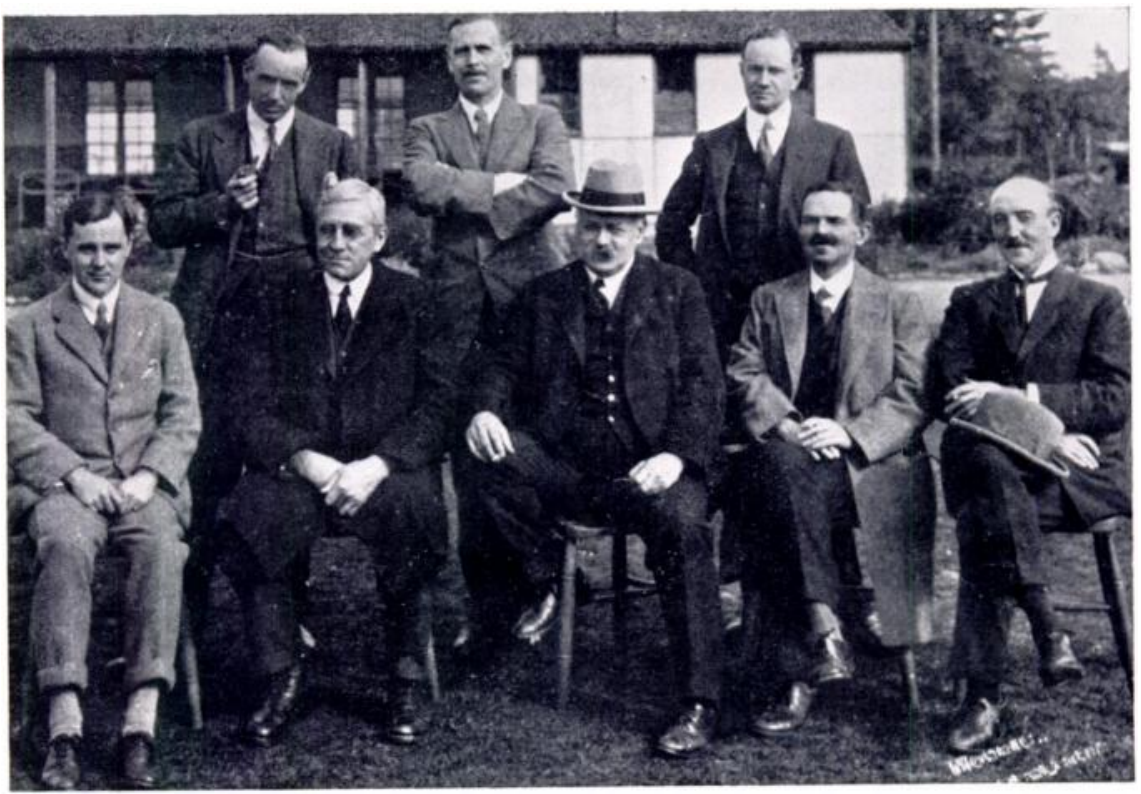

A photograph of office-bearers of the British Orthopaedic Association in 1921. Sitting (left to right)-Harry Platt (Secretary), Muirhead Little (President), Robert Jones (VicePresident), IIcCrae Aitken, W. E. Bennett (Treasurer). Standing-Rowley Bristow, Girdlestone, Elmslie.

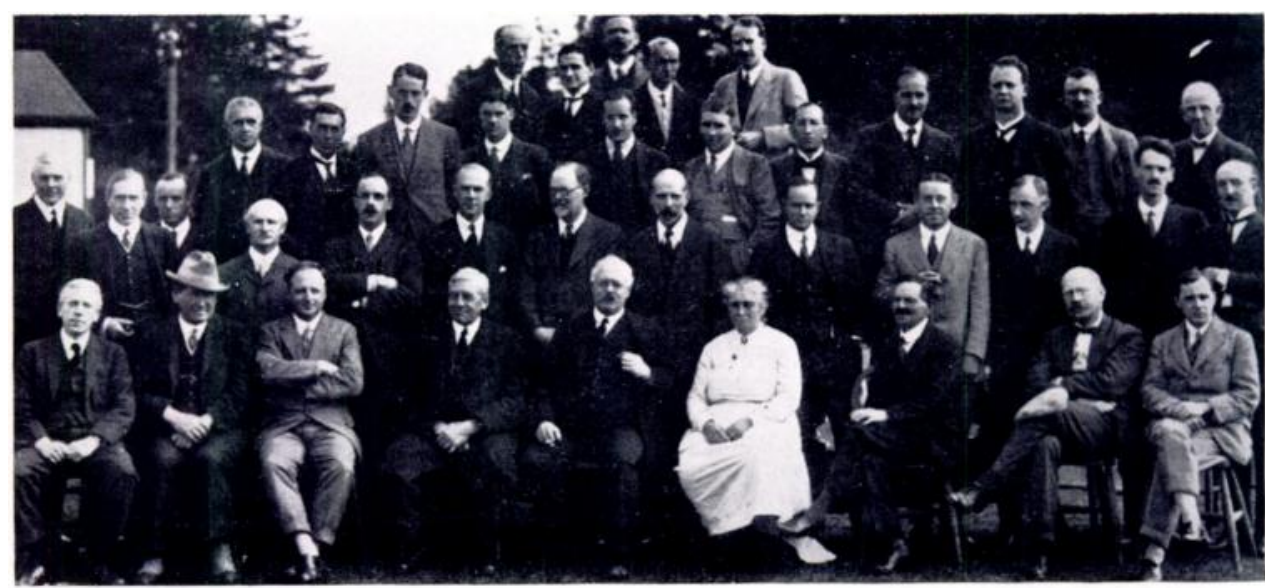

A meeting of the British Orthopaedic Association at Oswestry in 1921. Front row (left to right)-Naughton Dunn, L,ynn Thomas, Gauvain, Muirhead little, Robert Jones, Agnes Hunt, McCrae Aitken, Hey Groves, Harry Platt. Second ro $\dddot{-}$-llumford, Bankart, Bristow, Haughton, Verrall, Fairbank, Thurstan Holland, Mennell, Elmslie, Murray-Levick, Noble, Somerville, Bennett. Third row-McPhee, Russell, A. ‥ Other, A. N. Other, Whitchurch Howell, Nitchell Smith, Percival Mills, Barclay, Woodburn-Morrison, Colonel Thresher, Hough. Top row-Trethowan, Rocyn Jones, Girdlestone, A. X. Other, Brentnall. 


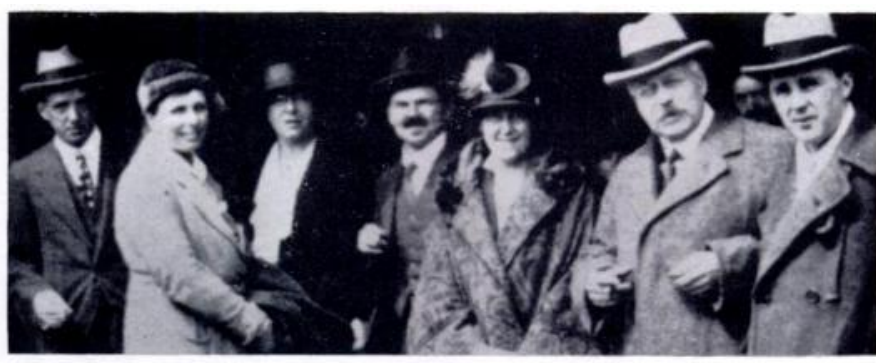

Visitors arriving in Holland. Itefl to right--Rowley Bristow, Miss Forrester-Brown, a guest, McCrae Aitken, Mrs Elmslie, Robert Jones, Harry l'latt were received with the courtesy typical of Murk Jansen, so well illustrated in the programme cover that is shown below:

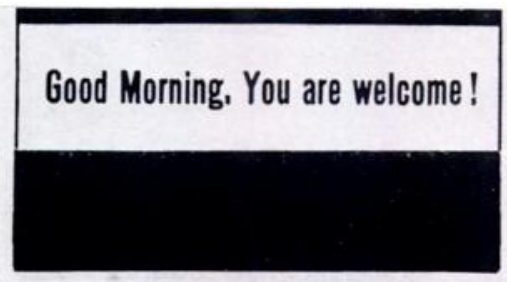

\title{
British
}

\section{Orthopedic Association}

\section{PROGRAMME}

OF THE

\author{
MEETING AT LEIDEN \\ ON \\ MAY 24 ${ }^{\text {th }}$ AND 25 th 1923 \\ \%ా
}

(On the platform in Leiden two carts and porters have been reserved for your luggage. Please, place the bags, not needed during the day, on these carts. No pay.) 
autumn for this purpose. Inevitably it has had to exert its influence in medical politics as well-another mixed blessing!

The first combined meeting of the American and British Orthopaedic Associations was held in London in 1929. It was an enormous success, occurring in days when there were no currency restrictions. In 1948 a second combined meeting took place in Quebec, joined on this occasion by the Canadian Orthopaedic Association. The meeting was conducted by R. I. Harris, president of the American Orthopaedic Association; Edouard Samson, president of the Canadian Orthopaedic Association; and Alan Malkin, president of the British Orthopaedic Association. This was an historic occasion and an outstanding event in the development of orthopaedics in Britain and the North American continent. It is hoped that similar meetings can be arranged at regular intervals in the future.

Repeated efforts had been made to found an International Society of Orthopaedic Surgery. Informal talks had taken place in London between Lovett, Robert Jones and Putti at the time of the meeting of the International Society of Medicine in 1913, and rules were drawn up. Because of the outbreak of war in 1914 the project was abandoned. It was discussed again in 1921 when Jones, Putti and Platt were guests of Lovett in Boston, but again postponed because of the still strained relations with Germany. However in 1929 at the combined meeting of the American and British Orthopaedic Associations in London, Robert Jones, Putti and Albee explored the ground again. In October 1929 a group of international surgeons met in Paris, founded the Society and elected Robert Jones as its first president. There are some fifty British members who are keenly interested in this Society, which has such an enormous potential for the promotion of international knowledge, friendships and goodwill. British orthopaedic surgeons are proud that another of its most distinguished figures, Sir Harry Platt, was elected to the presidency in 1948.

The British Medical Association formed an orthopaedic section in 1935. Since then it has been active at every annual meeting in providing information of value for the general practitioner. The Association has also an orthopaedic consultants' committee which looks after the interests of orthopaedics in the interminable consultations with Government departments.

Several small local orthopaedic clubs have grown up, the oldest of which is the Little Orthopaedic Club in London, named after W. J. Little, with a membership of nine. At present a similar club is being organised in Northern and Southern Ireland and there are similar developments in provincial centres.

The Robert Jones Dining Club was formed in 1928 by Robert's pupils and friends when they presented him with the famous Birthday book to which they had all made contributions in honour of his seventieth birthday. It meets annually after the Robert Jones Memorial Lecture at the Royal College of Surgeons of England. Its British membership is restricted to twenty, together with a few distinguished foreign members. At about the same time the friends and pupils of Robert Jones in the United States formed a similar club of very restricted membership in his memory.

\section{JOURNALS}

Orthopaedic activities in Great Britain were first reported formally in the Proceedings of the Royal Society of Medicine. In America The Transactions of the American Orthopaedic Association were published from 1889, and became The American Journal of Orthopaedic Surgery in 1903. In 1919 the name was again changed to The Journal of Orthopaedic Surgery when it became the official publication of the American and British Orthopaedic Associations. In 1922 Dr E. G. Brackett took over the Editorship and the journal was renamed The Journal of Bone and Joint Surgery. For more than twenty years this remarkable man devoted all his time, energies and literary acumen, until the very day he died. The Journal was his child and he nursed it to adult stature with intense individualistic zeal. In his determination to maintain

VOL. 32 B, No. 4, NOVEMBER 1950 


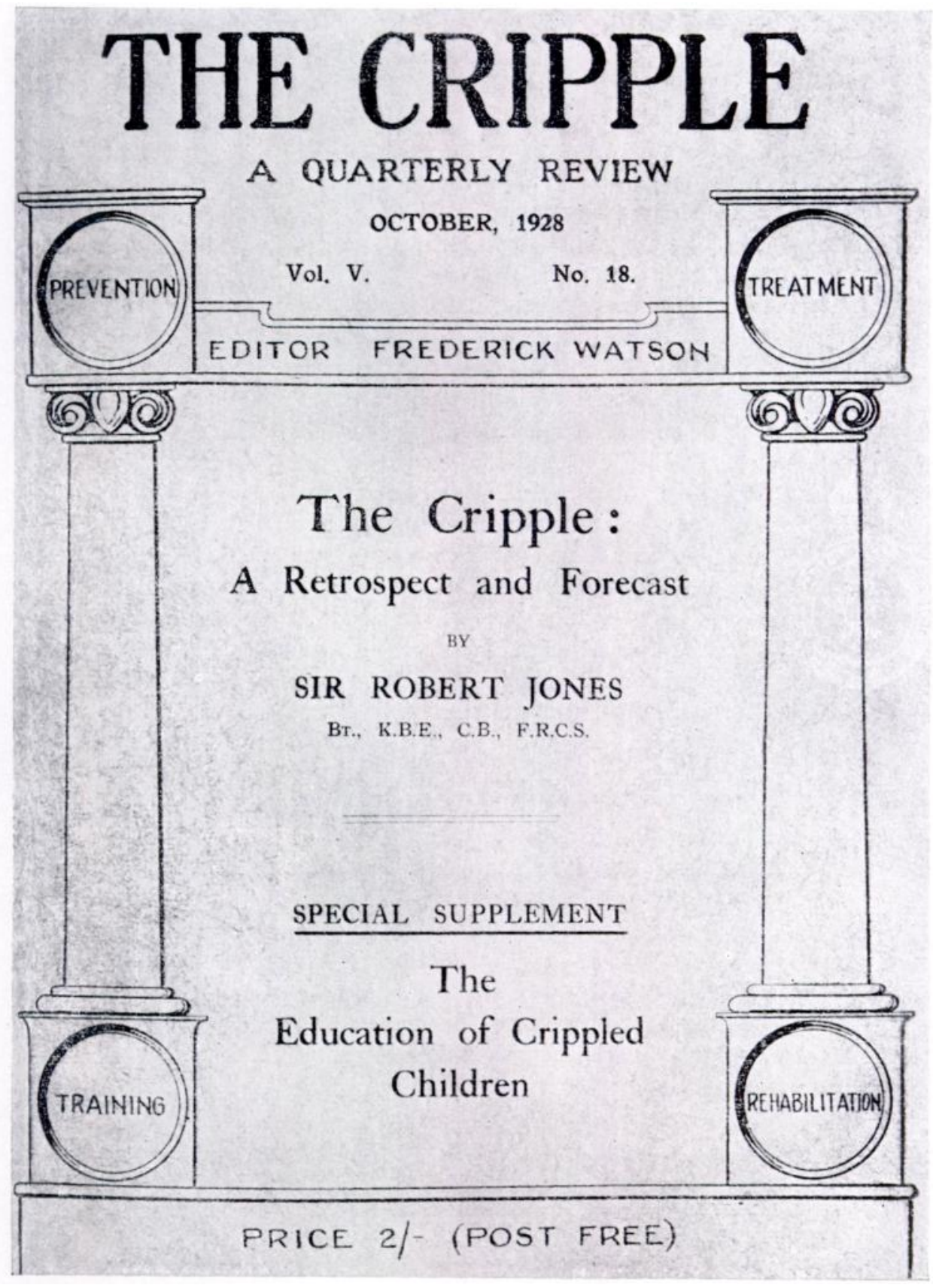

Title page of The Cripple, a journal published quarterly between 1924 and 1930 . 
a high standard of publication he was often firm even to the point of being stubborn, but his judgment was seldom wrong. Under his guidance the Journal acquired remarkable prestige and its circulation grew. As British orthopaedics developed it became increasingly obvious that more space for publication of British work was required than the American journal could possibly afford. Furthermore in 1933 it had become the official mouthpiece of the newly developed and very large American Academy of Orthopaedic Surgery-an additional commitment making voracious demands for space. At an historic meeting in London in 1947 between representatives of the two American bodies and the British Orthopaedic Association it was decided to continue a co-operative effort and to publish a British volume of four numbers annually in addition to the American volume. The first British number appeared in February 1948. It is intended that the Journal as a whole shall be representative of all English-speaking peoples and that it will eventually become world-wide in its scope.

In July 1924 there appeared the first number of a quarterly, The Cripples' Journal, later known as The Cripple. Its purpose was to keep all workers in the field of orthopaedics, including administrators, surgeons, physiotherapists and voluntary workers, informed of the progress of orthopaedic surgery as a technical and social service in Britain and the world. It was felt important too that it should use its influence in stimulating and moulding public opinion on behalf of the adult as well as the child cripple. It performed these functions nobly under the devoted editorship of Frederick Watson, the enlightened, energetic and persuasive son-in-law of Robert Jones. It is fascinating now to read all the numbers of this publication in its short life between 1924 and 1930. Its contributions contain the very essence of the history of orthopaedic development in this country and abroad. The voices of many orthopaedic surgeons and old friends of orthopaedics echo from its pages-Robert Jones, John Ridlon, Muirhead Little, Agnes Hunt, Mürk Jansen, Patrick Haglund, Robert Osgood, A. H. Tubby, Jacques Calvé, Hans Spitzy, Putti, Henry Turner, Alwyn Smith, de Courcy Wheeler, Daw, Lynn-Thomas, C. J. Macalister, Elmslie, Lyle Cummins, Varrier Jones, Henry Gauvain; and others still happily amongst us-McCrae Aitken, Harry Platt, Gathorne Girdlestone, Arthur Rocyn Jones, James Mennell, Maud Forrester-Brown and Edward Mellanby. Lay friends there are in abundance-Edgar Allen, the American president of the International Society for Crippled Children; Dame Georgiana Buller, still an ardent campaigner in orthopaedic development; Morley Roberts; Francis Brett Young; St John Ervine; Maud Royden, Sister Teresa Fraser, and the two immortals, Miss Eglantyne Jebb and Miss C. R. Buxton who in 1919 launched the "Save the Children Fund" on behalf of the children of ravaged Europe which led to the famous Declaration of Geneva by the League of Nations in 1924. This is to mention but a few.

We have noted how the problem of the crippled children stirred the public conscience. What happened to the child when adolescence and adult life were reached had no similar popular appeal in the 'twenties. When treatment, education and after-care of the crippled child were well established by the implementation of the Fisher Education Act in 1926, The Cripple concentrated its energies in the cause of the adult cripple. Its frontispiece aptly proclaims its creed-Prevention, Treatment, Rehabilitation, Training. It was sad that in 1930, mainly for lack of funds, this splendid venture ceased. A valediction by Frederick Watson, Civilization and the Cripple, published separately, is an outstanding historical and social analysis of the cripple problem and, like the Journal, can be read with great pleasure and profit even to-day.

\section{THREE WARS}

The first half of the century has been disturbed by three wars. In the Boer War it has been said that the organisation for the treatment of wounded soldiers was such that " a distinguished surgeon could rush out in a blaze of publicity to the seat of war, do a number of spectacular operations and return in six weeks with an enhanced reputation." We read of

VOL. 32 B, No. 4, NOVEMBER 1950 
T. H. Openshaw being carried shoulder-high along a London railway platform by his colleagues and students of the London Hospital when he left for the South African War. Our much respected doyen of orthopaedics, Sir H. A. Thomas Fairbank, served as a unit medical officer with the troops in South Africa.

World War I (1914-18) had not been many weeks old before the retreat from Mons, the battles of the Marne and the Aisne, and the first battle of Ypres, made it clear that casualties would be on an enormous scale. It should have been obvious that treatment of bone and joint, muscle and nerve injuries must play an important part in the restoration of the wounded. It was left to Robert Jones to indicate that there was no adequate provision for the treatment of crippled and deformed soldiers, who were being discharged rapidly from the services, as Jones put it, " unfitted either for military or civilian life . . to become foci for seething discontent and a menace to successful recruiting." The Director-General of the Army Medical Services asked Robert Jones for help. It was forthcoming quickly. Early in 1915, Alder Hey in Liverpool was opened with 400 beds with Robert Jones in charge of the surgical division assisted by Major T. Armour and Captain T. P. McMurray; the hospital was reserved entirely for patients likely to be benefited by orthopaedic treatment. Robert Jones travelled widely finding patients who required reconstructive surgery, demonstrating, lecturing and writing. He preached the importance of segregation of patients, and the need for continuity of treatment and for unity of control until the best possible result had been achieved. Only in this way could indiscriminate surgery be prevented; only in this way could surgeons, accustomed to treat an occasional accident in peace-time, be trained to deal with the shattering compound injuries of war. At the front in France he demonstrated how adequate splinting at the earliest possible moment could prevent shock and lower mortality. All now know how under his guidance the incidence of mortality for compound fractures of the femur fell from 80 per cent to 20 per cent. He wrote: "To what are we to ascribe this dramatic change ? First and foremost to the recognition, too long delayed, of the value of the Thomas splint, and to its distribution to the regimental aid posts." The caliper splint which had been used in Liverpool for forty years had again proved its value. By 1916 it was in general use throughout the entire front.

As casualties increased, Alder Hey was not enough; but its work had made a tremendous impression. In 1916 the Hammersmith Workhouse at Shepherd's Bush (now the hospital of the Postgraduate Medical School of London) was opened with the help of Red Cross funds as the Shepherd's Bush Military Orthopaedic Hospital with 800 beds. Some fifteen similar institutions, labelled with the daring and unfamiliar title of "Orthopaedic Centres," were organised all over the country until eventually 30,000 beds were available for the wounded. Because it was felt that something more was necessary than good primary treatment, sound definitive treatment and the physiotherapy available in those days, curative workshops were established. These were the ancestors of the rehabilitation centres of the present day. The monotony of treatment by massage, electricity and movements with elaborate mechanical apparatus was relieved or replaced by productive work with lathes, treadles, fretsaws and other tools of the workshop. Morale was improved enormously. "If hands and fingers are stiff," wrote Sir Robert, " working with a big swab to clean windows or with a paint brush is a more interesting occupation than gripping spring dumb-bells."

The most notable of these curative workshops was undoubtedly that at Shepherd's Bush where 500 of the 800 patients were employed at regular work "which fosters habits of diligence and self-respect, and converts indolent and often discontented patients into happy men who soon begin to feel that they are becoming useful members of society and not mere derelicts."

The rule that a soldier should be invalided and discharged from a military hospital immediately it was clear that he could never return to the front was opposed tenaciously and effectively by Robert Jones. He visualised perhaps more clearly than anyone else the 


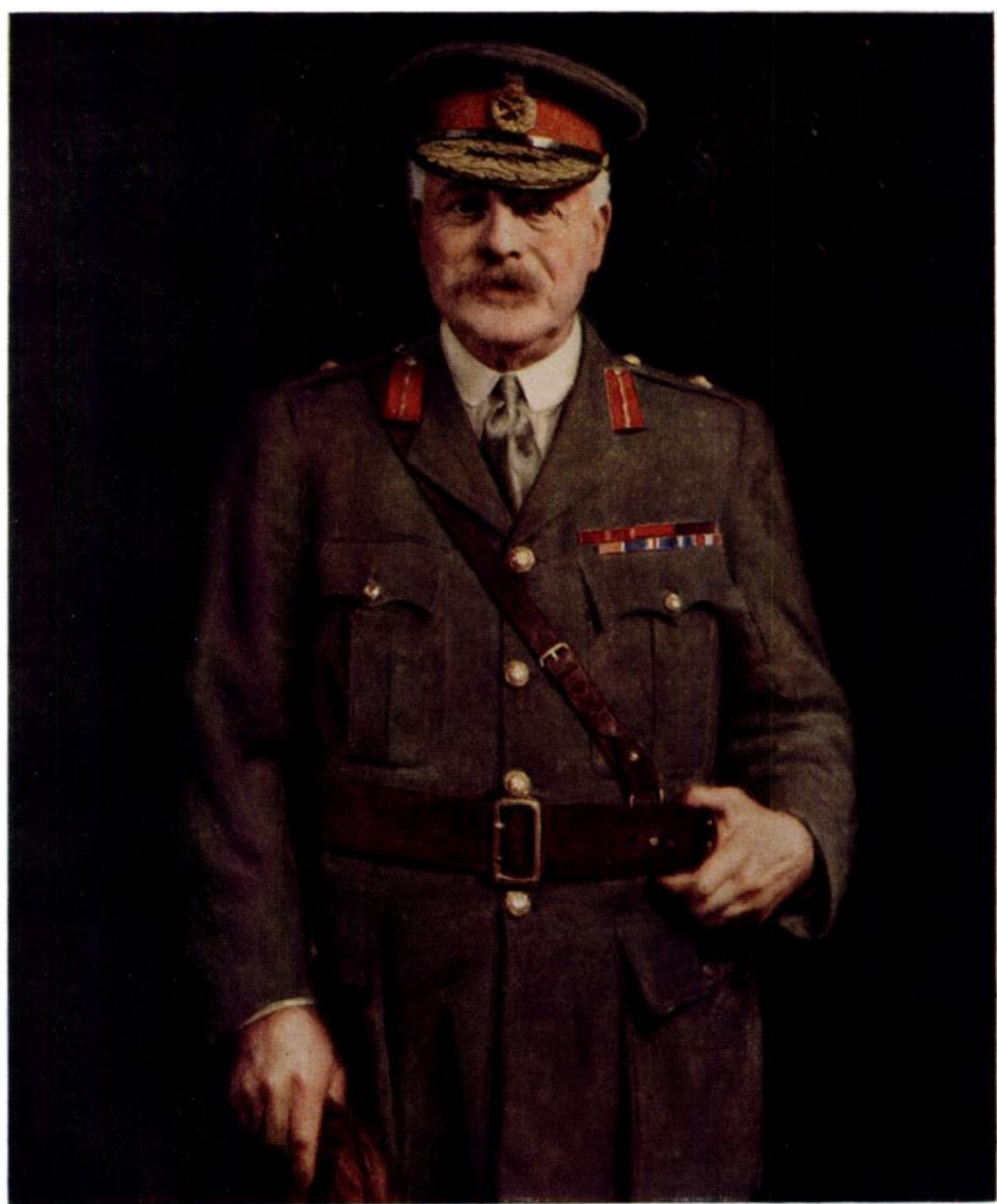

ROBERT JONES in uniform.

(Reproduced by permission of the Royal College of Surgeons of England.) 


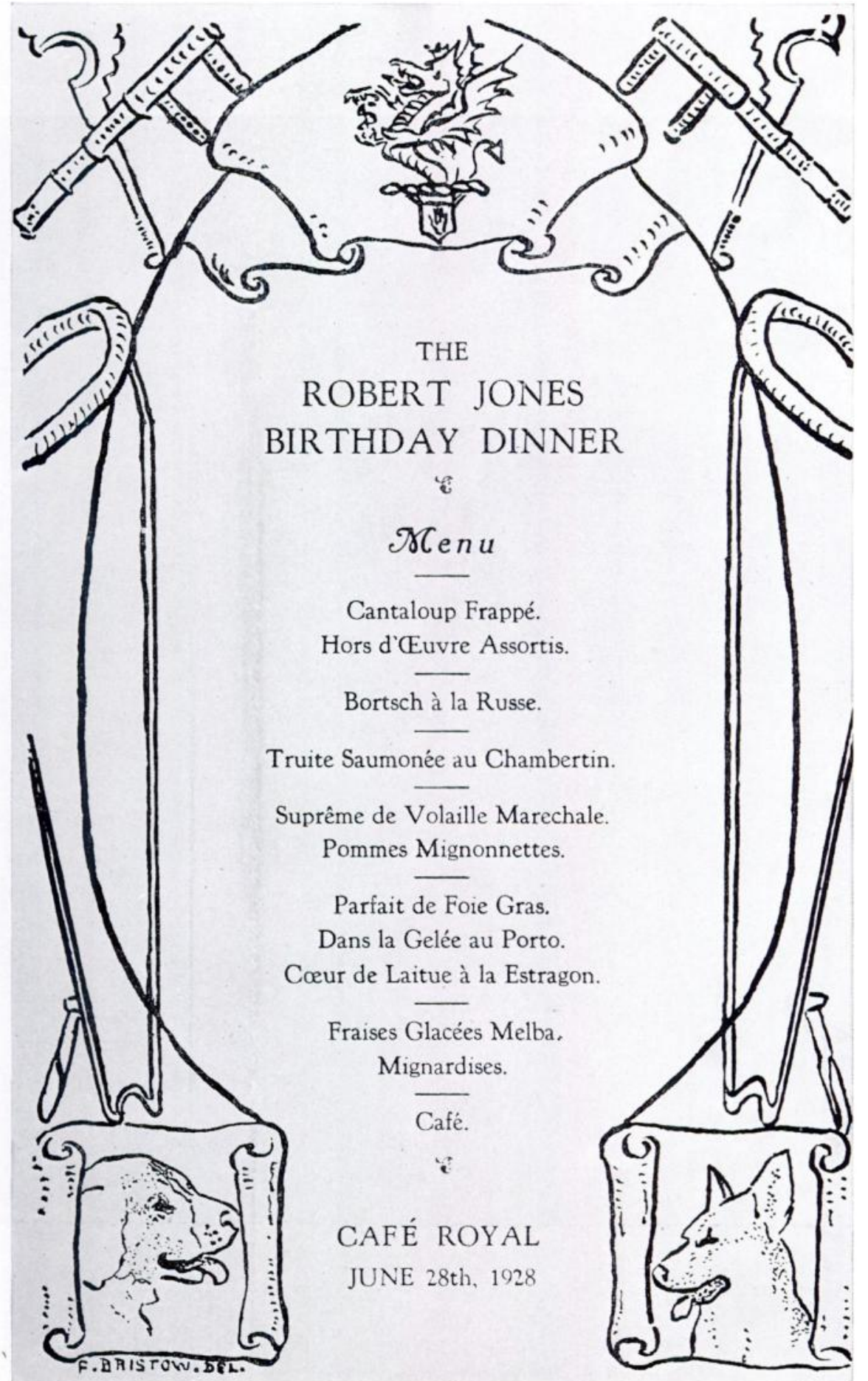

Menu of Robert Jones Birthday I)inner-illustrated by Mrs Rowley Bristow. The meal was almost certainly chosen by Bristow himself. 
size and importance of the social problem involved if this rule were followed. He wrote: "It is quite true that the most important object of the military mind is to end the war successfully; but there is absolutely no reason why that desire and determination should clash with the civil one. On the contrary, an early understanding is essential to the full success of either. When the War Office says that men should be discharged from the Army so soon as it is known that they will not be fit for service they cannot really mean it. If they did it would involve the discharge of half our wounded in the most critical stages of disease, many of them to die, and most of them destined to deformity and functional disability. It is clear, therefore, that whatever the War Office says, they would never dare to give effect to so inhuman an act ... The problem requires a telescope rather than a microscope. Statesmen must and will see that the economic solution is only satisfactory if the wounded soldier becomes a national asset instead of a discontented derelict ... My opinion is that no soldier should be discharged from the Army until everything is done for him to make him a healthy and efficient citizen, and when the war is ended he should not be discharged until he is declared to be fit and fortified by the necessary help or knowledge which will enable him to take an honourable part in life. If a soldier knows beforehand that we are striving to make him functionally useful, and not necessarily with the intention of sending him to fight, the psychological effect is such as to materially expedite his recovery." How true and how obvious. Yet in World War II the same crusade had to be fought by Robert Jones's successors. In the face of ineptitude, indifference and misunderstanding he fought and won the battle for the greatest possible restoration of function of the disabled soldier before his discharge to civil life. After the Armistice his principles and many of his orthopaedic centres were incorporated in the newly formed Ministry of Pensions to which he remained an adviser until his death. Regretfully and with great disappointment he was to see Shepherd's Bush, which with its well-proven organisation and its comprehensive amenities he had hoped would become a permanent home of British orthopaedics, returned in 1925 to its function and status as a Poor Law Hospital. It had been a landmark in the organised treatment of the crippled adult, as sixteen years earlier Heswall and Baschurch had been for the crippled child.

It is impossible to read the orthopaedic history of World War I, as indeed it is impossible to study the development of British orthopaedics, without being impressed over and over again by the stature of Robert Jones. His vision and singleness of purpose were remarkable. His resilience and tact enabled him to achieve almost every objective even in the uncongenial surroundings of the War Office. His unique experience as surgeon to the Manchester Ship Canal during its construction between 1887 and 1894 was indeed, as Frederick Watson wrote, "like a rehearsal in miniature for what was then not even a cloud the size of a man's hand." He had "learnt the elements of organisation, of supervision and of treatment of desperate casualties under primitive conditions." He was clearly the ideal Inspector of Military Orthopaedics, though the senior officers of that day could hardly have regarded him as an ideal Major-General, the rank which he finally achieved. But he could not have succeeded without support for his views and practical help to do the work. He was fortunate in having the support of powerful general surgeons-Berkeley Moynihan of Leeds, Harold Stiles of Edinburgh and Lynn-Thomas of Cardiff. For practical help he gathered round him a band of younger colleagues who became the leaders of orthopaedics in the second, third and fourth decades of this century; McCrae Aitken, Girdlestone, Fairbank, Bankart, Platt, Buxton and Whitchurch Howell are the only survivors. Almost the only active surgeons practising orthopaedics who were not associated with him were Tubby, who became consultant surgeon to the British Mediterranean and the Egyptian Expeditionary Forces; Openshaw, who was consultant surgeon to the Eastern Command and who was probably the only surgeon with orthopaedic leanings to fail in co-operating harmoniously with Robert Jones; and H. A. T. Fairbank, who spent most of the war as assistant consultant to Robert Kelly in Salonika, although on his return he and St. John Buxton worked together at Shepherd's Bush. This team of helpers worked unceasingly, but

Vol. 32 B, No. 4, NOVEMBER 1950 
from 1916 onwards, as casualties increased and more orthopaedic centres opened, the need for more surgeons became acute. The problem was solved when the United States came into the war in April 1917. Twenty American orthopaedic surgeons arrived at the end of May under the " command " of Joel Goldthwait, who soon returned to America to collect a further sixty. From then until the war ended there were never less than sixty or seventy young American orthopaedic surgeons officially assigned and paid by the American Army to serve with the British. About $\mathbf{4 0 0}$ American surgeons in all received training and worked hard under the aegis of Robert Jones, ably assisted by Robert Osgood of Boston who had become his second-in-command. From that time onwards the orthopaedic centres were fully and effectively staffed. This intermingling of English-speaking surgeons formed many lasting friendships and left an indelible stamp on orthopaedics in America and Britain.

In World War II the basic pattern of military orthopaedics conformed to that so well established in World War I. There were, of course, differences associated with the changed type of war, its world-wide extent, the development of new weapons and, in particular, the extensive use of tanks and aircraft. In spite of the lessons of 1914-18 it was some time before an effective orthopaedic machine was set in motion. The late Rowley Bristow was appointed Consultant in Orthopaedics to the War Office in 1941. St. John D. Buxton, the late James Eastwood of Liverpool and Philip Wiles were Consultants in the Middle East and India. The Royal Navy had the late Robert Milne as its Consultant. Watson-Jones and OsmondClarke were the Consultants to the Royal Air Force. An important advance on the conditions that prevailed in World War I was the establishment by the Ministry of Health of the Emergency Medical Service. New hutted hospitals were built and old ones extended to provide not only extra accommodation but also special centres for the segregation of battle and air-raid casualties in the military and civilian population. There were, for example, five special centres for nerve injuries, three in England and two in Scotland, to which most of these injuries in sailors, soldiers, airmen and civilians were diverted. Orthopaedic centres were numerous and provided what was lacking in World War I-a guarantee that the injured man or woman would receive adequate specialised treatment, including rehabilitation, whether he was in a military service or not. Thomas Fairbank was Consultant to the Ministry with Harry Platt as his deputy.

In general this orthopaedic organisation in World War II proved satisfactory. There was no doubt that segregation of patients into special centres, provided the experts were good, ensured the highest standard of treatment. So far as terrain, state of the fighting, water supplies and transport allowed, specialist centres were located as close as possible to the fighting fronts, usually in the Base Hospitals. Initial treatment was provided at Field Surgical Units, including resuscitation, wound excision and adequate splinting, before transportation back to the Casualty Clearing Station or the orthopaedic units of the Base General Hospitals. Long-term casualties were returned to Great Britain by sea or air when medical and other considerations permitted. A good example of organisation for this purpose occurred after the landing in Normandy on June 6, 1944. All serious casualties from France were evacuated by air to England, a suitable air base having been prepared and equipped for their reception at an airfield close to a large Royal Air Force orthopaedic centre specially enlarged and manned to deal with casualties on a large scale. Cases were sorted here and distributed to appropriate hospitals, military or civilian, throughout the country. Eventually, of course, as the fronts moved eastwards service hospitals with facilities for definitive treatment of orthopaedic patients were established in Western Europe.

In one of the services-the R.A.F.-it was possible to arrange an almost ideal orthopaedic organisation, an elaboration of Robert Jones's plan in World War I. It comprised twelve orthopaedic centres in England, three in Scotland and five overseas. Each of the main orthopaedic centres was a unit in a general hospital staffed by an orthopaedic surgeon with one or two assistants. Ancillary staff included secretaries, one radiographer, two rehabilitation orderlies, 
one plaster room orderly and one clinical photographer. A sister trained in orthopaedic technique was available in the operating theatre. Accommodation also included a consulting room, secretaries' room, out-patient waiting room (almost unheard of in a military hospital!), plaster room, photographic room and equipment store. In addition to the usual service documents a uniform system of orthopaedic records was common to all centres; out-patient and in-patient notes, including prints of all important radiographs and clinical photographs, were entered in the same case sheet which went with the patient if he was moved from one centre to another. Each surgeon was allowed full clinical freedom to treat his patients by whatever method he selected, provided that basic surgical and orthopaedic principles were observed. Advice was readily available by regular visits and complete ward rounds by the consultants who co-ordinated the work of all the centres. Perhaps one of the most difficult tasks encountered by the consultants was to convince high administrative authority of the importance of good records and the economy of clinical secretarial assistance. It seemed almost impossible to make the point that one doctor and a secretary can see and record the details of as many patients as can three or more doctors who have to write their findings in longhand; and secretaries cost less than doctors!

Rehabilitation-The lessons learnt from the experience of the "curative workshops" of Robert Jones at his orthopaedic centres in World War I and from the "Convalescent Camp" organised in Salonika after 1915 by Thomas Fairbank were quickly forgotten by most surgeons between the two great world wars. As we have noted before, organised rehabilitation-a disagreeable word but there seems none to replace it-was being carried out alone by $\mathrm{Dr}$ H. E. Moore at the Crewe Hospital for injured employees of the London, Midland and Scottish Railway. There were some, notably Watson-Jones, Gywnne Maitland and Hugh Griffiths, who, impressed by Moore's work, also strove unceasingly from the early 'thirties onwards for more comprehensive remedial treatment of the injured. It was fortunate that Watson-Jones as Consultant to the Royal Air Force was enabled, with the powerful co-operation of an enlightened Director-General of Medical Services, Sir Harold Whittingham, to organise a comprehensive orthopaedic scheme including rehabilitation for all injured airmen. Four main centres were in constant use during the war, working in the closest co-operation with the orthopaedic hospital units. They were staffed by hand-picked men-selected as much for their capacity to inspire confidence and to foster a high morale among patients as for their technical skill as doctors-physiotherapists, nurses, clinical secretaries and physical training instructors. It was a most gratifying aspect of orthopaedic work in the Royal Air Force that rehabilitation, physical and mental, began in the hospital ward within a day or two of the injury by rehabilitation orderlies whose sole job it was; and that the process was continued in a well-organised residential rehabilitation unit long after the gross features of the injury - fracture, dislocation or soft-tissue injury, had been overcome.

The principles laid down by Robert Jones were faithfully fulfilled-segregation and unity of control until maximum recovery was achieved. In the Royal Air Force it was fortunately possible to retain the injured until this result had been gained. There is little doubt that the value of rehabilitation was reflected in a more rapid and a more complete restoration of function. No less than 77 per cent of injured men and women returned to full duty, and 18 per cent were re-trained in other duties; and only 5 per cent were invalided because their recovery did not fit them for service life or because of psychological complications. Similar highly efficient units were organised by the Army both in Home and Overseas Commands, and by the Royal Navy. When the United States entered the war their medical corps stationed in this country was quick to appreciate the advantages of rehabilitation and two or more large and very effective units were quickly in use. It is an interesting commentary on the value of rehabilitation that the Royal Air Force has felt it wise to continue its centres in peace-time.

The surgical principles of orthopaedic treatment did not alter much in the two major

VOL. $32 \mathrm{~B}$, No. 4, NOVEMBER 1950 


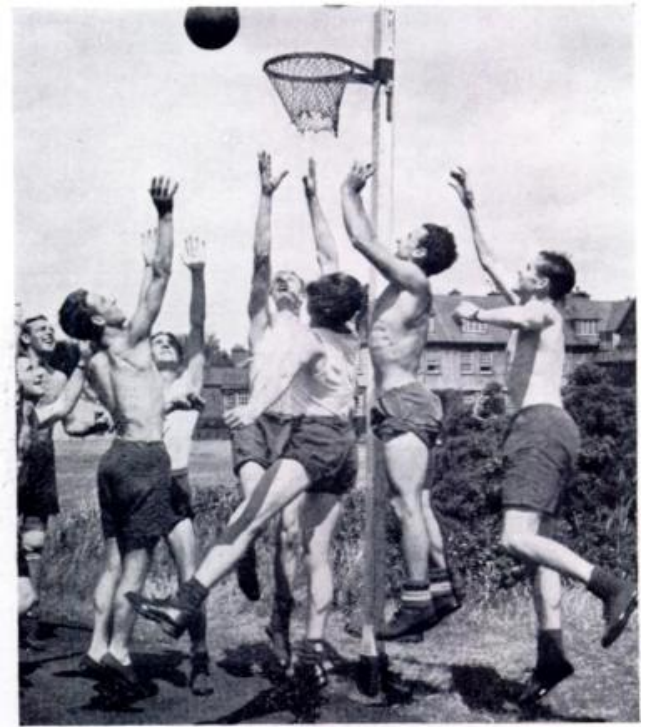

Rehabilitation. This view epitomises the spirit of rehabilitation. There is only one uninjured man in this group but it is impossible to single him out.

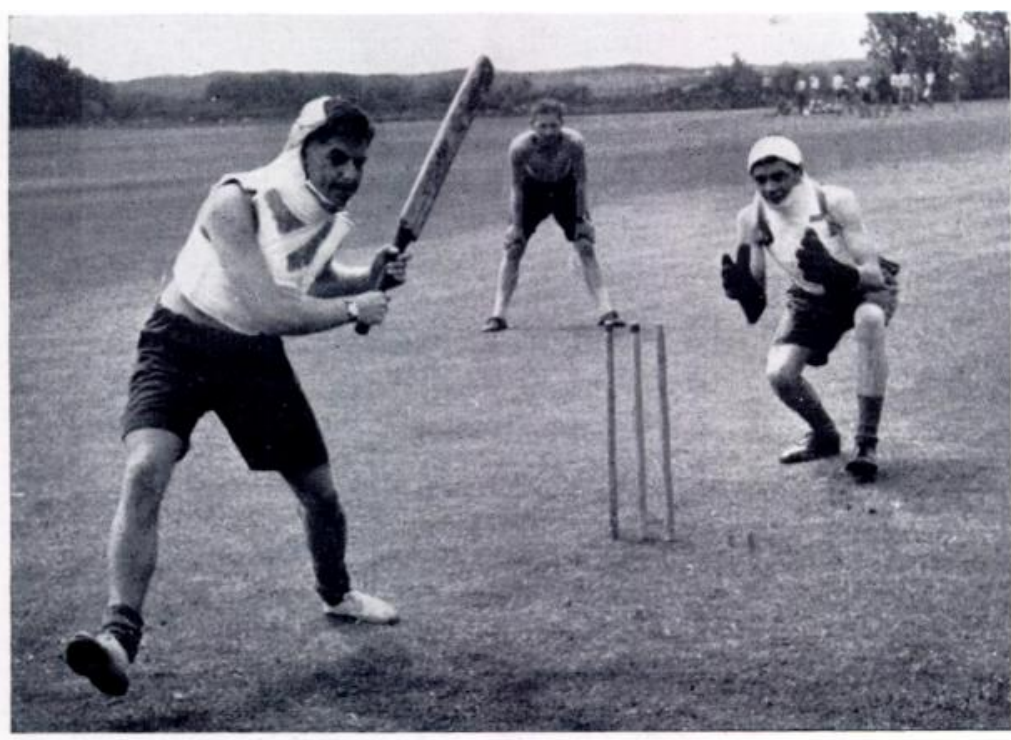

Rehabilitation. Plaster of Paris is no bar to the enjoyment of the traditional British sport, cricket! (Reproduced from Watson Jones's Fractures and Joint Injuries by permission of the author and publisher.) 
wars of the first half of the century. There were some changes in methods of treatment, and the " advance of civilisation" had made weapons of war more destructive and increased their range so that civilians of all ages were involved almost equally with the fighting men. Open wounds of the extremities comprised about 70 per cent of all injuries, but there were many new factors in World War II that added to the complexity of battle injuries-the increased destructive power of modern projectiles; the high speed of modern transport and combat vehicles on land and sea and in the air; the very great increase in bomb blast which, apart from its own direct action in causing injuries, added the problems of burial, crush syndrome and so forth; and the hazards associated with special tasks as, for example, parachuting. Thus injuries tended to be multiple and it was not uncommon to have to treat as many as a dozen or more separate injuries in the same patient. On the other hand, these factors were very considerably offset by better medical organisation at all stages of prophylaxis and treatment, by segregation of special injuries and by advances in chemotherapy, to mention but a few of the improvements in the medical care of the wounded.

First-aid treatment was greatly reinforced by the increased facilities for combating shock, haemorrhage and infection. The Thomas's splint performed the same life- and limb-saving functions as in World War I. Immobilisation afforded by the splint was often reinforced by plaster of Paris, the combination being termed the "Tobruk" splint, a predecessor of which was in use in the early days of the London " blitz." Tourniquets were discouraged, though they could not for reasons of morale be abandoned. Infection was combated by the early application of field service dressings, the injection of anti-tetanic serum and gas-gangrene antitoxin, and the oral administration of sulphonamides; and eventually by penicillin. But careful surgical excision of the damaged tissues and of débris was the most important factor in preventing wound infection. The incidence and mortality of gas gangrene had been reduced by competent surgery in World War I to 1 per cent and 22 per cent respectively. In the recent war, by adequate wound excision, transfusion and antibiotics, the mortality fell to negligible levels. During a brief but regrettable phase of the last war, when supplies of penicillin were plentiful, some surgeons felt that chemotherapy would be a substitute for wound excision. Fortunately this phase did not last long because the limitations of antiseptics in wound treatment became, as often before, obvious-a drug cannot remove clothing, metal or necrotic tissue from a wound. If wounds were already infected they were treated by free incision to promote drainage. After the teaching of Winnett Orr, and later of Trueta, wounds were left open and kept open by gauze dressings until healing from the depths of the wound by granulation tissue had occurred. Severed nerves and tendons were not sutured at the time of wound excision. By the middle of the war attention was directed to providing early skin cover for wounds. Eventually delayed primary suture or skin grafting undertaken within five to ten days of successful primary excision secured early healing in almost 90 per cent of patients. This was a notable advance because reinfection from the exterior was minimised, healing was more rapid, the formation of scar tissue in muscle, fascia and skin was much less; and a mobile and stable linear scar was often secured and the definitive treatment of an underlying fracture could be undertaken earlier by whatever appeared most desirable.

Perhaps the greatest advance in World War II was the efficacy of resuscitation. Glucose-saline, plasma and blood were available on a large scale and close to the front line. They were administered at advanced dressing stations, on board ship and in aircraft. These measures played a tremendous part in preventing infection and, by preserving life, confronted surgeons and particularly orthopaedic surgeons with problems of a complexity not previously encountered.

Definitive treatment-As noted, the Thomas's splint held its own in World War II as a first-aid splint. For compound and simple fractures of the femoral shaft it was used in World War I almost exclusively for definitive treatment. In the second war it was powerfully challenged, though never beaten, by the "closed" plaster of Paris spica. For all other

VOL. $32 \mathrm{~B}$, NO. 4, NOVEMRER 1950 
injuries plaster splints were used almost exclusively in the recent war. Internal fixation was used sparingly and carefully. The arrival of the Americans in 1942 gave it a new impetus, though British surgeons always avoided its use in compound injuries even when the claims for the sulphonamides and the antibiotics were at their peak. Internal fixation by metal or bone was judiciously used for unstable simple fractures; a few surgeons relied on metal plates alone for the splinting of tibial and forearm fractures. Towards the end of the war B. H. Burns had begun to revive an old method of operative treatment-intramedullary fixation by a metal nail of his own design. Soon afterwards a similar method of internal fixation was noted in returning prisoners of war. It had been advocated by Küntscher of Kiel in 1938-9 and was used extensively by the Germans from then onwards. Experience has shown that it possessed a very real place in fracture treatment, especially in transverse fractures of the mid-shaft of the femur. Its great advantage, and an important one in peace or war, is the rapid restoration of complete movement of the knee joint.

Burns-Severe burns were a frequent complication of fractures in the crews of aircraft, tanks and ships. First and second degree burns usually healed rapidly under the plaster of Paris splint immobilising the fracture. Burns of the third degree presented a formidable problem for which no hard and fast rules could be formulated except that the injury causing the greater immediate risk to life had priority in treatment-and this was usually the burn. A splint which combined immobilisiation with access to the burns for dressing and early skin grafting was the best compromise, and it consisted usually of plaster of Paris with a window over the burn. A burns centre and an orthopaedic unit in the same hospital provided the valuable combined efforts of plastic and orthopaedic surgeon, without both of whom these desperate injuries could not have been handled adequately.

Peripheral nerve injuries-The work of Henry Head and James Sherran in the first decade of the century is an outstanding British contribution to the problem of peripheral nerve injuries. In both wars large numbers of them were treated. In Britain, though not in America, they have been included in the scope of orthopaedic surgery since the 1914-18 war. Although then the organisation and treatment afforded-which included a comprehensive service of physiotherapy - were excellent, the documentation and follow-up system were unfortunately inadequate. Platt and Bristow in presenting a report on peripheral nerve injuries to the International Society of Surgery in 1923 were forced to rely largely on impressions in reaching their conclusions. In his Robert Jones Lecture in 1945 Bristow said: "Looking back and comparing the surgery of the war of 1914-18 and of the years which immediately followed with the surgery of the present war, it is doubtful whether there has been any great advance in technique or in operative skill which would lead us to expect an improvement in results." Nevertheless there were advances in methods of diagnosis and in technique which have been most carefully and accurately recorded and which will shortly become available as a report of the Medical Research Council. They include improvements in electrical testing; electromyography; the sweat test ; and the use of fibrinogen plasma as a cement for joining nerve ends. The lessons of both wars on the management of peripheral nerve injuries may be summarised as follows: 1) There is no indication for immediate suture and it must never be attempted in a grossly contaminated wound. 2) The best time for suture is about three or four weeks after division. By this time the extent of interstitial fibrosis is recognisable and the correct length of stump to be resected can be assessed. 3) The more distally placed the nerve division in the limb the better the prognosis after suture. 4) The technique of suture is important. The assumption of the extremes of joint movement to maintain end-to-end contact of the nerve ends is useless because the suture line is always disrupted later by stretching. 5) Autogenous nerve grafting has a place in treatment. 6) Post-operative treatment including galvanic muscle stimulation, is of great importance. 7) Investigation and treatment of peripheral nerve injuries is so highly specialised that patients with these injuries should be segregated in special centres. 
Major amputations-In consequence of better surgical management, better chemotherapy and the wider knowledge that a useful limb can be saved if its distal blood supply is adequate, the numbers of amputations in World War II were greatly reduced. Loss of soft tissue or of bone, however extensive, was not considered sufficient indication for immediate amputation. If urgent amputation proved necessary in compound injuries it was best done by an open technique, retraction of the skin being prevented by fixing it with a few sutures over a small dressing. From the combined experience of surgeons and limb-fitters definitive amputations were standardised so that in World War II only four major amputations were advised: a five-inch below-knee stump; an eleven-inch above-knee stump; a seven-inch below-elbow stump; and an eight-inch above-elbow stump. The end-bearing Stokes-Gritti and Symes amputations still advocated by the Canadians and others were, and to the regret of some of us still are, unpopular with British limb-makers. Nerves are divided cleanly with a sharp knife and not meddled with further; haemostasis is meticulous; flaps should include only skin, subcutaneous tissue and deep fascia; scars should usually be at the end and not the side of the stump. Cineplastic and Krukenberg's amputations have not been used to any extent in this country in either war. Suction sockets, started after World War I, whose limited use for thigh amputations has been improved, had achieved a greater though restricted popularity.

\section{CONCLUSION}

It has been fascinating to trace the gradual erection of the British edifice of orthopaedics, and nostalgic to recapture a memory, however fleeting, of some of the figures who built it and taught us so much of our sum of knowledge half-way through the twentieth century-the remarkable spell of Robert Jones, the lofty, ascetic Tubby, the pugnacious Openshaw, the forceful and enthusiastic Hey Groves, the earnest but irascible Laming Evans, the equable and thoughtful Elmslie, the restless and exuberant Trethowan. It is always tempting to conclude: " those were the days." It is probably wise to do no more than record the events and leave judgment of progress to a later century. But we are being judged already and not always kindly or even truthfully. We are justified surely in priding ourselves on what has already been achieved, and on the service that orthopaedic surgery now gives to the community and promises for the future. In concern for this aspect of our work we have perhaps tended to neglect our capacity for basic research. But we are aware of this shortcoming, as witness our closer relationships with research departments of universities and royal colleges, and our increasing contacts with colleagues in the basic sciences. Finally, apart from the most intellectual snob and the pessimistic cynic, all must surely rejoice at the enthusiasm, industry and ability of our young colleagues-the orthopaedic surgeons of to-morrow.

I acknowledge gratefully the help I have received from A. Rocyn Jones, W. E. Tanner, Harry Platt, R. Watson-Jones and a host of other colleagues. Mr L. T. Morton, the information officer of the British Medical Association, has done much to lighten my burden by his researches into Acts of Parliament. Among the enormous number of books and articles that have been consulted I am especially indebted to the Birthday Volume, the Official History of World War I, Menders of the Maimed, Life of Sir Robert Jones. This is my Life by Agnes Hunt, British Masters of Medicine, Civilisation and the Cripple, The Cripple, the Annual Reports of the Central Council for the Care of Cripples, and Bick's Source Book of Orthopaedics.

The illustrations of the early activities of the British Orthopaedic Association are taken from the papers of the late R. C. Elmslie through the kindness of Mrs R. C. Elmslie. 